\title{
Light Water Reactor Sustainability Program Integrated Program Plan
}

April 2013
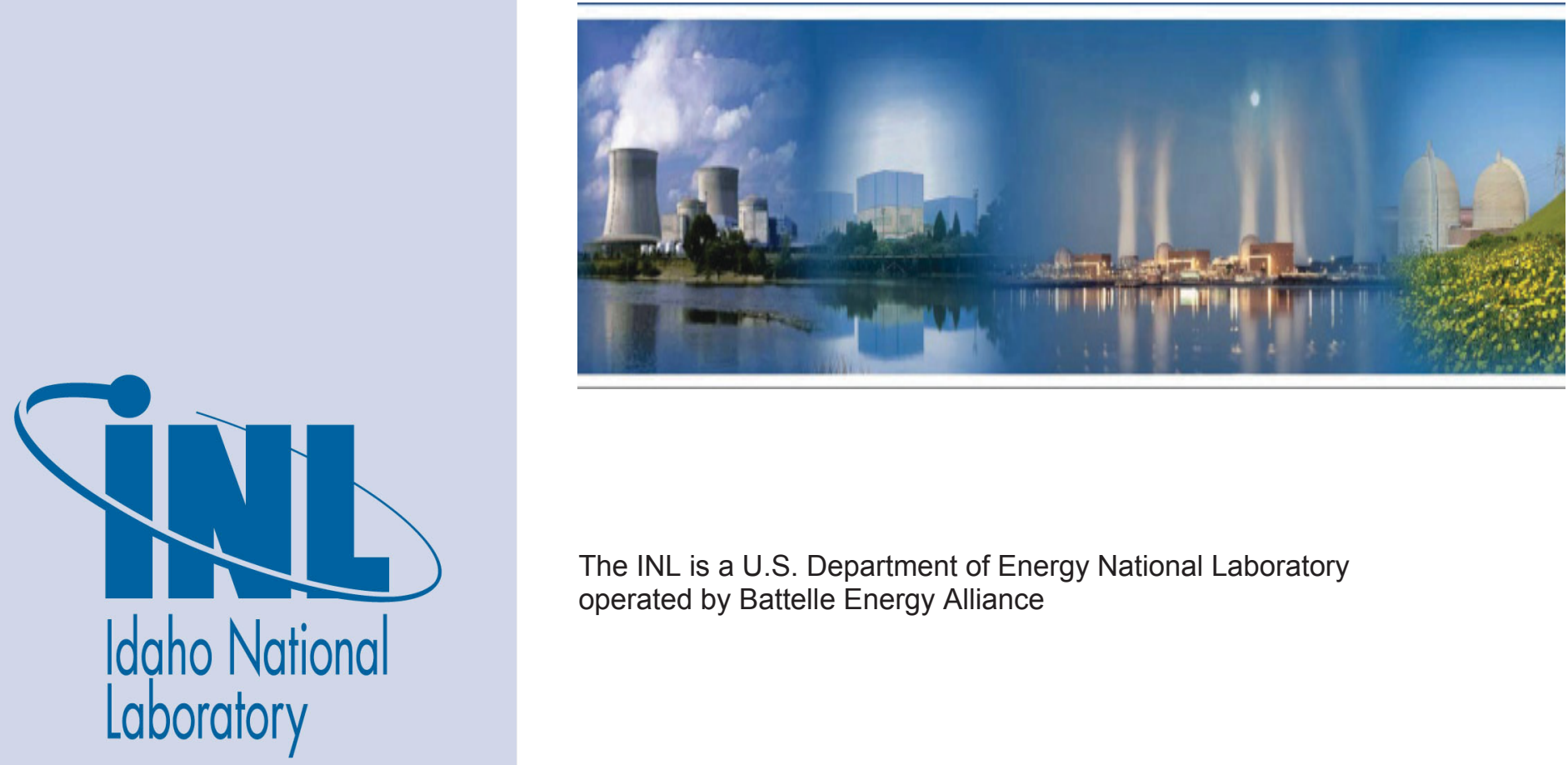

The INL is a U.S. Department of Energy National Laboratory operated by Battelle Energy Alliance 


\section{DISCLAIMER}

This information was prepared as an account of work sponsored by an agency of the U.S. Government. Neither the U.S. Government nor any agency thereof, nor any of their employees, makes any warranty, expressed or implied, or assumes any legal liability or responsibility for the accuracy, completeness, or usefulness, of any information, apparatus, product, or process disclosed, or represents that its use would not infringe privately owned rights. References herein to any specific commercial product, process, or service by trade name, trade mark, manufacturer, or otherwise, does not necessarily constitute or imply its endorsement, recommendation, or favoring by the U.S. Government or any agency thereof. The views and opinions of authors expressed herein do not necessarily state or reflect those of the U.S. Government or any agency thereof. 
INL/EXT-11-23452

Revision 1

\section{Light Water Reactor Sustainability Program Integrated Program Plan}

April 2013

Idaho National Laboratory
Idaho Falls, Idaho 83415

http://www.inl.gov

Prepared for

U.S. Department of Energy

Office of Nuclear Energy

Under DOE Idaho Operations Office

Contract DE-AC07-05ID14517 



\section{EXECUTIVE SUMMARY}

Nuclear power has safely, reliably, and economically contributed almost $20 \%$ of electrical generation in the United States over the past two decades. It remains the single largest contributor (more than 60\%) of non-greenhouse-gas-emitting electric power generation in the United States.

Domestic demand for electrical energy is expected to grow by more than $20 \%$ from 2011 to 2040 . At the same time, most of the currently operating nuclear power plants will begin reaching the end of their initial 20-year extension to their original 40-year operating license, for a total of 60 years of operation. Figure E-1 shows projected nuclear energy contribution to the domestic generating capacity for a range of scenarios. If current operating nuclear power plants do not operate beyond 60 years (and new nuclear plants are not built quickly enough to replace them), the total fraction of generated electrical energy from nuclear power will rapidly decline. That decline will be accelerated if plants are shut down before 60 years of operation. One scenario is shown by the dotted line in Figure E-1. A recent example is Dominion's decision to shut down their Kewaunee plant prior to entering their already approved first license extension period. Dominion's decision was based solely on the economics of the region where (currently inexpensive) natural gas is a competitor to nuclear power.

Decisions on extended operation ultimately rely on economic factors; however economics can often be improved through technical advancements. The oldest commercial plants in the United States reached their 40th anniversary in 2009.

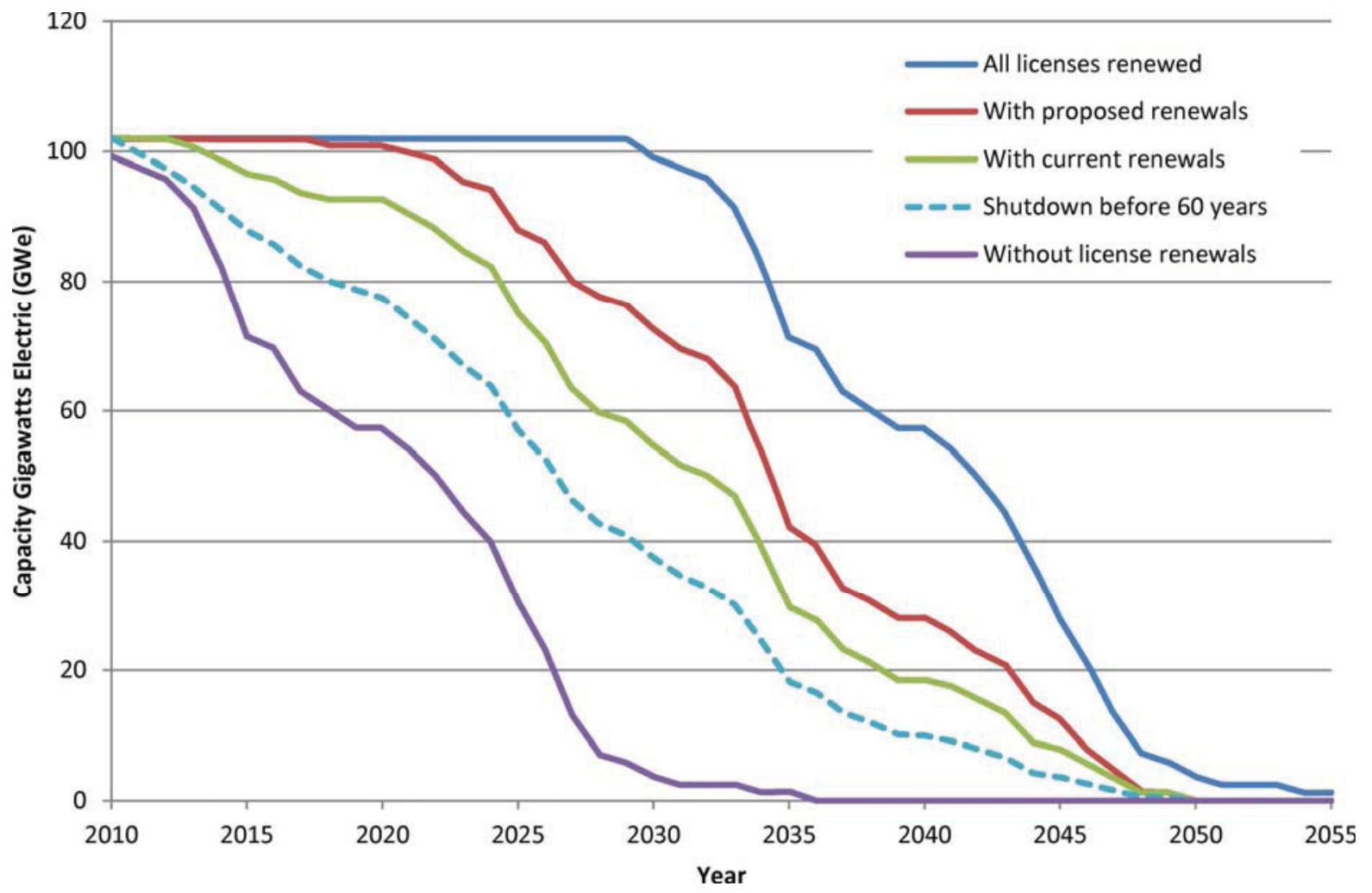

Figure E-1. Projected nuclear power generation for a range of license renewal scenarios. 
The U.S. Department of Energy Office of Nuclear Energy's 2010 Research and Development Roadmap (2010 Nuclear Energy Roadmap) organizes its activities around four objectives that ensure nuclear energy remains a compelling and viable energy option for the United States. The four objectives are as follows:

1. Develop technologies and other solutions that can improve the reliability, sustain the safety, and extend the life of the current reactors.

2. Develop improvements in the affordability of new reactors to enable nuclear energy to help meet the Administration's energy security and climate change goals.

3. Develop sustainable nuclear fuel cycles.

4. Understand and minimize the risks of nuclear proliferation and terrorism.

The Light Water Reactor Sustainability (LWRS) Program is the primary programmatic activity that addresses Objective 1. This document summarizes the LWRS Program's plans. For the purpose of the LWRS Program, "sustainability" means the prudent use of resources - in this case, our nation's commercial nuclear power plants. Sustainability is defined as the ability to maintain safe and economic operation of the existing fleet of nuclear power plants for a longerthan-initially-licensed lifetime. It has two facets with respect to long-term operations: (1) manage the aging of plant systems, structures, and components so that nuclear power plant lifetimes can be extended and the plants can continue to operate safely, efficiently, and economically; and (2) provide science-based solutions to the industry to implement technology to exceed the performance of the current labor-intensive business model.

Operation of the existing plants to 60 years, extending the operating lifetimes of those plants beyond 60 years and, where practical, making further improvements in their productivity is essential to realizing the administration's goals of reducing greenhouse gas emissions to $80 \%$ below 1990 levels by the year 2050 .

The Department of Energy's role in Objective 1 is to partner with industry and the Nuclear Regulatory Commission to support and conduct the research needed to inform major component refurbishment and replacement strategies, performance enhancements, plant license extensions, and age-related regulatory oversight decisions. The Department of Energy research, development, and demonstration role focuses on aging phenomena and issues that require long-term research and/or unique Department of Energy laboratory expertise and facilities and are applicable to a broad range of operating reactors. When appropriate, demonstration activities will be cost shared with industry or the Nuclear Regulatory Commission. Pilot projects and collaborative activities are underway at commercial nuclear facilities and with industry organizations.

The following LWRS Program research and development pathways address Objective 1 of the 2010 Nuclear Energy Roadmap:

1. Materials Aging and Degradation. Research and Development (R\&D) to develop the scientific basis for understanding and predicting long-term environmental degradation behavior of materials in nuclear power plants. This work will provide data and methods to assess the performance of 
Systems, Structures, and Components essential to safe and sustained nuclear power plant operations. The R\&D products will be used to define operational limits and aging mitigation approaches for materials in nuclear power plant systems, structures, and components subject to long-term operating conditions, providing key input to both regulators and industry.

\section{Advanced Instrumentation, Information, and Control Systems}

Technologies. R\&D to address long-term aging and modernization of current instrumentation and control technologies through development, demonstration, and testing of new instrumentation and control technologies and advanced condition monitoring technologies for more automated and reliable plant operation. The R\&D products will be used to design and deploy new Instrumentation, Information, and Control technologies and systems in existing nuclear power plants that provide an enhanced understanding of plant operating conditions and available margins and improved response strategies and capabilities for operational events.

3. Risk-Informed Safety Margin Characterization. R\&D to develop and deploy approaches to support the management of uncertainty in safety margins quantification to improve decision making for nuclear power plants. This pathway will (1) develop and demonstrate a risk-assessment method tied to safety margins quantification and (2) create advanced tools for safety assessment that enable more accurate representation of nuclear power plant safety margins. The R\&D products will be used to produce state-of-the-art nuclear power plant safety analysis information that yields new insights on actual plant safety margins and permits cost effective management of these margins during periods of extended operation.

4. Advanced Light Water Reactor Nuclear Fuels. R\&D to improve the scientific knowledge basis for understanding and predicting fundamental nuclear fuel and cladding performance in nuclear power plants, and applying this information to development of high-performance, high burn-up fuels with improved safety, cladding integrity, and improved nuclear fuel cycle economics. The R\&D products will be used to deploy new fuel/core designs for the existing nuclear power plant fleet with improved safety and economic operational capabilities. The Fuel Cycle Research and Development Program's Advanced Fuels Campaign is taking the lead on R\&D activities associated with the development of fuels with significantly increased safety benefits. The LWRS Program will maintain the lead role in performing analyses to determine the impact of advanced nuclear fuel rods on reactor safety margins via coordination with the RISMC Pathway.

Measurable milestones have been developed for each of the pathways; these include both near-term (i.e., 1 to 5 years) and longer-term (i.e., beyond 5 years) milestones. A listing of past accomplishments in the LWRS Program can be found in Appendix A. High-level planned accomplishments in the near term include: 
- Provide mechanistic understanding of key materials degradation processes, predictive capabilities, and high-quality data to inform decisions and processes by both industry and regulators including

- $\quad$ Containment Inspection Guidelines for extended-service conditions

- $\quad$ Predictive models for swelling in light water reactor components, aging of cast stainless steel components, cable degradation, and nickel-base alloy stress corrosion cracking susceptibility Model for transition temperature shifts in RPV steels, precipitate phase stability and formation in Alloy 316, and environmentally-assisted fatigue in light water reactor components

- $\quad$ Prototype proof-of-concept system for nondestructive examination of concrete sections, fatigue damage, and cable insulation

- Technical reports to implement digital technologies including

- Highly integrated control room incorporating digital upgrades in an analog control room, advanced alarm systems, and control room computer-based procedures

- Digital architecture for a highly automated plant

- Human performance improvement for nuclear power plant field workers including mobile technologies for nuclear power plant field workers, and automated work packages

- Advanced online monitoring facility for integrated operations

- Outage safety and efficiency including advanced outage coordination, advanced outage control center, and outage risk management improvement

- Online monitoring of active components

- Margins analysis techniques and associated models and tools to enable industry to conduct margins quantification exercises for their plants including

- Report describing the risk informed margin management process including a description of a pilot application of the Risk-Informed Safety Margin Characterization (RISMC) and Risk Informed Margin Management (RIMM) methodologies to an issue of interest at a host nuclear power plant

- A modern, validated safety analysis code (RELAP-7)

- Aging model (Grizzly) capable of modeling aging of steel (embrittlement) and selected concrete

Sections 1 through 5 in this document provide a comprehensive overview of the LWRS Program and how it functions, including detailed descriptions of the four pathways and the near-term and longer-term milestones. Appendix A is a summary of previous years' LWRS Program accomplishments, and Appendix B is a chronological listing (by pathway) of planned LWRS Program milestones. 


\section{CONTENTS}

EXECUTIVE SUMMARY

ACRONYMS

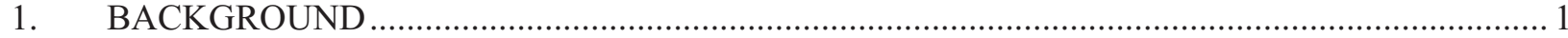

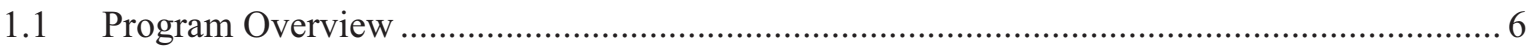

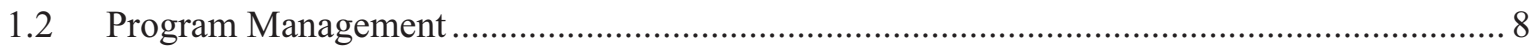

1.3 Program Research and Development Interfaces ........................................................ 8

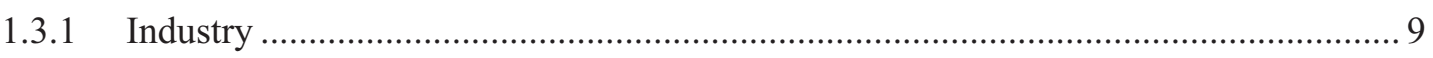

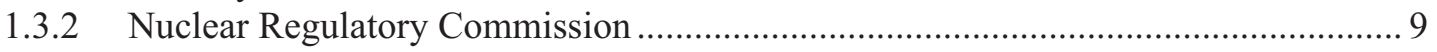

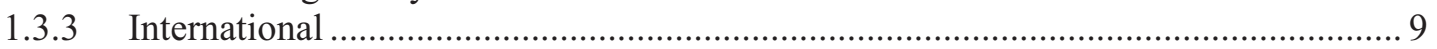

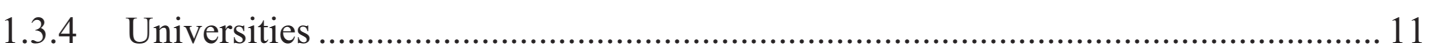

1.3.5 Advanced Modeling and Simulation Tools....................................................... 11

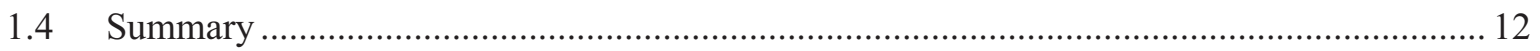

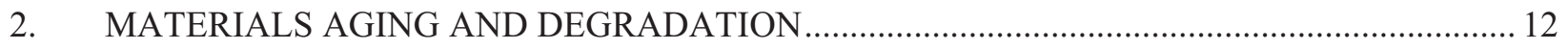

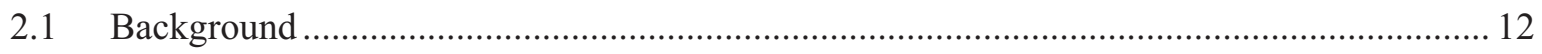

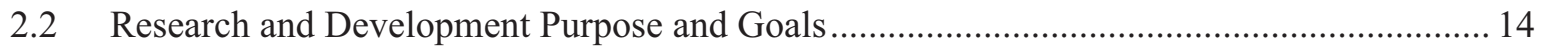

2.3 Pathway Research and Development Areas ................................................................. 15

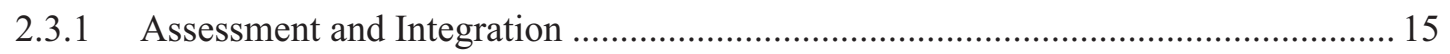

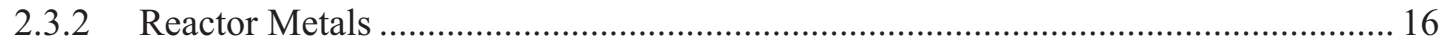

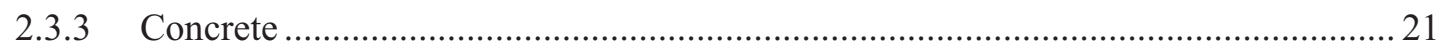

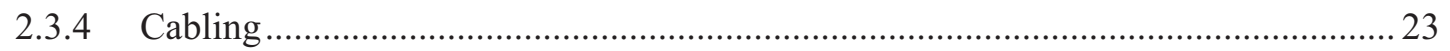

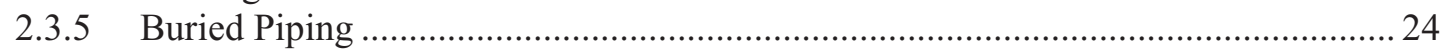

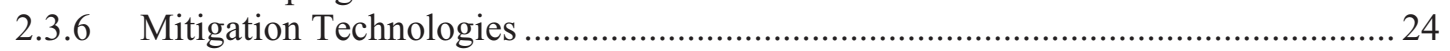

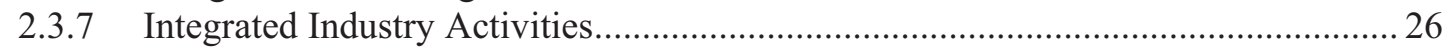

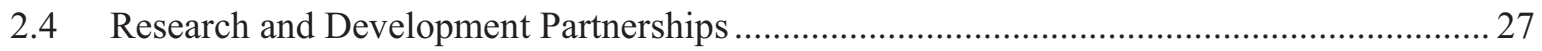

2.5 Summary of Research and Development Products and Schedule...................................... 28

3. ADVANCED INSTRUMENTATION, INFORMATION, AND CONTROL SYSTEMS

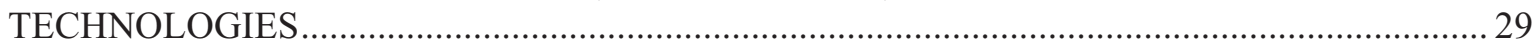

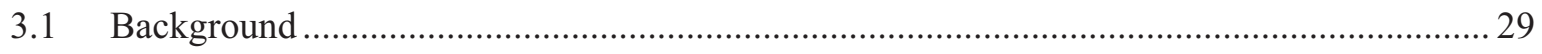

3.2 Research and Development Purpose and Goals ............................................................. 30

3.3 Pathway Research and Development Areas .................................................................. 31

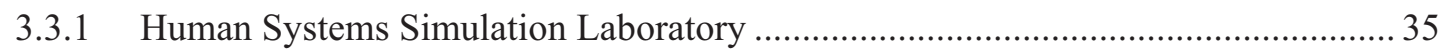

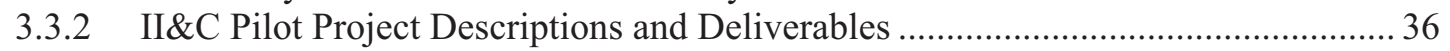

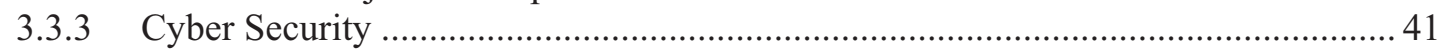

3.3.4 Contribution to Industry Consensus Guidelines …............................................. 42

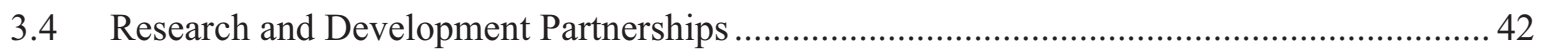

3.5 Summary of Research and Development Products and Schedule......................................... 43 
4. RISK-INFORMED SAFETY MARGIN CHARACTERIZATION …...................................... 44

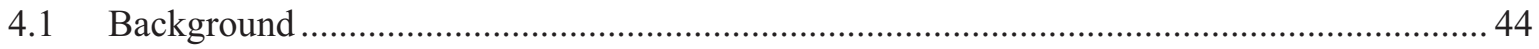

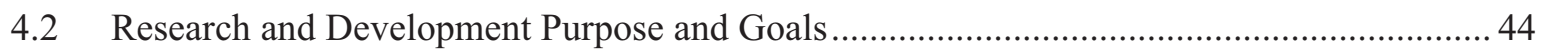

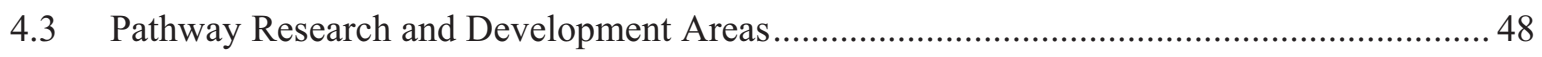

4.3.1 Technical Reports for Risk-Informed Margins Management .................................. 49

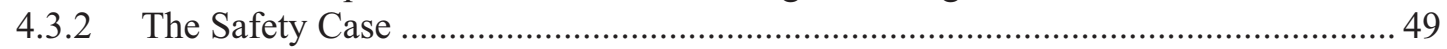

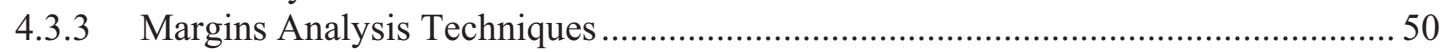

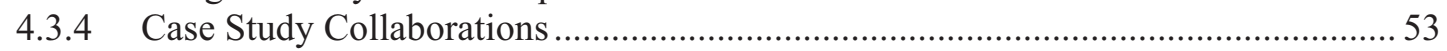

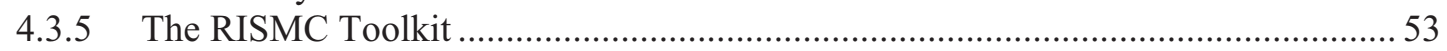

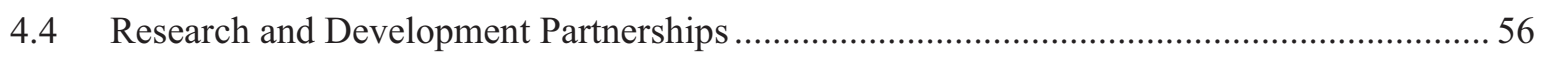

4.5 Research and Development Products and Schedule ....................................................... 56

5. ADVANCED LIGHT WATER REACTOR NUCLEAR FUELS ............................................. 56

5.1 Major Accomplishments in the Advanced Light Water Reactor Fuels Pathway .................. 57

5.1.1 Technical Program Plan for Nuclear Fuel Cladding Development........................... 58

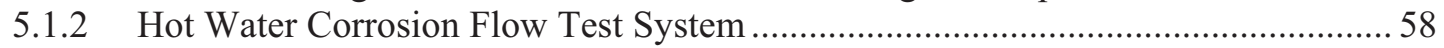

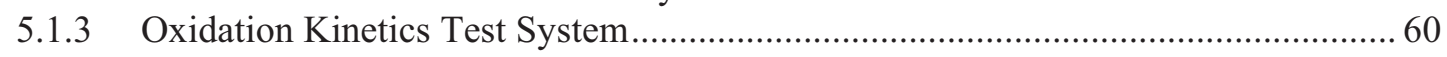

5.2 Advanced Light Water Reactor Pathway Planned Activities.............................................. 61

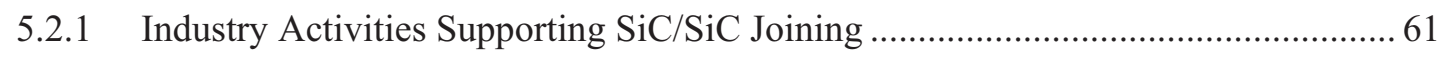

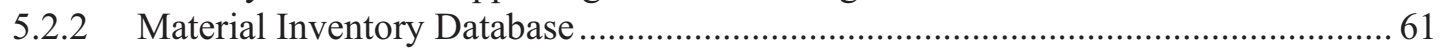

5.3 Path Forward for the Advanced LWRS Nuclear Fuels Pathway ........................................ 61

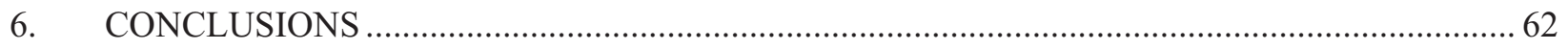

Appendix A LWRS Program Accomplishments ...................................................................................

Appendix B Chronological Listing of Planned LWRS Program Milestones........................................ B-1 


\section{FIGURES}

Figure E-1. Projected nuclear power generation for a range of license renewal scenarios........................iii

Figure 1. Current U.S. electric generating portfolio showing dominance of nuclear as a low carbon emission power source......

Figure 2. United States electrical generation capacity factors by energy source, showing high operating performance.

Figure 3. National distribution of operating nuclear power plants.

Figure 4. Nuclear power plant initial license date and license extension plans (as of January 2013).

Figure 5. Light Water Reactor Sustainability Program organization. 8

Figure 6. Complexity of interactions between materials, environments, and stresses in an operating nuclear power plant (source: A. Jennsen).

Figure 7. Cut-away of a typical pressurized water reactor, illustrating large volumes of concrete and the key role of concrete performance (source: NRC).

Figure 8. Process flow outline of cooperative research and development efforts between the Department of Energy and the Electric Power Research Institute. 25

Figure 9. Constellation pilot project activities and related research and development tasks in the Materials Aging and Degradation Pathway. .28

Figure 10. Typical nuclear power plant control room with analog technology.

Figure 11. The Advanced Instrumentation, Information, and Control Systems Technologies Pathway is developing an architecture that encompasses all aspects of plant operations and support, integrating plant systems, and immersing plant workers in a seamless digital environment.

Figure 12. A nuclear power plant field worker performs his work using a portable, wireless, hand-held device developed for LWRS Program research instead of paper-based work packages.

Figure 13. An outage manager at a commercial nuclear power plant uses new prototype interactive display technology developed by LWRS Program-sponsored research to monitor the progress of outage work activities at the station.

Figure 14. Pilot projects for the Advanced Instrumentation, Information, and Control Systems Technologies Pathway.

Figure 15. Goals of the Advanced Instrumentation, Information, and Controls Systems Technologies Pathway.

Figure 16. An operator workshop with a nuclear utility being conducted in the HSSL using the bench-board-style touch panel control bays ... .36

Figure 17. RISMC example when evaluating alternatives for risk-informed margins management.......... 46

Figure 18. Family of load and capacity distributions representing different accident conditions. .47

Figure 19. Types of analysis that are used in the Risk-Informed Safety Margin Characterization Pathway. .48 
Figure 20. Attributes of the Risk-Informed Safety Margin Characterization approach for supporting decision-making......

Figure 21. Depiction of the high-level steps required in the Risk-Informed Safety Margin Characterization method.

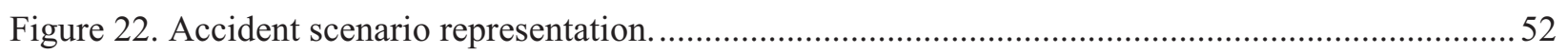

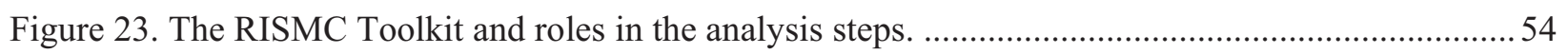

Figure 24. Schematic of the Hot Water Corrosion Flow (HWCF) test system.

Figure 25. Oxidation Kinetics System (OKS) test chamber, steam generator, water reservoir and data acquisition system 


\section{ACRONYMS}

BISON Implicit Simulation Of Nuclear Fuel (fuel performance model)

BWR Boiling Water Reactor

CASL Consortium on Advanced Simulation of LWRs

CASS Cast Stainless Steel

CFR Code of Federal Regulations

CMC Ceramic Matrix Composite

CSNI Committee on the Safety of Nuclear Installations

DOE Department of Energy

EMDA Expanded Materials Degradation Analysis

EPRI Electric Power Research Institute

FAVOR Fracture Analysis of Vessels: Oak Ridge

GALL Generic Aging Lessons Learned

Grizzly Component aging and damage evolution application

HPC High Performance Computing

HSSL Human Systems Simulation Laboratory

HWCF Hot Water Corrosion Flow

I\&C Instrumentation and Control

II\&C Instrumentation, Information, and Control

IASCC Irradiation-Assisted Stress Corrosion Cracking

INL Idaho National Laboratory

IPP Integrated Program Plan

LOCA Loss of Coolant Accident

LWR Light Water Reactor

LWRS Light Water Reactor Sustainability

MAaD Materials Aging and Degradation

MDM Materials Degradation Matrix

NDE Nondestructive Examination

NE $\quad$ Office of Nuclear Energy

NEAMS Nuclear Energy Advanced Modeling and Simulation

NEA-OECD Nuclear Energy Agency -Organization for Economic Co-operation and Development

NEUP Nuclear Energy University Program

NRC U.S. Nuclear Regulatory Commission

NULIFE Nuclear Plant Life Prediction 


$\begin{array}{ll}\text { NUREG } & \text { (NRC technical report) } \\ \text { OKS } & \text { Oxidation Kinetics System } \\ \text { PMDA } & \text { Proactive Materials Degradation Assessment } \\ \text { PTS } & \text { Pressurized Thermal Shock } \\ \text { PWR } & \text { Pressurized Water Reactor } \\ \text { PWSCC } & \text { Primary Water Stress Corrosion Cracking } \\ \text { R\&D } & \text { Research and Development } \\ \text { RAVEN } & \text { Reactor Analysis and Virtual Control Environment (simulation controller for RISMC) } \\ \text { RELAP-7 } & \text { Reactor Excursion and Leak Analysis Program } \\ \text { RIMM } & \text { Risk-Informed Margins Management } \\ \text { RISMC } & \text { Risk-Informed Safety Management Characterization } \\ \text { RPV } & \text { Reactor Pressure Vessel } \\ \text { SC } & \text { Stress Corrosion } \\ \text { SCC } & \text { Stress Corrosion Cracking } \\ \text { SiC } & \text { Silicon Carbide } \\ \text { SSC } & \text { Systems, Structures, and Components } \\ \text { U.S. } & \text { United States } \\ \text { UWG } & \text { Utility Working Group }\end{array}$




\section{Light Water Reactor Sustainability Program Integrated Program Plan}

\section{BACKGROUND}

The U.S. electric energy sector is in a time of serious challenges and tremendous opportunities. Expanding demand for energy and a growing awareness of the environmental impact caused by various forms of electricity generation prompts debate on how to best achieve sustainable, affordable, and environmentally sensitive solutions to the generation, transmission, distribution, and utilization of electricity. Nuclear energy is an important contributor to meeting the electricity generation objective.

The Light Water Reactor Sustainability (LWRS) Program is a research and development (R\&D) program sponsored by the U. S. Department of Energy (DOE), performed in close collaboration and cooperation with related industry R\&D programs. The LWRS Program provides technical foundations for licensing and managing the long-term, safe, and economical operation of current nuclear power plants, utilizing the unique capabilities of the national laboratory system.

Electric power is a vital component of the nation's economy and is essential to continuing improvements in the quality of life. Currently, almost $70 \%$ of domestic electricity generation relies on fossil fuels. Greenhouse gas emissions from burning fossil fuels are a mounting problem that threatens the future production of electricity from coal and natural gas. The President has set a goal of reducing greenhouse gas emissions to $80 \%$ below 1990 levels by the year 2050. Meeting these aggressive emission reduction goals, while continuing to increase the overall energy supply to meet domestic demand, requires that all non-emitting technologies be used and improved. Further reduction of greenhouse gas emissions requires increased electrification of the transportation infrastructure, which places even greater challenges on the electric sector.

Nuclear energy is the nation's largest contributor of non-greenhouse-gas-emitting electric power generation, comprising over $60 \%$ of the non-emitting sources (Figure 1). Energy efficiency, renewable energy, and carbon capture and storage technologies are expected to play increasing roles in providing clean and reliable energy. Nevertheless, our nation and others will depend on nuclear energy for largescale supply of economical, dependable, and clean electricity.

The other forms of low carbon dioxide-emitting and renewable energy production methods (e.g., hydroelectric, wind, geothermal, and solar) have the potential to produce substantial energy; however, none of these other energy sources appear to be available in a sufficient scale to provide baseload power for the foreseeable future. Hydroelectric power is the most widely used renewable energy source in the United States; however, there is limited opportunity for expansion. While wind, geothermal, and solar power have demonstrated promise in meeting the nation's growing demand, these sources currently contribute only a small fraction of the nation's growing energy demands. In addition, wind and solar power are inherently dilute with low power density and are intermittent, resulting in low capacity factors. Geothermal is not intermittent, but is limited to locations or regions, such as the Geysers in California, where very hot water is easily accessible. Figure 2 provides a graph of the current capacity factors by energy source. The very high capacity factor for nuclear power makes it the only reliable, noncarbon dioxide-emitting source of baseload power available. 


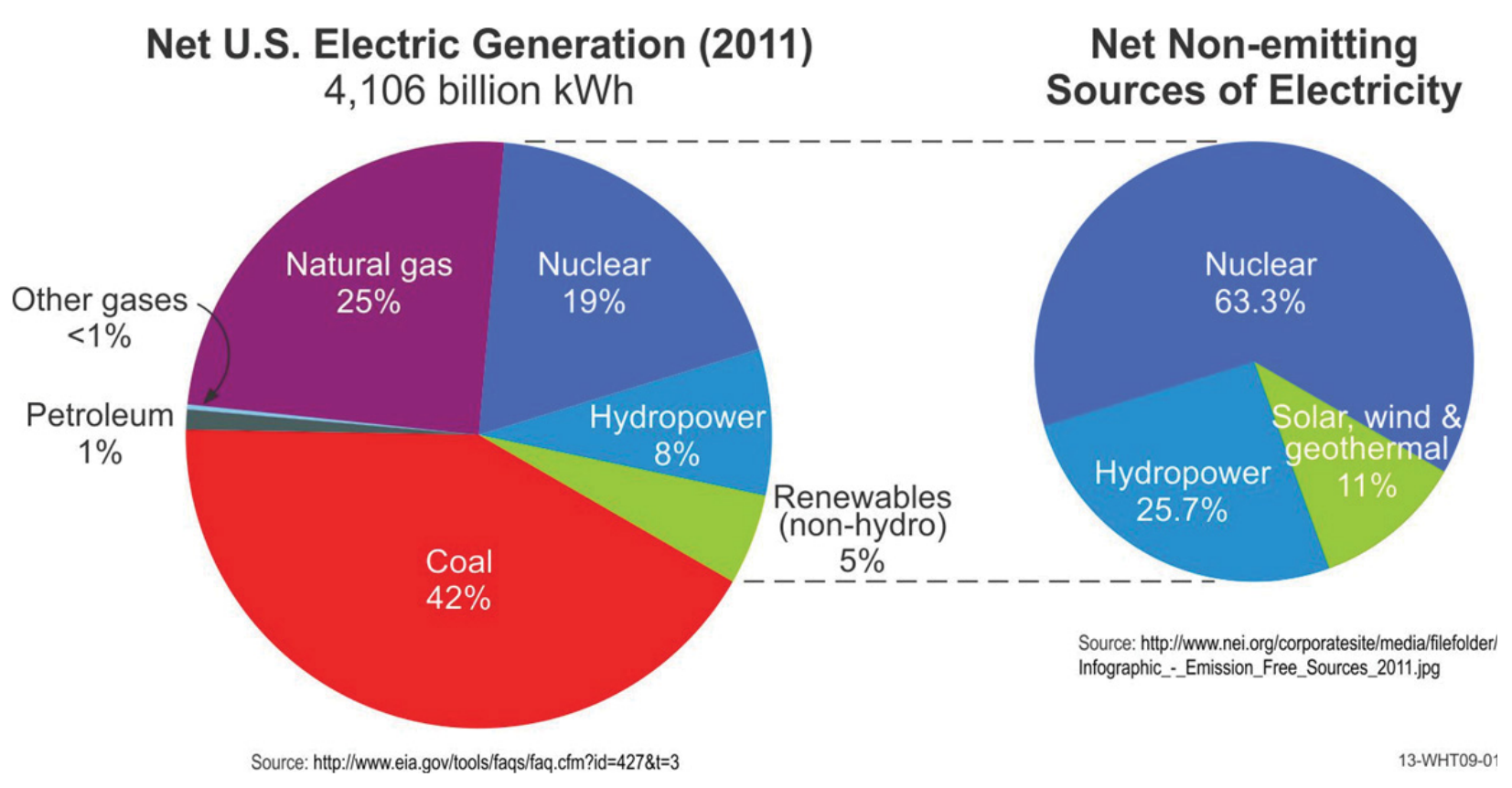

Figure 1. Current U.S. electric generating portfolio showing dominance of nuclear as a low carbon emission power source.

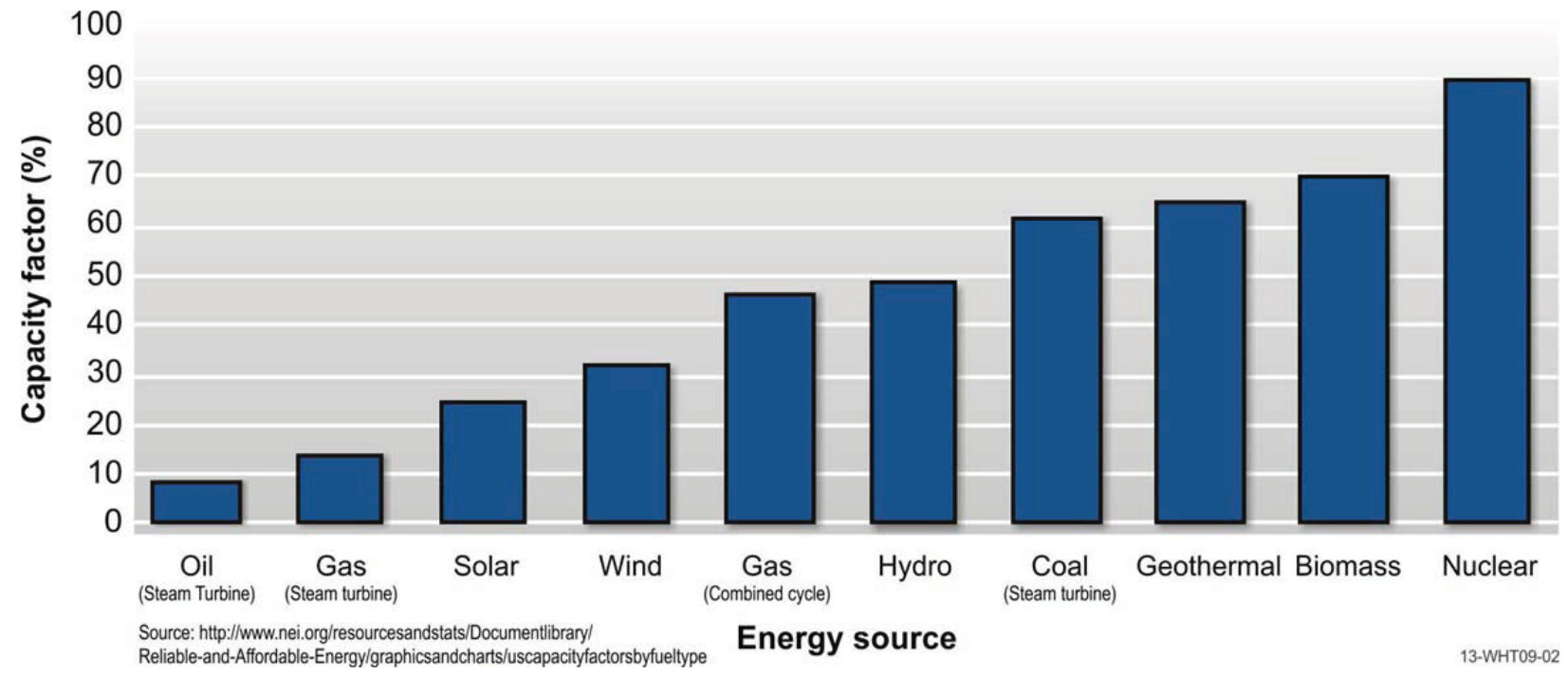

Figure 2. United States electrical generation capacity factors by energy source, showing high operating performance. 
Construction of new nuclear power plants is a clear option for new, emission-free, electrical generating capacity. However, bringing new nuclear power plants online is facing substantial challenges and uncertainties, including high upfront capital cost, high financing cost, long construction time, and competition from low natural gas prices. A modest pace of new nuclear power plant construction is anticipated. For example, the U.S. Energy Information Administration's Annual Energy Outlook for 2012 predicts only $6.8 \mathrm{GW}$ of new capacity (Vogtle Units 3 and 4, Summer Units 2 and 3, Watts Bar Unit 2, and Bellefonte Unit 1) to be brought online by 2020.

Currently, 104 nuclear power plants operate in 31 states (Figure 3). Note that Dominion recently announced that they will shut down Kewaunee in 2013, and Duke recently announced they will not restart the Crystal River plant which has been idle since 2009. That will bring the number of operating nuclear plants to 102. The existing, operating fleet of U.S. nuclear power plants has consistently maintained outstanding levels of nuclear safety, reliability, and operational performance over the last two decades and operates with an average capacity factor of about $90 \%$. Nuclear power plant capacity factors improved from around $50 \%$ in the early 1970 s to over $90 \%$ in 2010 . Over the same period of time, the safety of the nuclear power plants has improved substantially, as measured by predicted core damage frequency. The significant improvements in performance, reliability, and safety have made nuclear power plants considerably more economical to operate. Major improvements were made in all areas of plant operation, including operations, training, equipment maintenance and reliability, technological improvements, and improved understanding of component degradation. More broadly, these improvements reflect effective management practices, advances in technology, and the sharing of safety and operational experience among utilities. Today, nuclear production costs are the lowest among the major U.S. power-generating options.

Figure 4 shows the following: (1) the oldest operating nuclear power plant started operation in 1969 and the newest plant started operation in 1996, (2) the first group of nuclear power plants were brought online between 1969 and 1979 and the second group between 1980 and 1996, and (3) almost all operating nuclear power plants have been issued, are applying for, or plan to apply for a 20-year license extension. This license extension will result in a licensed operating period of 60 years. Note however, that receiving a license extension doesn't necessarily mean that the plant will continue to operate, as evidenced by the recent decision of Dominion to shut down their Kewaunee plant prior to entering their license extension period. Business decisions on extended operation ultimately rely on economic factors; however economics can often be improved through technical advancements.

In about the year 2030, unless subsequent license renewals are granted, decommissioning of the current fleet of nuclear power plants will begin. Over the next three decades beyond 2030, decommissioning of the existing fleet would result in a loss of nearly $100-G W e$ of emission-free electrical generating capacity, leaving a shortfall of required emission-free generating capacity. Note that early (prior to 60 years of operation) shutdowns due to economic factors will increase this shortfall. This gap might be filled with higher construction rates of new nuclear power plants or with other technologies. However, the continued safe and economical operation of current plants to and beyond the current license limit of 60 years is an option for filling this energy gap and maintaining the existing level of emissionfree power generation capability at a fraction of the cost of building new plants. 


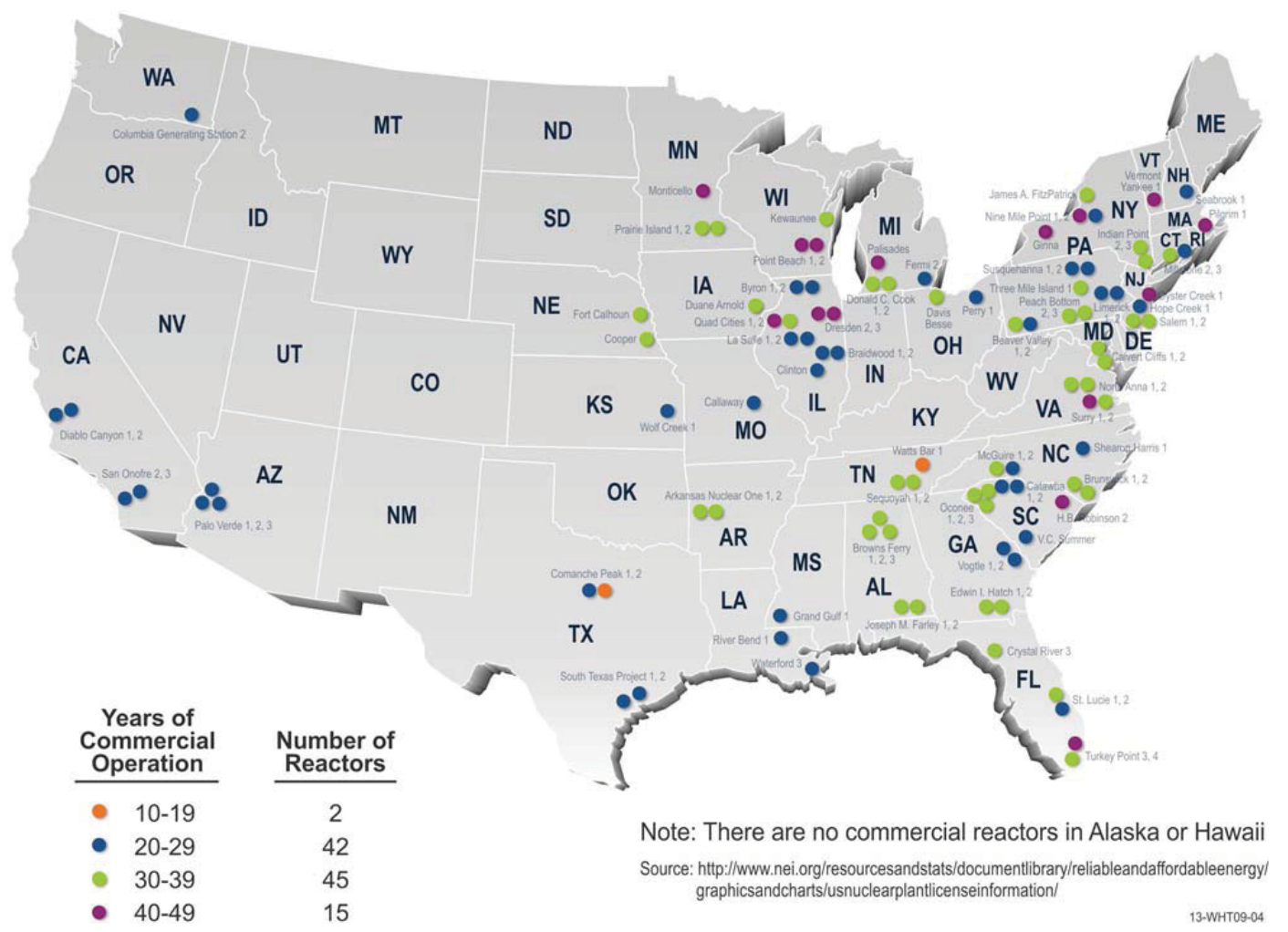

Figure 3. National distribution of operating nuclear power plants. Note that Dominion recently announced that they will shut down Kewaunee in 2013, and Duke will not restart the currently idled Crystal River plant. Those plans are not reflected in this figure.

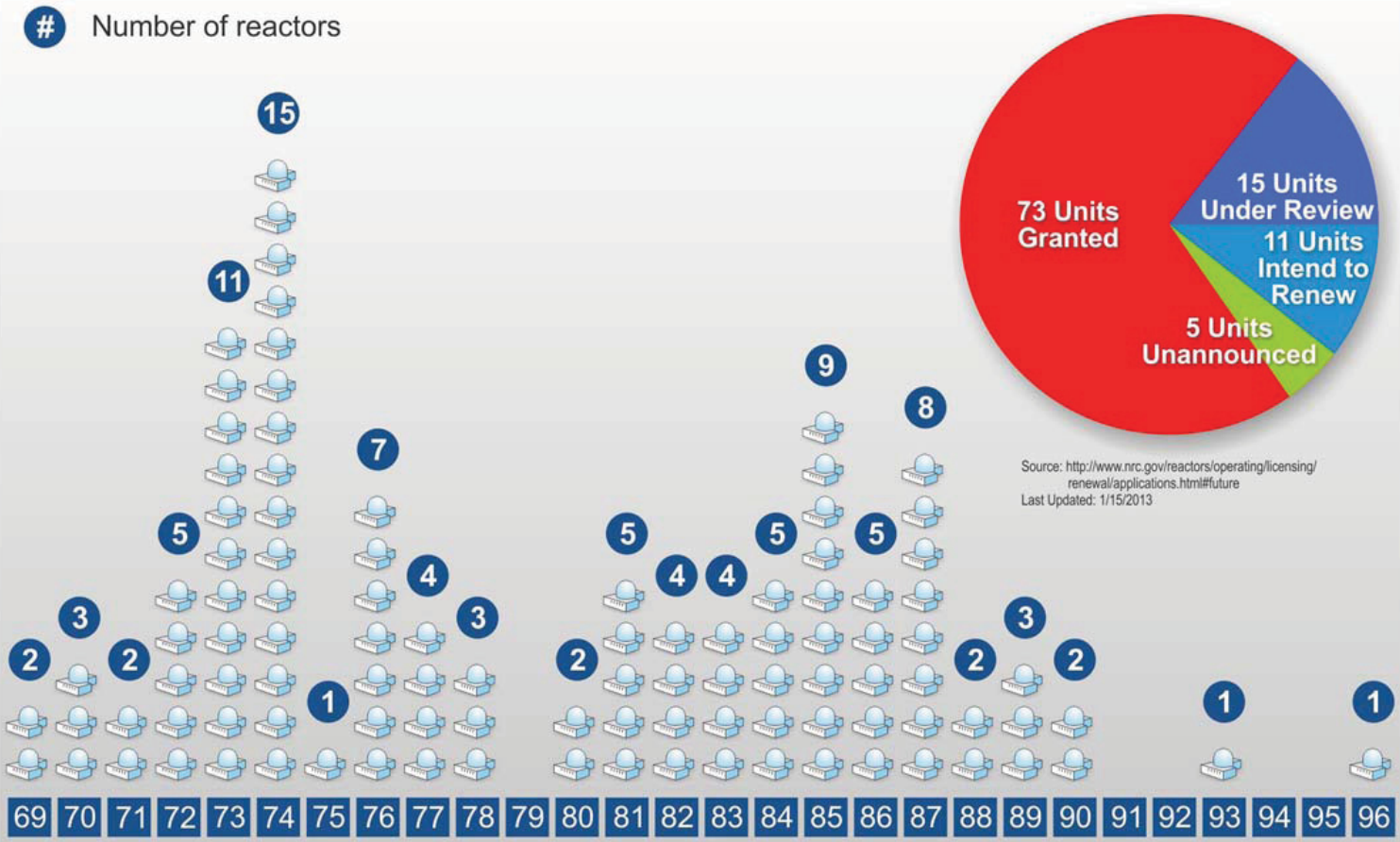

Date of U.S. NRC License

13-WHT09-03

Figure 4. Nuclear power plant initial license date and license extension plans (as of January 2013). 
To receive a 20-year license extension, a nuclear power plant operator must ensure the plant will operate safely for the duration of the license extension. The 40-year initial operating license period established in the Atomic Energy Act was based on antitrust and capital depreciation considerations, not technical limitations. The 20 -year license extension periods are presently authorized under the governing regulation of 10 CFR Part 54, "Requirements for Renewal of Operating Licenses for Nuclear Power Plants." This rule places no limit on the number of times a plant can be granted a 20 -year license renewal as long as the licensing basis is maintained during the renewal term in the same manner and to the same extent as during the original licensing term (e.g., the licensee can demonstrate continued safe and secure operation during the extended period).

This regulatory process ensures continued safe operation of nuclear power plants during future renewal periods. The license extension process requires a safety review and an environmental review, with multiple opportunities for public involvement. The license extension applicant must demonstrate how they are, or are planning to be, addressing aging-related safety issues through technical documentation and analysis, which the U.S. Nuclear Regulatory Commission (NRC) confirms before granting a license extension. A solid technical understanding of how systems, structures, and components (SSCs) age is necessary for nuclear power plants licensees to demonstrate continued safe operation. A well-established knowledge base for the current period of licensed operation exists; however, additional research is needed to obtain the same robust technical basis required for continued operational evaluations beyond 60 years.

In early 2007, DOE, with the Idaho National Laboratory (INL) engaging the Electric Power Research Institute (EPRI) and other industry stakeholders, initiated planning that led to the LWRS Program. The aim was to develop an R\&D strategy that addresses nuclear energy issues within the framework of the National Energy Policy and the National Energy Policy Act of 2005. Based on considerable analysis and information gathering, the "Strategic Plan for Light Water Reactor Research and Development," was developed and reviewed by an independent committee of experts. The plan, which recommended ten top priority areas for a government-industry, cost-shared R\&D program, was issued in November 2007.

Building on the strategic plan and collaborative relationships that were developed while preparing it, DOE and INL immediately started developing the LWRS Program. In February 2008, DOE and NRC cosponsored a workshop, which identified necessary R\&D for long-term operation and licensing of nuclear power plants. ${ }^{\mathrm{c}}$ Participation by industry along with other stakeholders provided important definition of needs and focused program objectives on long-term operation of existing nuclear power plants. A followon workshop was held in February 2011 to review progress and discuss challenges with R\&D for longterm operation.

In developing the strategic plan and the more specific program plans, it became apparent that a government/industry collaborative cost-sharing arrangement for R\&D was needed to address the long-range, policy-driven goals of government and the acceptability and usefulness of derived solutions to industry. The national strategic interests in the long-term operation of existing nuclear power plants included meeting climate change objectives, providing energy security, and minimizing cost impacts (due to plant replacements) to rate payers. The nuclear industry also had an incentive to ensure the continued safe and reliable operation of their operating nuclear power plants.

Therefore, at the nexus of these mutual interests, "cost-sharing" is being employed through cooperative R\&D activities. DOE and industry are independently funding specific, related projects and sharing information to achieve goals of mutual interest. DOE-funded R\&D addresses fundamental

a 10 CFR 54, "Requirements for Renewal of Operating Licenses for Nuclear Power Plants," Code of Federal Regulations.

b INL/EXT-07-13543, Strategic Plan for Light Water Reactor Research and Development, INL, November 2007.

c "Life Beyond 60 Workshop Summary Report, NRC/DOE Workshop U.S. Nuclear Power Plant Life Extension Research and Development," NRC and DOE, prepared by Energetics Inc., February 19 through 21, 2008. 
scientific questions, where private investment or capabilities are insufficient to make progress on broadly applicable technology issues for public benefit. The U.S. government (i.e., DOE and its national laboratories) holds large theoretical, computational, and experimental expertise in nuclear R\&D that is not available within the industry. As such, the benefits will extend to the next generation of reactor technologies being deployed and those still in development.

Nuclear power can involve rare but high consequence events like those at Three Mile Island, Chernobyl, and Fukushima. When these events happen, the government invests substantial quantities of resources (financial and personnel) to deal with the consequences. Therefore, the government has an incentive to mitigate its risk by developing advanced materials, technologies, and analytical tools to better predict plant response and prevent/mitigate such accidents.

While industry is likely to invest in applied research programs that are directed toward enhancing operations or in developing incremental improvements, industry is unlikely to invest significantly in research programs that focus on longer-term or higher-risk gains. Additionally, because research necessary for nuclear power plant long-term operation is of a broad nature that provides benefits to the entire industry, it is unlikely that a single company will make the necessary investment on its own.

Government cost sharing and involvement is required to promote the necessary programs that are of crucial long-term, strategic importance. The LWRS Program, by incorporating collaborative industry stakeholder inputs and shared costs, supports the strategic national interest of maintaining nuclear power as an available resource.

Decisions on subsequent license renewal and the investments required to support long-term operation will be made by plant owners. The science-based technical results from the LWRS Program provide data, that translates into cost/benefit information, for owners to make informed decisions on long-term operation and subsequent license renewal, reducing the uncertainty, and therefore the risk, associated with those decisions. The LWRS Program creates an environment (by reducing uncertainty and risk) that provides incentives for industry to make the investments required for nuclear power operation periods to and beyond 60 years.

\subsection{Program Overview}

Sustainability in the context of light water reactors (LWRs) is defined as the ability to maintain safe and economic operation of the existing fleet of nuclear power plants for a longer-than-initially-licensed lifetime. It has two facets with respect to long-term operations: (1) manage the aging of hardware so the nuclear power plant lifetime can be extended and the plant can continue to operate safely, efficiently, and economically; and (2) provide science-based solutions to the industry to implement technology to exceed the performance of the current labor-intensive business model.

In April 2010, DOE's Office of Nuclear Energy (NE) issued the R\&D Roadmap (2010 NE Roadmap). The NE Roadmap organized DOE-NE activities in accordance with four objectives that ensure nuclear energy remains a compelling and viable energy option for the United States. Objective 1 of the NE Roadmap focuses on developing the technologies and other solutions that can improve reliability, sustain safety, and extend the life of the current fleet of commercial nuclear power plants. The LWRS Program is the primary programmatic activity that addresses Objective 1. The LWRS Program is focused on the following three goals:

1. Developing the fundamental scientific basis to understand, predict, and measure changes in materials and SSCs as they age in environments associated with continued long-term operations of the existing reactors,

2. Applying this fundamental knowledge to develop and demonstrate methods and technologies that support safe and economical long-term operation of existing reactors, and 
3. Researching new technologies to address enhanced plant performance, economics, and safety.

The LWRS Program consists of the following four primary technical areas of R\&D:

1. Materials Aging and Degradation (MAaD): R\&D to develop the scientific basis for understanding and predicting long-term environmental degradation behavior of materials in nuclear power plants. This work will provide data and methods to assess the performance of SSCs essential to safe and sustained nuclear power plant operations. The R\&D products will be used to define operational limits and aging mitigation approaches for materials in nuclear power plant SSCs subject to longterm operating conditions, providing key input to both regulators and industry.

2. Advanced Instrumentation, Information, and Control (II\&C) Systems Technologies: R\&D to address long-term aging and modernization of current instrumentation and control (I\&C) technologies through development/testing of new I\&C technologies and advanced condition monitoring technologies for more automated and reliable plant operation. The R\&D products will be used to design and deploy new II\&C technologies and systems in existing nuclear power plants that provide an enhanced understanding of plant operating conditions and available margins and improved response strategies and capabilities for operational events.

3. Risk-Informed Safety Margin Characterization (RISMC): R\&D to develop and deploy approaches to support the management of uncertainty in safety margins quantification to improve decision making for nuclear power plants. This pathway will (1) develop and demonstrate a riskassessment method tied to safety margins quantification and (2) create advanced tools for safety assessment that enable more accurate representation of nuclear power plant safety margins. The R\&D products will be used to produce state-of-the-art nuclear power plant safety analysis information that yields new insights on actual plant safety/operational margins and permits cost effective management of these margins during periods of extended operation.

4. Advanced LWR Nuclear Fuels: R\&D to improve the scientific knowledge basis for understanding and predicting fundamental nuclear fuel and cladding performance in nuclear power plants, and applying this information to development of high-performance, high burn-up fuels with improved safety, cladding integrity, and improved nuclear fuel cycle economics. The R\&D products will be used to deploy new fuel/core designs for the existing nuclear power plant fleet with improved safety and economic operational capabilities. The Fuel Cycle Research and Development Program's Advanced Fuels Campaign is taking the lead on R\&D activities associated with the development of fuels with significantly increased safety benefits. The LWRS Program will maintain the lead role in performing analyses to determine the impact of advanced nuclear fuel rods on reactor safety margins via coordination with the RISMC Pathway.

The technical plans for each of the four pathways are discussed in Sections 2 through 5. Measurable milestones have been developed for each of the pathways, including both near-term (i.e., 1 to 5 years) and longer-term (i.e., beyond 5 years) milestones. This Integrated Program Plan is updated yearly; a listing of major accomplishments from previous fiscal years can be found in Appendix A, and Appendix B includes a chronological listing (by pathway) of planned LWRS Program milestones. 


\subsection{Program Management}

The entire LWRS Program is organizationally aligned within The Department of Energy Office of Nuclear Energy (DOE-NE). Program management and oversight, including programmatic direction, project execution controls, budgetary controls, and Technical Integration Office performance oversight, are provided by the DOE Office of LWR Technologies in conjunction with the DOE Idaho Operations Office. The functional organization, reporting relationships, and roles and responsibilities for the Technical Integration Office are explained in the following sections and Figure 5.

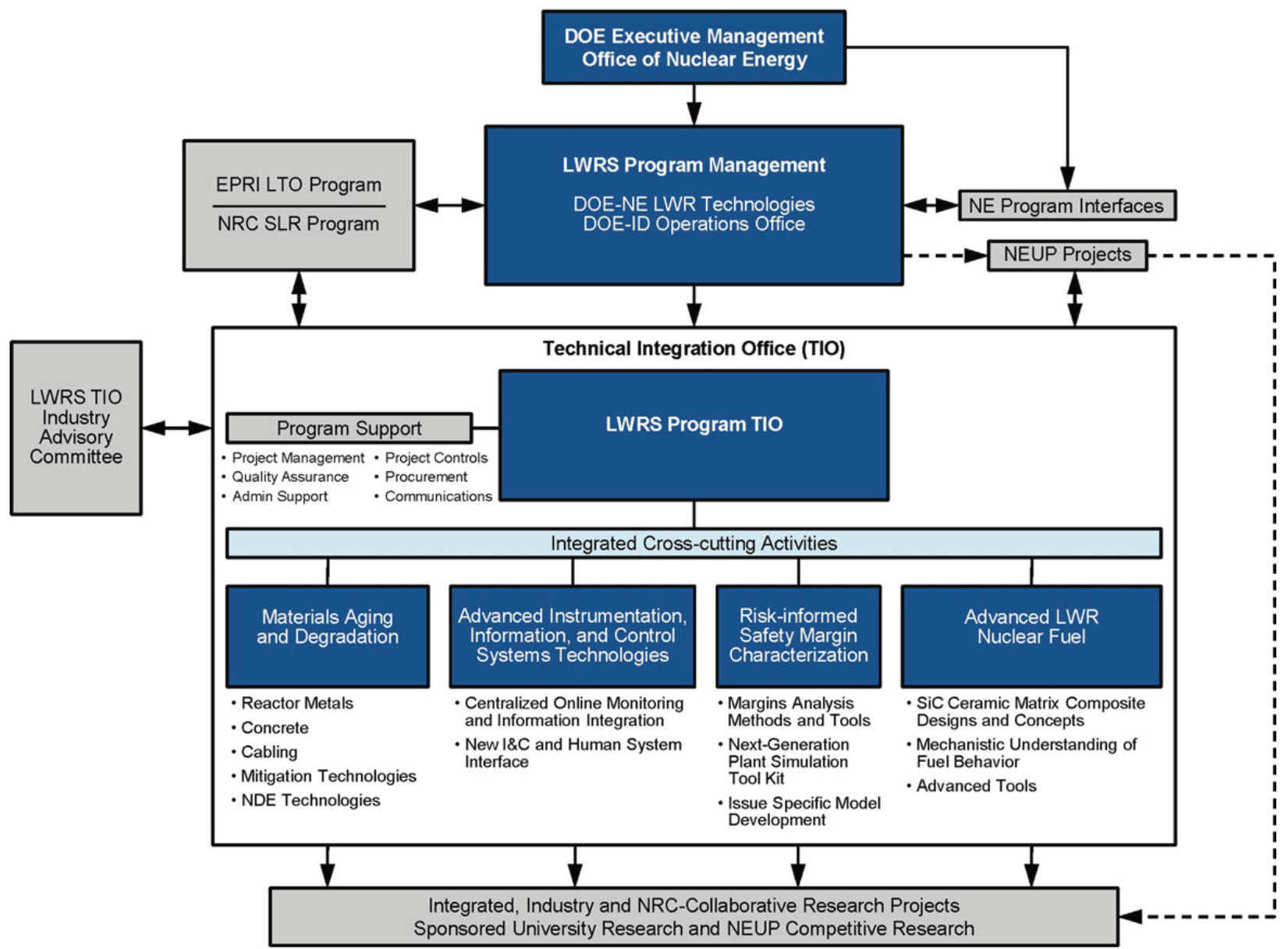

Figure 5. Light Water Reactor Sustainability Program organization.

\subsection{Program Research and Development Interfaces}

Planning, execution, and implementation of the LWRS Program are done in coordination with the nuclear industry, NRC, universities, and related DOE R\&D programs (e.g., Nuclear Energy Advanced Modeling and Simulation, Consortium for Advanced Simulation of LWRs, Nuclear Energy Enabling Technologies, and the Fuel Cycle R\&D Program) to assure relevance, efficiency, and effective management of the work.

The development of the scientific basis to support service operation extensions up to and beyond 60 years and facilitate high-performance, economic operations of the existing LWR operating fleet over the extended operating period is the central focus of the LWRS Program. Therefore, coordination with industry and NRC is needed to ensure a uniform approach, shared objectives, and efficient integration of collaborative work for the LWRS Program. This coordination requires that articulated criteria for the 
work appropriate to each group be defined in memoranda of understanding that are executed among these groups.

\subsubsection{Industry}

The LWRS Program works with industry on nuclear energy supply technology R\&D needs of common interest. The interactions with industry are broad and include cooperation, coordination, and direct cost-sharing activities. The guiding concepts for working with industry are leveraging limited resources through cost-shared $\mathrm{R} \& \mathrm{D}$, direct work on issues related to the long-term operation of nuclear power plants, the need to develop state-of-the-art technology to ensure safe and efficient operation, and the need to focus government-sponsored R\&D on the higher-risk and/or longer-term projects incorporating scientific and qualitative solutions using the unique expertise and facilities at the DOE laboratories. These concepts are included in memorandums of understanding, nondisclosure agreements, and cooperative $R \& D$ agreements. Cost-shared activities are planned and executed on a partnership basis and include significant joint management and funding. Periodic coordination meetings are held at the program and technical pathway levels to facilitate communication.

EPRI has established the Long-Term Operations Program, which is complementary to the DOE LWRS Program. EPRI and industry's interests include applications of the scientific understanding and the tools to achieve the safe and economical long-term operation of the current LWR fleet. Therefore, the government and private sector interests are similar and interdependent, leading to strong mutual support for technical collaboration and cost sharing. The interface between DOE-NE and EPRI for R\&D work supporting long-term operations of the existing fleet is defined in a memorandum of understanding ${ }^{\mathrm{d}}$. A joint R\&D plan defining the collaborative and cooperative R\&D activities between the LWRS Program and the Long-Term Operations Program was issued in 2012 and will be updated annually. ${ }^{\mathrm{e}}$ Also, contracts with EPRI or other industrial organizations are used as appropriate for some work.

\subsubsection{Nuclear Regulatory Commission}

NRC has a memorandum of understanding ${ }^{f}$ in place with DOE, which specifically allows for collaboration on research supporting long-term operation of nuclear power plants. Although the goals of the NRC and DOE research programs may differ, fundamental data and technical information obtained through joint research activities are recognized as potentially of interest and useful to each agency under appropriate circumstances. Accordingly, to conserve resources and to avoid duplication of effort, it is in the best interest of both parties to cooperate and share data and technical information and, in some cases, the costs related to such research, whenever such cooperation and cost sharing may be done in a mutually beneficial fashion.

\subsubsection{International}

DOE is coordinating LWRS Program activities with several international organizations with similar interests and R\&D programs. The LWRS Program participants continue to develop relationships with international partners, including the following international organizations, to gain awareness of emerging issues and their scientific solutions:

d "Memorandum of Understanding Between United States Department of Energy (DOE) and The Electric Power Research Institute (EPRI) on Light Water Reactor Research Programs," dated November 1, 2010, and signed by John E. Kelly, Deputy Assistant Secretary for Nuclear Reactor Technologies, Office of Nuclear Energy, DOE and Neil Wilmshurst, Vice President Nuclear, EPRI.

e INL/EXT-12-24562 Rev. 1, DOE-NE Light Water Reactor Sustainability Program and EPRI Long Term Operation ProgramJoint Research and Development Plan, Idaho National Laboratory.

f "Memorandum of Understanding Between U.S. Nuclear Regulatory Commission and U.S. Department of Energy on Cooperative Nuclear Safety Research," dated April 22, 2009, and signed by Brian W. Sheron, Director, Office of Nuclear Regulatory Research, NRC, and Rebecca Smith-Kevern, Acting Deputy Assistant Secretary for Nuclear Power Deployment, DOE-NE. 
- Organization for Economic Cooperation and Development's Halden Reactor Project: The Halden Reactor Project is a jointly financed R\&D program under the Organization for Economic Cooperation and Development - Nuclear Energy Agency (OECD-NEA) and is comprised of national organizations in 18 countries, including licensing and regulatory bodies, vendors, utilities, and research organizations. The Norwegian Institute for Energy Technology executes the program at its Halden establishment in Norway.

INL is an associate member of the Halden Reactor Project on behalf of DOE. Membership in the Halden Reactor Project will be maintained over the course of this research program to leverage the wide spectrum of advanced capabilities developed for nuclear operations and support. Halden has been on the cutting edge of new nuclear power plant technologies for several decades and their research is directly applicable to the capabilities being pursued under the MAaD, II\&C, and Advanced LWR Nuclear Fuels Pathways.

- Materials Aging Institute (MAI): The Materials Aging Institute was founded as a partnership between Électricité de France, EPRI, and the Tokyo Electric Power Company and is dedicated to understanding and modeling materials degradation. The collaborative interface with the LWRS Program is coordinated through EPRI, a founding member of the Materials Aging Institute.

- International Atomic Energy Agency (IAEA) Plant Life Management (PLiM): The International Atomic Energy Agency is the world's center of cooperation in the nuclear field. The Agency works with its member states and multiple partners worldwide to promote safe, secure, and peaceful nuclear technologies.

- International Forum for Reactor Aging Management (IFRAM): The International Forum for Reactor Aging Management facilitates the appropriate exchange of information among those parties and organizations around the world that presently are planning to address or are addressing issues of nuclear power plant SSCs aging management.

- Nuclear GENeration II \& III Association (NUGENIA): NUGENIA is an international collaborative R\&D network of major stakeholders in nuclear power generation from industry, the utilities, research institutions and technical safety organizations. It was launched in Brussels (Belgium) in 2012, hosted by the EC's Joint Research Centre. NUGENIA aims to provide a single framework for collaborative $\mathrm{R} \& \mathrm{D}$ on nuclear fission technologies, with a focus on the current fleet of nuclear reactors (known as Generation II and III). It brings together existing nuclear power generation R\&D under a single umbrella, including several European Networks of Excellence, such as NULIFE (see item below), SARNET (Severe Accident Research NETwork) and ENIQ (the European Network on Inspection and Qualification).

- European Nuclear Plant Life Prediction (NULIFE): The European network of excellence Nuclear Plant Life Prediction has been launched under the Euratom Framework Programme with a clear focus on integrating safety-oriented research on materials, structures, and systems and using the results of this integration through the production of consistent lifetime assessment methods.

- Nuclear Energy Agency (NEA) Committee on the Safety of Nuclear Installations (CSNI): The mission of the Nuclear Energy Agency Committee on the Safety of Nuclear Installations is to assist member countries in maintaining and further developing the scientific and technical knowledge base required to assess the safety of nuclear reactors and fuel-cycle facilities.

- Bilateral Activities: There are several U.S. bilateral activities either underway (e.g., U.S.-Argentina) or under discussion (e.g., U.S.-Japan) that include activities specific to the LWRS Program. These bilateral activities provide an opportunity to leverage work ongoing in other countries. 


\subsubsection{Universities}

Universities participate in the program in at least two ways: (1) through the Nuclear Energy University Program (NEUP) and (2) via direct contracts with the national laboratories that support the LWRS Program. NEUP also funds nuclear energy research and equipment upgrades at U.S. colleges and universities and provides scholarships and fellowships to students (see www.neup.gov). In addition to contributing funds to NEUP, the LWRS Program provides descriptions of research activities important to the LWRS Program and the universities submit proposals that are technically reviewed. The top proposals are selected and those universities work closely with the LWRS Program in support of key LWRS Program activities. Universities also are engaged in the LWRS Program via direct subcontracts where unique capabilities and/or facilities are funded by the program.

\subsubsection{Advanced Modeling and Simulation Tools}

A common theme for the pathways is use of computer modeling of physical processes or development of a larger system computer model. Extensive use of computer modeling is intended to distill the derived information so that it can be used for further research and as the basis for decisionmaking.

Computer modeling occurs in three forms, with many overlapping aspects within the LWRS Program:

1. Modeling a physical behavior (such as crack initiation in steel) is an example of direct computer modeling. The resulting model is used to store information for use in other pathways and to use in its own right for further research.

2. Development of more detailed computer modeling tools capable of encoding more complex behaviors (such as component aging models).

3. Creation of larger integrated databases that roll up results and allow decision-making. The large, system-wide, integrated models allow complex behavior to be understood in new ways and new conclusions to be drawn. These integrated databases can be used to further guide physical and modeling research, improving the entire program.

Because of their overlapping nature and numerous interfaces, these modeling activities tend to be naturally cross-cutting activities between pathways.

\subsubsection{Nuclear Energy Advanced Modeling and Simulation}

A critical interaction of the LWRS Program is with the DOE Nuclear Energy Advanced Modeling and Simulation (NEAMS) Program. The LWRS Program is leveraging the detailed, multiscale, sciencebased models developed by the NEAMS Program. These advanced computational tools under development in NEAMS are being used to create a new set of modeling and simulation capabilities that will be used to better understand the safety performance of the aging reactor fleet. These capabilities are information sources and tools for advancing the LWRS Program's goals.

\subsubsection{Department of Energy's Energy Innovation Modeling and Simulation Hub}

The LWRS Program is coordinating with the DOE Energy Innovation Modeling and Simulation Hub managed by the Consortium for Advanced Simulation of Light Water Reactors (CASL). The hub is addressing long-term operational challenges faced by U.S. nuclear utilities and is leveraging existing models (including models developed by industry), as well as developing new models.

A primary initial product of the hub is a sophisticated integrated model of a LWR (i.e., a virtual reactor with focus on modeling the reactor core). The virtual reactor will be used to address issues for existing LWRs (e.g., long-term operation and power uprates). The hub has a series of "challenge 
problems" selected principally to demonstrate the capability of the virtual reactor to enable long-term operation and power uprates. Some of these challenge problems may utilize models under development in the LWRS Program (e.g., systems analysis and component aging models) because the legacy tools have computational limitations that make them unsuited for some of the challenge problems. The LWRS Program will link with CASL models when detailed core modeling is needed for LWRS Program activities.

\subsection{Summary}

The DOE-NE Office of LWR Technologies directs the LWRS Program and closely coordinates with other agencies, the nuclear industry, and international partners to achieve LWRS Program goals. The LWRS Program Technical Integration Office supports DOE-NE in accomplishing these goals. Technical integration and program execution is accomplished by using facilities and staff from multiple national laboratories, universities, industrial alliance partners, consulting organizations, and research groups from cooperating foreign countries.

In summary, the electrical energy sector is challenged to supply increasing amounts of electricity in a safe, dependable, and economical manner and with reduced carbon dioxide emissions. Nuclear energy is an important part of answering the challenge through the long-term safe and economical operation of current nuclear power plants and with building new nuclear power plants. DOE-NE supports a strong and viable domestic nuclear industry and preserves the ability of that industry to participate in nuclear projects here and abroad. The LWRS Program provides, in collaboration with industry programs, the technical basis for extended safe, reliable, and economical operations of the existing commercial fleet of nuclear power plants.

\section{MATERIALS AGING AND DEGRADATION 2.1 Background}

Nuclear reactors present a very challenging service environment. Components within the containment of an operating reactor must tolerate high-temperature water, stress, vibration, and an intense neutron field. Degradation of materials in this environment can lead to reduced performance and, if unmitigated, can lead to failure. Materials degradation in a nuclear power plant is very complex due to the variety of materials, environmental conditions, and stress states. Over 25 different metal alloys can be found within the primary and secondary systems; additional materials exist in concrete, the containment vessel, instrumentation and control equipment, cabling, buried piping, and other support facilities. Dominant forms of degradation may vary greatly between the different SSCs and can have an important role in the safe and efficient operation of an nuclear power plant.

Extending reactor service lifetimes to and beyond 60 years increases the demands on materials and components. Therefore, an early evaluation of the possible effects of extended lifetime is critical.

NUREG/CR- $6923^{\mathrm{g}}$ gives a detailed assessment of many of the key issues in today's reactor fleet and provides a starting point for evaluating those degradation forms particularly important for consideration in extended lifetimes. While extending operation will add additional time and neutron fluence, the primary impact will be increased susceptibility to degradation mechanisms. In the area of crack-growth mechanisms for nickel-based alloys alone, there are up to 40 variables known to have a measurable effect. Further, many variables have complex interactions (see Figure 6). In this same instance (i.e., crackgrowth mechanisms for nickel-based alloys), a purely experimental approach would require greater than a trillion experiments to address all variables and interactions. Therefore, the application of modern materials science to mechanistic studies and careful inclusion of field service conditions is required to resolve these issues in a timely manner.

g Expert Panel on Proactive Materials Degradation Assessment, NUREG/CR-6923, Nuclear Regulatory Commission, February 2007. 


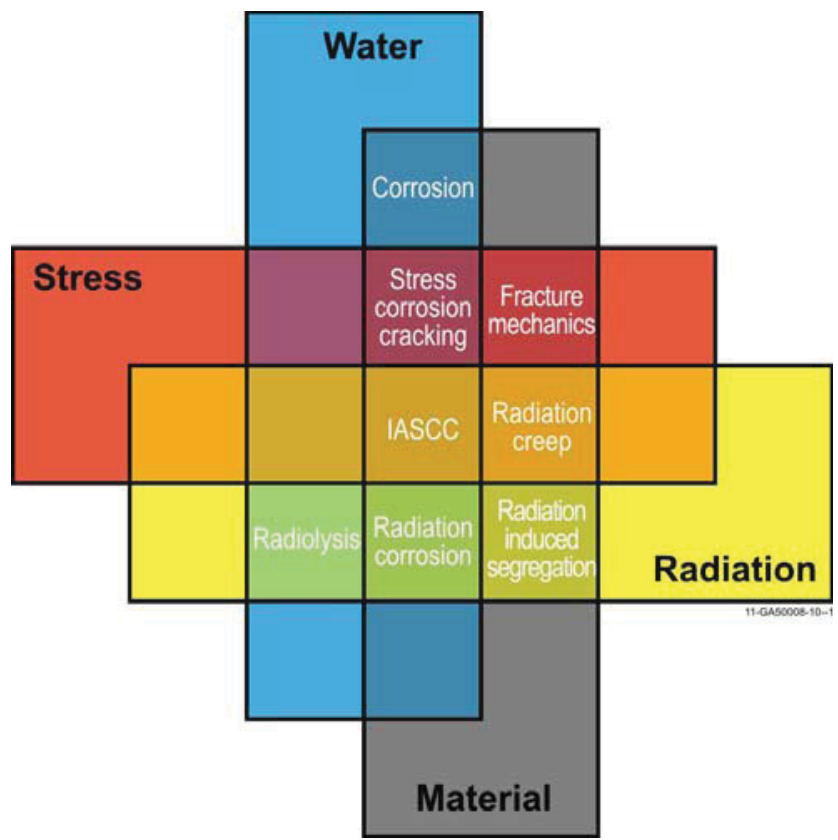

Figure 6. Complexity of interactions between materials, environments, and stresses in an operating nuclear power plant (source: A. Jennsen).

In the past two decades, there have been great gains in techniques and methodologies that can be applied to the nuclear materials problems of today. Indeed, modern materials science tools (e.g., advanced characterization tools and computational tools) must be employed. While specific tools and the science-based approach can be described in detail for each particular degradation mode, many of the diverse technical topics and information needs in this area can be organized the following key areas:

- Measurements of degradation: High-resolution measurements of degradation in all components and materials are essential to assess the extent of degradation under extended service conditions, support development of mechanistic understanding, and validate models. High quality data are of value to regulatory and industry interests in addition to academia.

- Mechanisms of degradation: Basic research to understand the underlying mechanisms of selected degradation modes can lead to better prediction and mitigation. For example, research on irradiation assisted stress corrosion cracking (IASCC) and primary water stress corrosion cracking (PWSCC) would be very beneficial for extended lifetimes and could build on existing programs within EPRI and NRC. Other forms of degradation such as swelling and embrittlement are better understood and mechanistic studies are not needed.

- Modeling and simulation: Improved modeling and simulation efforts have great potential in reducing the experimental burden for long-term operation studies. These methods can help interpolate and extrapolate data trends for extended life. Simulations predicting phase transformations, radiation embrittlement, and swelling over component lifetimes would be extremely beneficial to licensing and regulation in extended service.

- Monitoring: While understanding and predicting failures are extremely valuable tools for the management of reactor components, these tools must be supplements to active monitoring. Improved monitoring techniques will help characterize degradation of core components. For example, improved crack detection techniques will be invaluable. New nondestructive examination (NDE) techniques may also permit new means of monitoring reactor pressure vessel embrittlement or swelling of core internals. 
- Mitigation strategies: While some forms of degradation have been well researched, there are few options in mitigating their effects. Techniques such as post-irradiation annealing have been demonstrated to be very effective in reducing hardening of entire pressure vessels. Annealing may be effective in mitigating IASCC, based on initial studies. Water chemistry techniques such as NobelChem ${ }^{\mathrm{h}}$ have been very effective in reducing some corrosion problems. Additional research in these areas may provide other alternatives to component replacement.

While all components potentially can be replaced, decisions to simply replace components may not be practical or economically favorable. Therefore, understanding, controlling, and mitigating materials degradation processes and establishing a sound technical basis for long-range planning of necessary replacements are key priorities for extended nuclear power plant operations and power uprate considerations.

\subsection{Research and Development Purpose and Goals}

Materials research provides an important foundation for licensing and managing the long-term, safe, and economical operation of nuclear power plants. Aging mechanisms and their influence on nuclear power plant SSCs are predictable with sufficient confidence to support planning, investment, and licensing for necessary component repair, replacement, and license extension. Understanding, controlling, and mitigating materials degradation processes are key priorities. Proactive management is essential to help ensure that any degradation from long-term operation of nuclear power plants does not affect the public's confidence in the safety and reliability of those nuclear power plants. The strategic goals of the pathway are to develop the scientific basis for understanding and predicting long-term environmental degradation behavior of materials in nuclear power plants and to provide data and methods to assess performance of SSCs essential to safe and sustained nuclear power plant operations.

DOE, through the Materials Aging and Degradation (MAaD) Pathway is involved in this R\&D activity for the following reasons:

1. MAaD tasks provide fundamental understanding and mechanistic knowledge via science-based research. Mechanistic studies provide better foundations for prediction tool development and focused mitigation solutions. These studies also are complementary to industry efforts to gain relevant, operational data. The U.S. national laboratory and university systems are uniquely suited to provide this information given their extensive facilities, research experience, and specific expertise.

2. Selected MAaD tasks are focused on development of high-risk, high-reward technologies to understand, mitigate, or overcome materials degradation. This type of alternative technology research is uniquely suited for government roles and facilities. These pursuits also are outside the area of normal interest for industry sponsors due to the risk of failure.

3. MAaD tasks support collaborative research with industry and regulators (and meet at least one of the above objectives). The focus of these tasks is on supporting and extending industry capability by providing expertise, unique facilities, or fundamental knowledge.

Combined, these thrusts provide high quality measurements of degradation modes, improved mechanistic understanding of key degradation modes, and predictive modeling capability with sufficient experimental data to validate these tools; new methods of monitoring degradation, and development of advanced mitigation techniques to provide improved performance, reliability, and economics.

h International Conference of Water Chemistry of Nuclear Reactor Systems 8: Proceedings of Volumes 1-2, Page 116, "NobleChem ${ }^{\mathrm{TM}}$ Technology for Life Extension of BWRs - Field Experiences, GE Nuclear Energy, S. Hettiarachchi, R. L. Cowan, R. J. Law, T. P Diaz, Published 2000 
This information must be provided in a timely manner to support subsequent license decisions within the next 5-7 years. Near-term research is focused primarily on providing mechanistic understanding, predictive capabilities, and high-quality data to inform decisions and processes by both industry and regulators. Longer-term research will focus on alternative technologies to overcome or mitigate degradation. Task outputs and products are designed to inform license extension decisions and regulatory processes. Specific products and impacts will be discussed in the following sections.

\subsection{Pathway Research and Development Areas}

The MAaD Pathway activities have been organized into five principal areas: (1) reactor metals (which consists of multiple tasks), (2) concrete, (3) cables, (4) buried piping, and (5) mitigation strategies. These research areas cover material degradation in SSCs that were designed for service without replacement throughout the life of the plant. Management of long-term operation of these components can be difficult and expensive. As nuclear power plant licensees seek approval for extended operation, the way in which these materials age is evaluated and their capabilities reassessed to ensure they maintain the ability to perform their intended functions in a safe and reliable manner.

Identifying, formulating, and prioritizing all of these competing needs has been done in a collaborative manner with industrial and regulatory partners. The primary objective of a workshop and follow-on activities focusing on materials aging and degradation held at the EPRI offices in Charlotte, North Carolina on August 5 and 6,2008 was to identify an initial list of the most pressing research tasks. Twenty technical experts, providing broad institutional representation, attended the MAaD Pathway workshop. Points of discussion included organization and structure of the MAaD Pathway, need and benefits of an advisory group, and identification and prioritization of research tasks to support the LWRS Program. Tasks were identified and prioritized, and formed the basis for the priorities in the MAaD Pathway. Research since that workshop has identified additional needs and these research topics have also been considered. Continued dialogue with EPRI, NRC, vendors, utilities and other institutions around the world has helped prioritize these emerging needs into the MAaD research portfolio.

\subsubsection{Assessment and Integration}

The objectives of this research task are to provide comprehensive assessment of materials degradation, relate to consequences of SSCs and economically important components, incorporate results, guide future testing, and integrate with other pathways and programs. This task will provide an organized and updated assessment of key materials aging degradation issues and support NRC and EPRI efforts to update the Proactive Materials Degradation Assessment (PMDA) or the Materials Degradation Matrix (MDM) documents. Successful completion will provide a valuable means of task identification and prioritization within this pathway, as well as identify new needs for research.

An Expanded Materials Degradation Analysis (EMDA) of degradation mechanisms for 60 - 80 years or beyond was identified as a useful tool in further prioritizing degradation for research needs. Based on joint discussions between DOE and the NRC, it was decided that the EMDA would consist of separate and focused documents covering the key SSCs. This approach will yield a series of independent assessments (core internals and primary and secondary piping, RPV, concrete civil structures, and electrical power and I\&C cabling and insulation) that, when combined, will create a comprehensive EMDA. The LWRS Program will use this as a tool for identifying and prioritizing research in future years. The NRC will use the EMDA to inform the regulatory framework. The nuclear industry will use the EMDA results as a complementary tool to their Materials Degradation Matrix.

The major milestones associated with this task are:

- (2013) Complete and deliver gap analysis of key materials degradation modes via the Expanded Materials Degradation Analysis

- (2018) Complete and deliver revised Expanded Materials Degradation Analysis. 


\subsubsection{Reactor Metals}

Numerous types of metal alloys can be found throughout the primary and secondary systems of nuclear power plants. Some of these materials (in particular, the reactor internals) are exposed to high temperatures, water, and neutron flux, creating degradation mechanisms in the materials that are unique to reactor service. Research projects in this area will provide a technical foundation to establish the ability of those metals to support extended operations.

\subsubsection{High Fluence Effects on Reactor Pressure Vessel Steels}

The last few decades have seen much progress in developing a mechanistic understanding of irradiation embrittlement for the RPV. However, there are still significant technical issues that need to be addressed to reduce the uncertainties in regulatory application.

The objective of this research task is to examine and understand the influence of irradiation at high fluences on RPV embrittlement. Both industrial capsules and single variable experiments may be required to evaluate potential for embrittlement and to provide a better mechanistic understanding of this form of degradation. Acquisition of samples from past programmatic campaigns (such as NRC programs), specimens harvested from decommissioned reactors (e.g. Zion 1 and 2), surveillance specimens from operating nuclear power plants, and materials irradiated in new test campaigns all have value in understanding high fluence effects. Testing will include impact and fracture toughness evaluations, hardness, and microstructural analysis (atom probe tomography, small angle neutron scattering, and/or positron-annihilation spectroscopy). These research tasks all support development of a predictive model for transition-temperature shifts for RPV steels under a variety of conditions. This tool can be used to predict RPV embrittlement over a variety of conditions key to irradiation-induced changes (e.g., time, temperature, composition, flux, and fluence) and extends the current tools for RPV management and regulation to extended-service conditions. This model will be delivered in 2015 in a detailed report, along with all supporting research data. In addition, the library of assembled materials will be available for examination and testing by other stakeholders.

The major milestones associated with this task are:

- (2013) Complete detailed analysis of RPV samples from Ringhals and R. E. Ginna nuclear power plants

- (2014) Complete acquisition of experimental data on commercial and model RPV alloys

- (2015) Provide validated model for transition temperature shifts in RPV steels.

Future milestones and specific subtasks will be based on the results of the previous years testing as well as ongoing, industry-led research. Both industry and regulators will use the experimental data and model. Completion of data acquisition to permit prediction of embrittlement in RPV steels at high fluence is a major step in informing long-term operation decisions, and high quality data can be used to inform operational decisions for the RPV by industry. For example, data and trends will be essential in determining operating limits. The data will also allow for extension of regulatory limits and guidelines to extended service conditions. The delivery of a validated model for prediction of transition temperature shifts in RPV steels will allow for estimation of RPV performance over a wide range of conditions. This will enable extension of current tools for RPV embrittlement (e.g. Fracture Analysis of Vessels: Oak Ridge $\left[\mathrm{FAVOR}^{\mathrm{i}}\right]$ ) to extended service conditions.

i NUREG/CR-6854, ORNL/TM-2004/244, Fracture Analysis of Vessels - Oak Ridge FAVOR, v04.1, Computer Code: Theory and Implementation of Algorithms, Methods, and Correlations, P.T. Williams, T.L. Dickson, and S. Yin, Oak Ridge National Laboratory, October 2004 


\subsubsection{Material Variability and Attenuation Effects of Reactor Pressure Vessel Steels}

The subject of material variability has experienced increasing attention in recent years as additional research programs began to focus on the development of statistically viable databases. The objective of this task is to develop new methods to generate meaningful data out of previously tested specimens. Embrittlement margins for a vessel can be accurately calculated using supplementary alloys and experiments using higher flux test reactors. The potential for non-conservative estimates resulting from these methodologies must be evaluated to fully understand the potential influence on safety margins. Critical assessments and benchmark experiments will be conducted. Harvesting of through-thickness RPV specimens may be used to evaluate attenuation effects in a detailed and meaningful manner. Testing will include impact and fracture toughness evaluations, hardness, and microstructural analysis (atom probe tomography, small angle neutron scattering, and/or positron-annihilation spectroscopy). The results of these examinations can be used to assess the operational implications of high-fluence effects on RPVs. Furthermore, the predictive capability developed in earlier tasks will be modified to address these effects.

The major milestones associated with this task are:

- (2013) Complete a detailed review of the NRC Pressurized Thermal Shock (PTS) re-evaluation project relative to the subject of material variability and identify specific remaining issues

- (2016) Complete analysis of hardening and embrittlement through the RPV thickness for the Zion RPV sections.

Future milestones and specific subtasks will be based on the results of the previous years testing as well as ongoing, industry-led research. The analysis of hardening and variability through the thickness of an actual RPV section from service has considerable value to all stakeholders. This data will provide a first-look at embrittlement trends through the thickness of the RPV wall and inform operating limits, fracture mechanics models, and safety margins.

\subsubsection{Nondestructive Evaluation of RPV Degradation}

In the context of long-term operations, the RPV will see increased exposure to time-at-temperature, along with the effects of extended irradiation as described in previous sections. This exposure is expected to reduce the fracture toughness of the pressure vessel. As a result of this exposure and the operational stresses experienced, issues of concern in RPV durability will include phase transformations due to irradiation as well as embrittlement and hardening. Preexisting flaws in the RPV are also of interest for their implications on RPV structural performance during accident scenarios. Development of one or more NDE techniques that can assist in the determination of current RPV fracture toughness as well as in prediction of fracture toughness with further aging of the vessel is essential. The NDE measurements and the corresponding models that can verify their applicability to the problem, sensitivity to embrittlement and microcracking, and accuracy in characterizing physical properties of RPV steels to establish correlations with RPV fracture toughness will provide important information for long-term operation.

The major milestone associated with this task is:

- (2019) Demonstrate and deploy new or improved NDE technologies for RPV components.

The development of NDE techniques to permit in-situ monitoring of the RPV could be revolutionary and allow for an assessment of RPV performance at specific locations of interest and more frequent intervals, a significant difference from today's surveillance coupon methodology. This would reduce uncertainty in safety margins and is valuable to both industry and regulators.

\subsubsection{Mechanisms of Irradiation-Assisted Stress Corrosion Cracking}

The objective of this work is to evaluate the response and mechanisms of IASCC in austenitic stainless steels with single-variable experiments. Crack growth rate tests and complementary microstructure analysis will provide a more complete understanding of IASCC by building on past 
EPRI-led work for the Cooperative IASCC Research Group ${ }^{j}$. Experimental research will include crackgrowth testing on high-fluence specimens of single-variable alloys in simulated LWR environments, tensile testing, hardness testing, microstructural and microchemical analysis, and detailed efforts to characterize localized deformation. Combined, these single-variable experiments will provide mechanistic understanding that can be used to identify key operational variables to mitigate or control IASCC, optimize inspection and maintenance schedules to the most susceptible materials/locations, and, in the long-term, design IASCC-resistant materials.

The major milestones associated with this task are:

- (2015) Complete mechanistic testing for IASCC research

- (2019) Deliver predictive model capability for IASCC susceptibility

Detailed testing and specific subtasks will be based on the results of the previous years testing, as well as ongoing, industry-led research. Understanding the mechanism of IASCC will enable more focused material inspections, material replacements, and more detailed regulatory guidelines. In the long-term, mechanistic understanding also enables development of a predictive model, which has been sought for IASCC for decades.

\subsubsection{High Fluence Irradiation-Assisted Stress Corrosion Cracking}

The objective of this task is to assess high-fluence effects on IASCC for core internals. Crack growthrate testing is especially limited for high-fluence specimens. Intergranular fracture observed in recent experiments suggests more work is needed. Also of interest is identification of high-fluence materials available for research and testing in all tasks.

Research includes a detailed plan to obtain high-fluence specimens for IASCC testing from irradiation of as-received material to high fluence in a test reactor, obtaining high-fluence materials for sample manufacturing, or a combination of those two factors. In addition, both tests (i.e., crack growth and tensile tests) will be performed in simulated water environments in addition to complementary postirradiation examination of irradiation effects. Results from this task can be used to investigate the potential for IASCC under extended service conditions, extend the mechanistic studies from other tasks in the LWRS Program, and be used to validate predictive models at high fluence.

The major milestone associated with this task is:

- (2013) Complete detailed experimental plan, timeline, and assessment of irradiation needs for highfluence IASCC testing.

Future milestones and specific subtasks will be based on the plan developed in 2013. Completing a detailed experimental plan for high-fluence IASCC testing is an essential first step in estimating the impact of IASCC at high fluence. This plan is also critical for building support and partnerships with industry and regulators.

\subsubsection{High Fluence Phase Transformations of Core Internal Materials}

This task will provide detailed microstructural analysis of phase transformation in key samples and components (both model alloys and service materials), including transmission electron microscopy, magnetic measurements, and hardness examinations. Mechanical testing to quantify any impacts on embrittlement also may be performed. These results will be used to develop and validate a phenomenological model of phase transformation under LWR operating conditions. This will be accomplished by use of computational thermodynamics and extension of models for radiation-induced segregation (RIS). The generated data and mechanistic studies will be used to identify key operational

j EPRI, "Final Review of the Cooperative Irradiation-Assisted Stress Corrosion Cracking Research Program, Product ID. 1020986, June 3, 2010 
limits (if any) to minimize phase transformation concerns, optimize inspection and maintenance schedules to the most susceptible materials/locations and, if necessary, qualify radiation-tolerant materials for LWR service.

The major milestones associated with this task are:

- (2014) Complete basic model development for phase transformations in LWR components

- (2017) Deliver experimentally validated, physically-based thermodynamic and kinetic model of precipitate phase stability and formation in Alloy 316 under anticipated extended lifetime operation of LWRs.

Future milestones and specific tasks will be based on the results of the previous years testing as well as ongoing, industry-led research. The development and delivery for a validated model for phase transformations in core internal components at high fluence is an important step in estimating the useful life of core internal components. Understanding which components are susceptible to this form of degradation is of value to industry and regulators, as it will permit more focused component inspections, component replacements, and more detailed regulatory guidelines.

\subsubsection{High Fluence Swelling of Core Internal Materials}

This task will provide detailed microstructural analysis of swelling in key samples and components (both model alloys and service materials), including transmission electron microscopy and volumetric measurements. These results will be used to develop and validate a phenomenological model of swelling under LWR conditions. This will be accomplished by extension of past models developed for fast reactor conditions. The data generated and mechanistic studies will be used to identify key operational limits (if any) to minimize swelling concerns, optimize inspection and maintenance schedules to the most susceptible materials/locations, and, if necessary, qualify swelling-resistant materials for LWR service.

The major milestones associated with this task are:

- (2014) Complete model development for swelling in LWR components

- (2016) Deliver predictive capability for swelling in LWR components.

Future milestones and specific tasks will be based on the results of the previous years testing, as well as ongoing, industry-led research. The development and delivery for a validated model for swelling in core internal components at high fluence is an important step in estimating the useful life of core internal components. Understanding which components are susceptible to this form of degradation is of value to industry and regulators, as it will permit more focused component inspections, component replacements, and more detailed regulatory guidelines.

\subsubsection{Cracking-Initiation in Ni-base Alloys}

The objective of this task is the identification of underlying mechanisms of stress corrosion cracking (SCC) in Ni-base alloys. Understanding and modeling the mechanisms of crack initiation is a key step in predicting and mitigating SCC in the primary and secondary water systems. An examination into the influence of surface conditions on precursor states and crack initiation also is a key need for Ni-base alloys and austenitic stainless steels. This effort focuses on SCC crack-initiation testing of Ni-base alloys and stainless steels in simulated LWR water chemistries, but includes direct linkages to SCC crackgrowth behavior. Carefully controlled microstructure and surface states will be used to generate singlevariable experiments. The experimental effort in this task will be highly complementary to efforts being initiated at the Materials Aging Institute, which are focused primarily on modeling of crack initiation. This mechanistic information could provide key operational variables to mitigate or control SCC in these materials, optimize inspection and maintenance schedules to the most susceptible materials/locations, and potentially define SCC-resistant materials. 
The major milestones associated with this task are:

- (2014) Complete Phase 1 mechanistic testing for SCC research

- (2017) Deliver predictive model capability for Ni-base alloy SCC susceptibility.

Completing research to identify the mechanisms and precursor states is an essential step to predicting the extent of this form of degradation under extended service conditions. Understanding underlying causes for crack-initiation may allow for more focused material inspections and maintenance, new SCCresistant alloys, and development of new mitigation strategies, all of which are of high interest to the nuclear industry. This mechanistic understanding may also drive more informed regulatory guidelines and aging-management programs. In the long-term, mechanistic understanding also enables development of a predictive model, which has been sought by industry and regulators for many years.

\subsubsection{Nondestructive Evaluation of Cracking Precursors}

The purpose of this task is to investigate and demonstrate the technical basis for, and feasibility of, advanced NDE methods for evaluation of cracking precursors. These activities will build on the current state-of-the-art in NDE, and leverage advances occurring in non-nuclear applications.

The major milestones associated with this task are:

- (2017) Complete capability demonstrations for crack precursor detection on prototypic materials

- (2019) Complete demonstration of the technical basis and feasibility for use of crack precursor detection NDE, diagnostics, and prognostics for LWR long-term operation (60 to 80 years).

The development of NDE techniques to permit detection of crack-precursors in piping or core internal materials could be revolutionary and allow for an assessment of material performance at specific locations of interest and more frequent intervals. This would reduce uncertainty in safety margins, allow for efficient and timely component repair or replacement, and is valuable to both industry and regulators.

\subsubsection{Environmentally Assisted Fatigue}

The objective of this task is to develop a model of environmentally assisted fatigue mechanisms. This will be supported by experimental studies to provide data for identification of mechanisms and key variables and provide data for model validation. The experimental data will inform regulatory and operational decisions, while the model will provide a capability to extrapolate the severity of this mode of degradation to extended-life conditions. A final report will be delivered in the 2017 to 2021 timeframe, providing both the model of fatigue mechanisms and the supporting experimental data.

The major milestones associated with this task are:

- (2014) Complete base model development for environmentally-assisted fatigue in LWR components

- (2017) Complete experimental validation and deliver model for environmentally-assisted fatigue in LWR components.

Completing research to identify the mechanisms of environmentally assisted fatigue to support model development is an essential step to predicting the extent of this form of degradation under extended service conditions. This knowledge has been identified as a key need by regulators and industry. Delivering a model for environmentally assisted fatigue will enable more focused material inspections, material replacements, and more detailed regulatory guidelines.

\subsubsection{Nondestructive Evaluation of Environmentally-Assisted Fatigue Degradation}

In parallel with research on long-term performance of reactor metals, techniques for NDE of key reactor metals are needed toward development of technologies to monitor material and component performance. This task follows the R\&D plan developed in 2012 for sensor development to monitor reactor metal performance. In future years, sensor development will be performed with a demonstration of 
key prototypes by 2016. This ambitious date will require collaboration with other tasks within the LWRS Program and other programs and critical assessment and use of technologies from other industries. Validation and qualification of the sensors will be established and documented in the 2017 to 2021 timeframe.

The major milestones associated with this task are:

- (2017) Demonstrate key prototypes of fatigue damage NDE sensors in field test

- (2021) Complete validation of fatigue damage NDE sensors.

The development of NDE techniques to permit in-situ monitoring of fatigue damage in a variety of metallic components could be revolutionary and allow for an assessment of material performance at specific locations of interest and more frequent intervals, a significant difference from today's methodology and aging management practices. This would reduce uncertainty in safety margins and is valuable to both industry and regulators.

\subsubsection{Thermal Aging of Cast Stainless Steels}

In this research task, the effects of elevated temperature service in cast stainless steel (CASS) will be examined. Possible effects include phase transformations that can adversely impact mechanical properties. This task will provide conclusive predictions for the integrity of the CASS components of LWR power plants during the extended service life. Mechanical and microstructural data obtained through accelerated aging experiments and computational simulation will be the key input for the prediction of CASS behaviors and for the integrity analyses for various CASS components. While accelerated aging experiments and computational simulations will comprise the main components of the knowledge base for CASS aging, the data will also be obtained from operational experience. This data is required to validate the accelerated aging methodology. In addition to using existing data, therefore, a systematic campaign to obtain mechanical data from used materials or components will be pursued. Further, the detailed studies on aging and embrittlement mechanisms as well as on deformation and fracture mechanisms are performed to understand and predict the aging behavior over extended lifetime.

The major milestones associated with this task are:

- (2016) Complete analysis of cast stainless steel specimens harvested from service conditions

- (2017) Complete analysis and simulations on aging of cast stainless steel components and deliver predictive capability for cast stainless steel components under extended service conditions.

Completing research to identify potential thermal aging issues for CASS components is an essential step to identifying possibly synergistic effects of thermal aging (corrosion, mechanical, etc.) and predicting the extent of this form of degradation under extended service conditions. Understanding the mechanisms of thermal aging will enable more focused material inspections, material replacements, and more detailed regulatory guidelines. This data will also help close gaps identified in the EPRI MDM and upcoming EMDA reports.

\subsubsection{Concrete}

Figure 7 serves as a reminder that large areas of most nuclear power plants have been constructed using concrete and there are some data on performance through the first 40 years of service. In general, the performance of reinforced concrete structures in nuclear power plants has been very good. Incidents of degradation initially reported generally occurred early in the life of the structures and primarily have been attributed to construction/design deficiencies or improper material selection. Although the vast majority of these structures will continue to meet their functional or performance requirements during the current and any future licensing periods, it is reasonable to assume that there will be isolated examples where as a result primarily of environmental effects, the structures may not exhibit the desired durability 
(e.g., water-intake structures and freezing/thawing damage of containments) without some form of intervention.

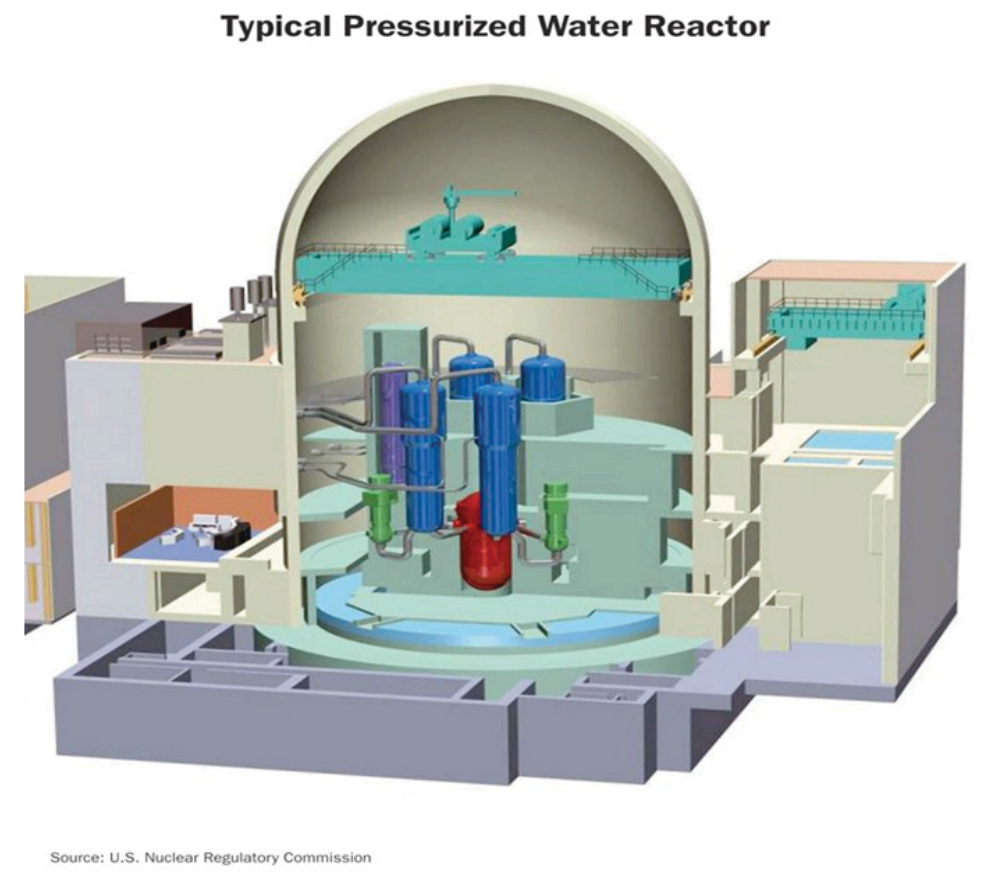

Figure 7. Cut-away of a typical pressurized water reactor, illustrating large volumes of concrete and the key role of concrete performance (source: NRC).

\subsubsection{Concrete and Civil Structure Degradation}

Although a number of organizations have sponsored work addressing the aging of nuclear power plant structures (e.g., Nuclear Regulatory Commission, Nuclear Energy Agency, and International Atomic Energy Agency), there are still several areas where additional research is desired to demonstrate that the structures will continue to meet functional and performance requirements (e.g., maintain structural margins). Activities under the MAaD Pathway are focused on compilation of material property data for long-term performance and trending, evaluation of environmental effects, and assessment and validation of NDE methods; evaluation of long-term effects of elevated temperature and radiation; non-intrusive methods for inspection of thick, heavily-reinforced concrete structures and basemats; and data on application and performance (e.g., durability) of repair materials and techniques. Complementary activities are being conducted under an NRC program at Oak Ridge National Laboratory, by EPRI, and by the Nuclear Energy Standards Coordination Collaborative headed by the National Institute for Standards and Technology.

To support these activities, a detailed and populated database on concrete performance, with data for performance into the first life-extension period, high-temperature effects, and irradiation effects, will be delivered by 2016. Plans for research at EPRI and NRC will continue to be evaluated to confirm the complementary and cooperative nature of concrete research under the MAaD Pathway. In addition, the formation of an Extended Service Materials Working Group for concrete issues will provide a valuable resource for additional and diverse input. 
The major milestones associated with this task are:

- (2013) Complete validation of data contained in the concrete performance database and place database in public domain

- (2018) Complete concrete and civil infrastructure toolbox development with EPRI and Materials Aging Institute partners.

Future milestones and specific tasks will be based on the results of the previous years testing as well as ongoing, industry-led research. Completing and publishing a database of concrete performance will yield a high-value tool accessible to all stakeholders. This will allow for more focused research on remaining knowledge gaps and enable more focused material inspections. In the long-term, completion of a concrete and civil structures toolkit may allow for more robust prediction of concrete performance over extended service conditions. These tools are of high value to industry, a partner in their development.

\subsubsection{Nondestructive Evaluation of Concrete and Civil Structures}

Techniques for NDE of concrete provide new technologies to monitor material and component performance. This task will build on an R\&D plan developed in 2012 for sensor development to monitor reactor concrete performance. Key issues for consideration can include new or adapted techniques for concrete surveillance. Specific areas of interest may include reinforcing steel condition, chemical composition, strength, or stress-state.

The major milestones associated with this task are:

- (2016) Complete prototype proof-of-concept system for NDE of concrete sections

- (2018) Complete prototype of concrete NDE system.

The development of NDE techniques to permit monitoring of the concrete and civil structures could be revolutionary and allow for an assessment of performance that is not currently available via core drilling in operating plants. This would reduce uncertainty in safety margins and is valuable to both industry and regulators.

\subsubsection{Cabling}

Cable aging mechanisms and degradation is an important area of study. The plant operators carry out periodic cable inspections using NDE techniques to measure degradation and determine when replacement is needed. Degradation of these cables is primarily caused by long-term exposure to high temperatures. Additionally, stretches of cables that have been buried underground are frequently exposed to groundwater. Wholesale replacement of cables is likely economically undesirable for plant operation beyond 60 years.

\subsubsection{Mechanisms of Cable Insulation Aging and Degradation}

This task provides an understanding of the role of material type, history, and the environment on cable insulation degradation; understanding of accelerated testing limitations; and support to partners in modeling activities, surveillance, and testing criteria. This task will provide experimental characterization of key forms of cable and cable insulation in a cooperative effort with NRC and EPRI. Tests will include evaluations of cable integrity following exposure to elevated temperature, humidity, and/or ionizing irradiation. This experimental data will be used to evaluate mechanisms of cable aging and determine the validity or limitations of accelerated aging protocols. The experimental data and mechanistic studies can be used to help identify key operational variables related to cable aging, optimize inspection and maintenance schedules to the most susceptible materials/locations, and, in the long-range, design tolerant materials.

The major milestones associated with this task are:

- (2014) Complete analysis of key degradation modes of cable insulation 
- (2015) Complete assessment of cable mitigation strategies

- (2017) Deliver predictive model for cable degradation.

Future milestones and specific tasks will be based on the results of the previous years testing as well as ongoing, industry-led research. Completing research to identify and understand the degradation modes of cable insulation is an essential step to predicting the performance of cable insulation under extended service conditions. These data are clearly critical to develop and deliver a predictive model for cable insulation degradation. Both will enable more focused inspections, material replacements, and better informed regulations. The development of in-situ mitigation strategies may also allow for an alternative to cable replacement and would be of high value to industry by avoiding costly replacements.

\subsubsection{Nondestructive Evaluation of Cable Insulation}

The objectives of this task include the development and validation of new NDE technologies for the monitoring of condition of cable insulation. This task will build on an R\&D plan developed in 2012 for sensor development to monitor reactor metal performance. In future years, this research will include an assessment of key aging indicators; development of new and transformational NDE methods for cable insulation; and utilize the NDE signals and mechanistic knowledge from other areas of the LWRS Program to provide predictions of remaining useful life. A key element underpinning these three thrusts will be harvesting of aged materials for validation.

The major milestones associated with this task are:

- (2015) Complete assessment of cable insulation precursors to correlate with performance and NDE signals

- (2017) Demonstrate field testing of prototype system for NDE of cable insulation.

The development of NDE techniques to permit in-situ monitoring of the cable insulation performance could be revolutionary and allow for an assessment of cable insulation performance at specific locations of interest and more frequent intervals, a significant difference from today's methodology. This would reduce uncertainty in safety margins and is valuable to both industry and regulators.

\subsubsection{Buried Piping}

Maintaining the many miles of buried piping at a reactor is an area of concern when evaluating the feasibility of extended plant operations. While much of the buried piping is associated with either the secondary side of the plant or other non-safety-related cooling systems, some buried piping serves a direct safety function. Maintaining the integrity of the buried piping in these systems is necessary to ensure the systems can continue to perform their intended functions under extended plant service periods. Industry and regulators already are performing considerable work in this area. The LWRS Program continues to evaluate this area for gaps and needs relative to extended service.

\subsubsection{Mitigation Technologies}

Mitigation technologies include weld repair, post-irradiation annealing, and water chemistry modifications. Welding is widely used for component repair. Weld-repair techniques must be resistant to long-term degradation mechanisms. Extended lifetimes and increased repair frequency welds must be resistant to corrosion, irradiation, and other forms of degradation. The purpose of this research area is to develop new welding techniques, weld analysis, and weld repair. A critical assessment of the most advanced methods and their viability for LWR repair weld applications is needed. Post-irradiation annealing may be a means of reducing irradiation-induced hardening in the RPV. Water chemistry modification is another mitigation technology that warrants evaluation. 


\subsubsection{Advanced Weld Repair}

This task for developing and demonstrating advanced welding technology for repair applications is being performed collaboratively with EPRI (highlighted in Figure 8). Research includes mechanistic understanding of helium effects in weldments. This modeling task is supported by characterization of model alloys before and after irradiation and welding. This model can be used by stakeholders to further improve best practices for repair welding for both existing technology and advanced technology. In addition, this task will provide validation of residual stress models under development using advanced characterization techniques such as neutron scattering. Residual stress models also will improve best practices for weldments of reactors today and under extended service conditions. These tools could be expanded to include other industry practices such as peening. Finally, advanced welding techniques (such as friction-stir welding, laser welding, and hybrid techniques) will be developed and demonstrated on relevant materials (model and service alloys). Characterization of the weldments and qualification testing will be an essential step.

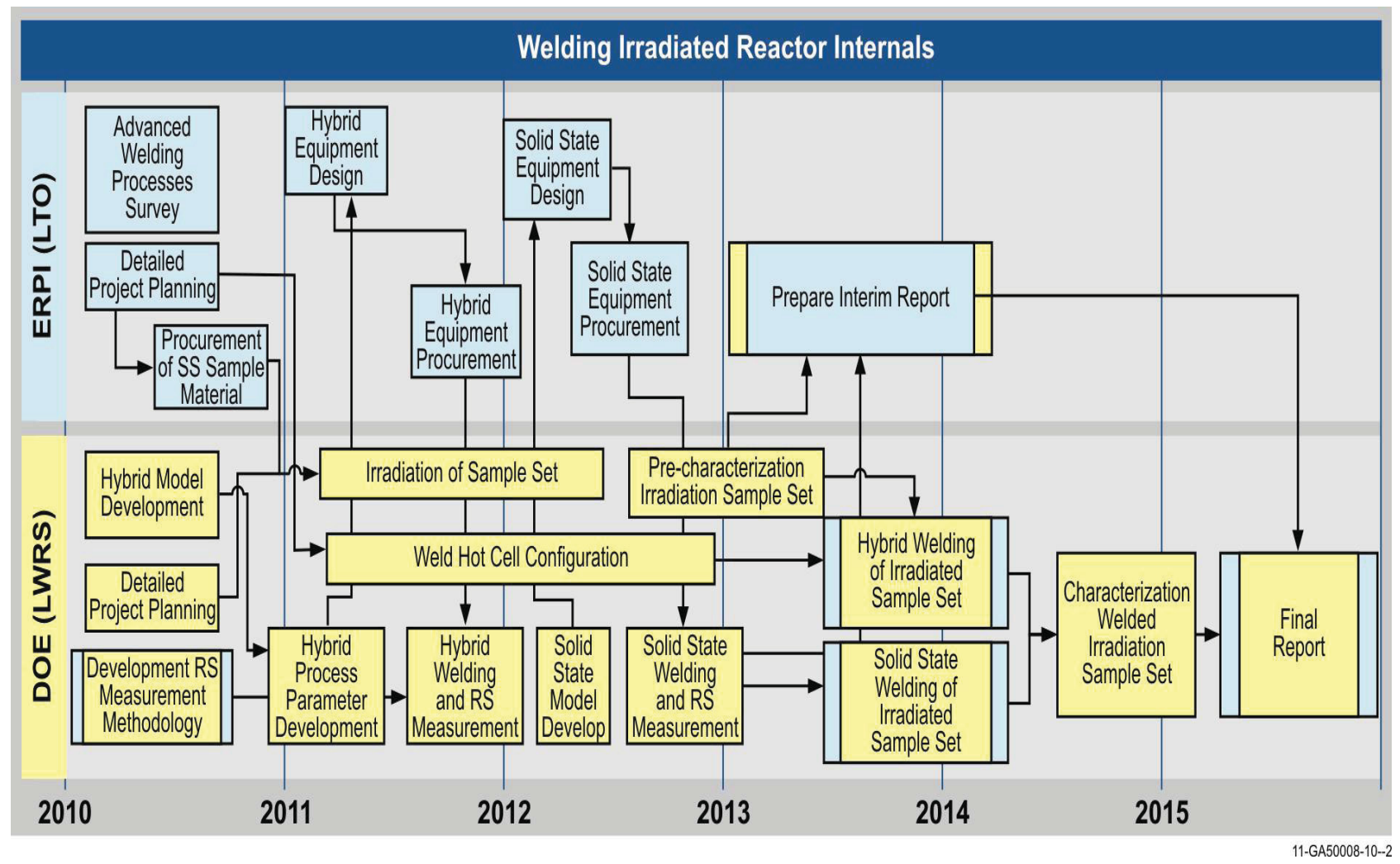

Figure 8. Process flow outline of cooperative research and development efforts between the Department of Energy and the Electric Power Research Institute.

The major milestones associated with this task are:

- (2015) Demonstrate initial solid-state welding on irradiated materials

- (2018) Complete transfer of weld-repair technique to industry.

Future milestones and specific tasks will be based on the results of the previous years testing as well as ongoing, industry-led research. Demonstration of advanced weldment techniques for irradiated materials is a key step in validating this mitigation strategy. Successful deployment may also allow for an alternative to core internal replacement and would be of high value to industry by avoiding costly 
replacements. Further, these technologies may also have utility in repair or component replacement applications in other locations within a power plant).

\subsubsection{Advanced Replacement Alloys}

Advanced replacement alloys provide new alloys for use in LWR applications that may provide greater margins and performance and support to industry partners in their programs. This task will explore and develop new alloys in collaboration with the EPRI Advanced Radiation-Resistant Materials Program. Specifically, the LWRS Program will participate in expert panel groups to develop a comprehensive R\&D plan for these advanced alloys. Future work will include alloy development, alloy optimization, fabrication of new alloys, and evaluation of their performance under LWR-relevant conditions (e.g., mechanical testing, corrosion testing, and irradiation performance among others) and, ultimately, validation of these new alloys. Based on past experience in alloy development, an optimized alloy (composition and processing details) that has been demonstrated in relevant service conditions can be delivered to industry by 2020 .

The major milestone associated with this task is:

- (2013) Complete down-selection and development plan on advanced replacement alloys in cooperation with EPRI.

Future milestones and specific tasks will be assigned following release of EPRI's Advanced Radiation Resistant Materials plan in early 2013. Completing the joint effort with EPRI on alloy downselect and development plan is an essential first step in this alloy development task. This plan will help identify future roles and responsibilities in this partnership with EPRI.

\subsubsection{Thermal Annealing}

This task provides critical assessment of thermal annealing as a mitigation technology for RPV and core internal embrittlement and research to support deployment of thermal annealing technology. This task will build on other RPV tasks and extend the mechanistic understanding of irradiation effects on RPV steels to provide an alternative mitigation strategy. This task will provide experimental and theoretical support to resolving technical issues required to implement this strategy. Successful completion of this effort will provide the data and theoretical understanding to support implementation of this alternative mitigation technology.

The major milestone associated with this task is:

- (2023) Complete characterization of RPV sections (harvested from a reactor) that have been irradiated, annealed (post-harvesting), and then reirradiated in a test reactor.

\subsubsection{Integrated Industry Activities}

Access to service materials from active or decommissioned nuclear power plants provides an invaluable access to materials for which there is limited operational data or experience to inform license extension decisions and, in coordination with other materials tasks, an assessment of current degradation models to further develop the scientific basis for understanding and predicting long-term environmental degradation behavior. LWRS Program is currently engaged in two key activities that support multiple research tasks in the previous sections: Constellation Pilot Project and Zion Harvesting Project.

The Constellation Pilot Project is a joint venture between the LWRS Program, EPRI, and the Constellation Energy Nuclear Group. The project utilizes two of Constellation's nuclear stations, R. E. Ginna and Nine Mile Point 1, for research opportunities to support extended operation of nuclear power plants. Specific areas of joint research have included development of a concrete inspection guideline, installation of equipment for monitoring containment rebar and concrete strain, and additional analysis of RPV surveillance coupons. Opportunities for additional and continued collaboration will be explored in 
coming years. A document describing containment inspection guidelines for extended service will be developed and delivered collaboratively in 2013.

The Zion Harvesting Project, in cooperation with Zion Solutions, is coordinating the selective procurement of materials, structures, components, and other items of interest to the LWRS Program, ERPI, and NRC from the decommissioned Zion 1 and Zion 2 nuclear power plants, as well as possible access to perform limited, onsite testing of certain structures and components. Materials of high interest include low-voltage cabling, concrete core samples, and through-wall thickness sections of RPV.

The major milestone associated with this task is:

- (2013) Complete Containment Inspection Guidelines for extended-service conditions through partnership with Constellation Energy and EPRI.

\subsection{Research and Development Partnerships}

Effective and efficient coordination will require contributions from many different institutions, including input from EPRI's parallel activities in the Long-Term Operations Program's strategic action plan $^{\mathrm{k}}$ and NRC's subsequent license renewal activities. In addition to contributions from EPRI and NRC, participation from utilities and vendors will be required. Given the breadth of the research needs and directions, all technical expertise and research facilities must be employed to establish the technical basis in this R\&D area for extended operations of the current nuclear power plant fleet.

The activities and results of other research efforts in the past and present must be considered on a continuous basis. Collaborations with other research efforts may provide a significant increase in cost sharing of research and may speed up research for both partners. This approach also reduces unnecessary overlap and duplicate work. Many possible avenues for collaboration exist, including the following:

- EPRI: Considerable research efforts on a broad spectrum of nuclear reactor materials issues that are under way to provide a solid foundation of data, experiences, and knowledge. R\&D cooperation on selected material's R\&D activities is reflected in the LWRS Program and EPRI's Long-Term Operation Program Joint R\&D Plan. ${ }^{1}$

- NRC: Broad research efforts of NRC are considered carefully during task selection and implementation. In addition, cooperative efforts through conduct of the Extended Proactive Materials Degradation Assessment and formation of an Extended Service Materials Working Group will provide a valuable resource for additional and diverse input.

- Boiling Water Reactor and Pressurized Water Reactor Owners Groups: These groups provide a forum for understanding key materials degradation issues for each type of reactor.

- Materials Aging Institute: The Materials Aging Institute is dedicated to understanding and modeling materials degradation; a specific example is the issue of environmental-assisted cracking. The collaborative interface with the Materials Aging Institute is coordinated through EPRI, which is a member of the Materials Aging Institute.

- Programs in other industries and sectors: Research in other fields may be applicable in the LWRS Program. For example, the Advanced Cement-Based Materials Program ${ }^{\mathrm{m}}$ may provide a valuable starting point for developing a database on concrete performance for structures.

\footnotetext{
$\mathrm{k}$ This document is an internal EPRI document and is not publicly available

1 DOE-NE Light Water Reactor Sustainability Program and EPRI Long-Term Operations Program - Joint Research and Development Plan, INL-EXT-12-24562, April 2012

m Northwestern University McCormick School of Engineering \&Applied Science, Center for Advanced cement-Based Materials, Last updated 03/02/2010,Accessed on 2/27/2013 http://acbm.northwestern.edu/
} 
- Nuclear facilities: Examination of materials from nuclear facilities provides a unique opportunity to evaluate degradation modes in relevant service materials. For example, the primary focus of the Constellation Pilot Project centers on material aging effects (Figure 9). This is a significant project commitment. However, degradation of concrete, buried piping, and cabling are not unique to nuclear reactors; other nuclear facilities (e.g., hot cells and reprocessing facilities) may be a key resource for understanding long-term aging of these materials and systems.

Constellation Pilot Project Activity

Ginna Baffle Bolts

Ginna RPV Samples

Nine Mile Point Unit 1 RPV Samples

Nine Mile Point Unit 1 Top Guide Samples

\section{LWRS Tasks Supported}

Irradiated-assisted stress corrosion cracking, swelling, phase transformations, and repair welding

Reactor pressure vessel embrittlement, thermal annealing, and representative materials

Reactor pressure vessel embrittlement, thermal annealing, and representative materials

Irradiated-assisted stress corrosion cracking and repair welding

Concrete degradation

Figure 9. Constellation pilot project activities and related research and development tasks in the Materials Aging and Degradation Pathway.

- Other nuclear materials programs: In addition, research within fast reactor and fusion reactor programs may provide key insights into high-fluence effects on materials because the mechanisms and models of degradation for fast reactor applications can be modified and provide a starting and proven framework for degradation issues in this effort. This research element includes (1) international collaboration to conduct coordinated research with international institutions (e.g., the Materials Aging Institute) to provide more collaboration and cost sharing, (2) coordinated irradiation experiments to provide a single integrated effort for irradiation experiments, (3) advanced characterization tools to increase materials testing capability, improve quality, and develop new methods for materials testing, and (4) additional research tasks based on the results and assessments of current research activities.

Participation and collaboration with all of these partners may yield new opportunities for collaboration. Cost sharing is being pursued for each task. Cost sharing can take many forms, including direct sharing of expenses, shared materials (or rescued specimens), coordinated plans, and complementary testing.

\subsection{Summary of Research and Development Products and Schedule}

The strategic goals of the pathway are to develop the scientific basis for understanding and predicting long-term environmental degradation behavior of materials in nuclear power plants and to provide data and methods to assess performance of SSCs essential to safe and sustained nuclear power plant operations. Near-term research is focused primarily on providing mechanistic understanding, predictive capabilities, and high-quality data to inform decisions and processes by both industry and regulators. Longer-term research is focused on alternative technologies to overcome or mitigate degradation. A chronological listing of the major milestones in MAaD Pathway can be found in Appendix B. 


\section{ADVANCED INSTRUMENTATION, INFORMATION, AND CONTROL SYSTEMS TECHNOLOGIES}

\subsection{Background}

Reliable Instrumentation, Information, and Control (II\&C) systems technologies are essential to ensuring safe and efficient operation of the U.S. LWR fleet. These technologies affect every aspect of nuclear power plant and balance-of-plant operations. In 1997, the National Research Council conducted a study concerning the challenges involved in modernization of digital I\&C systems in nuclear power plants. Their findings identified the need for new II\&C technology integration.

Digital II\&C technologies are deployed in a number of power generation settings worldwide. Current instrumentation and human-machine interfaces employ analog systems in the nuclear power sector. These systems, though generally considered by other industries to be obsolete, continue to function reliably, but do not enable utilities to take full advantage of digital technologies to achieve performance gains.

The nuclear power plant owners and operators realize that this analog technology represents a significant challenge to sustaining safe and economic operation of the current fleet of nuclear power plants. Beyond control systems, new technologies are needed to monitor and characterize the effects of aging and degradation in critical areas of key SSCs. The objective of these efforts is to develop, demonstrate, and deploy new digital technologies for II\&C architectures and provide monitoring capabilities to ensure the continued safe, reliable, and economic operation of the nation's nuclear power plants.

Today, digital technologies are implemented as point solutions to performance concerns with individual II\&C components as depicted in Figure 10. This reactive approach is characterized by planning horizons that are short and typically only allow for 'like-for-like' replacements. This results in a fragmented, nonoptimized approach that is driven by immediate needs. As a long-term strategy, this is inefficient in light of the evolution of II\&C technology, the availability of skills needed to maintain this legacy technology, and the associated high costs and uncertainties.

To displace the piecemeal approach to digital technology deployment, a new vision for efficiency, safety, and reliability is needed that leverages the future potential of a range of digital options. This includes consideration of goals for nuclear power plant staff numbers and types of specialized resources; targeting

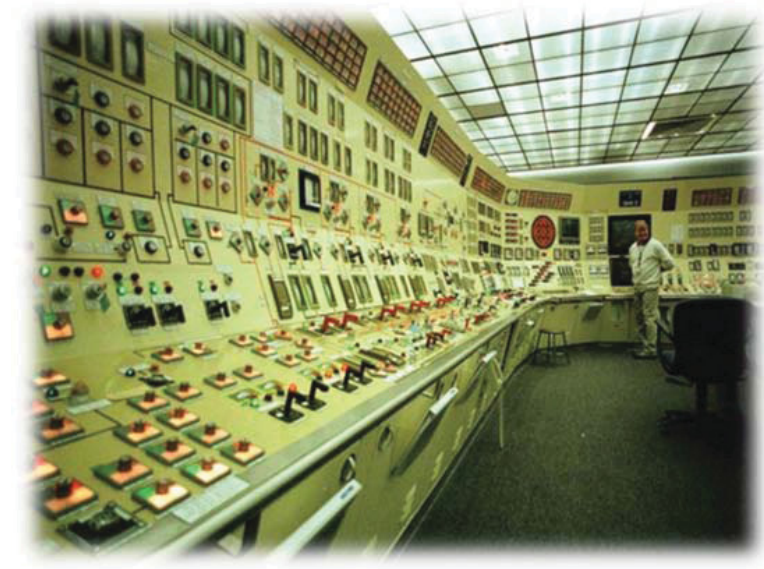

Figure 10. Typical nuclear power plant control room with analog technology. operation and management costs and the plant capacity factor to ensure commercial viability of proposed long-term operations; improved methods for achieving plant safety margins and reductions in unnecessary conservatisms; and leveraging expertise from across the nuclear enterprise. This last point is especially noteworthy because mergers and acquisitions have redefined nuclear power plant ownership and nuclear energy supply in the United States and Europe. Nuclear power plant ownership is spread across a smaller number of utilities due to mergers and acquisitions, and ownership is no longer typically characterized by regional location or even national boundaries. Digital technology can enable plant owners to effectively manage the ongoing operations and support of the nuclear power plants from wherever the owner resides.

An effective R\&D initiative must engage the stakeholders (i.e., plant owners, regulators, vendors, and $R \& D$ organizations) to initiate relevant $R \& D$ activities. This requires the development and execution of a long-term strategy for nuclear power plant II\&C technology modernization based on the unique 
characteristics of the U.S. nuclear industry and its regulatory environment. In the near term, this strategy should lead to the ability to transition to a business model for nuclear power plant operation, employing a new technology base that becomes less labor intensive, facilitates greater digital application deployments, and can be deployed seamlessly across the operational enterprise. The execution of this R\&D approach will lay the foundation for a technology base that is more stable and sustainable over the long-term and assures the continued safety of power generation from nuclear energy systems.

\subsection{Research and Development Purpose and Goals}

The purpose of the research pathway is to enable the modernization of the legacy II\&C systems in a manner that creates a seamless digital environment encompassing all aspects of plant operations and support - building a three-dimensional information architecture as shown in Figure 11, that integrates plant systems, plant processes, and plant workers in an array of interconnected technologies as follows:

- Plant systems - beyond the monitoring and control functions of these systems, extend plant information within these systems directly into the processes that support the plant work activities and directly to the workers performing these activities.

- $\quad$ Plant processes - integrate processes with realtime plant information to enable task automation, plant status control, more accurate procedure and work package usage, enhanced risk management, and other such functions, based on actual plant configuration, performance, and operational constraints.

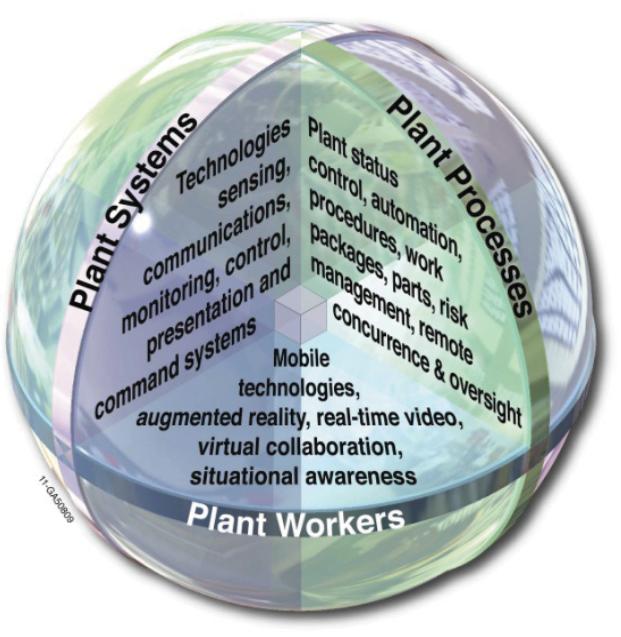

- Plant workers - immerse plant workers in an information-rich environment that provides immediate, accurate plant information and allows the workers to conduct plant processes directly at the plant location, using mobile technologies, augmented reality (e.g., "seeing" radiation fields), and real-time video, enabling virtual collaboration and collective situational awareness among all participants in a work activity, both at the job site Figure 11. The Advanced Instrumentation, Information, and Control Systems Technologies Pathway is developing an architecture that encompasses all aspects of plant operations and support, integrating plant systems, and immersing plant workers in a seamless digital environment. and in remote locations.

This development will transform the current nuclear power plant operating model from one that relies on a large plant staff and predominately manual activities to one based on smaller, technologyempowered staff conducting largely automated activities. Such an operating model will significantly enhance nuclear safety, worker productivity, and overall plant performance. This digital transformation is critical to addressing an array of difficult issues currently facing the plants, including the aging of legacy II\&C systems, the need for long-term plant asset management, a potential shortage of technical workers, susceptibility to consequential human error, ever-increasing expectations for nuclear safety improvement, and relentless pressure to reduce cost.

The development and collaborations through this pathway are intended to overcome the inertia that sustains the current status quo of today's II\&C systems technology and to motivate transformational change and a shift in strategy - informed by business objectives - to a long-term approach to II\&C 
modernization that is more sustainable. Accordingly, DOE (through the LWRS Program Advanced II\&C Systems Technologies Pathway) is involved in this activity for the following reasons:

- I\&C modernization is critical to the sustainability of the operating nuclear fleet.

- Because of its short-term operational focus, the U.S. commercial nuclear industry could modernize its legacy I\&C systems and still miss the opportunity to transform its operating model, thereby missing out on efficiencies in the advanced technologies that could reduce the costs of plant operations and outages.

- A national research program is needed to develop the transformative technologies and implementation roadmap for a performance-based I\&C replacement strategy.

- DOE's national laboratories maintain unique capabilities to develop and deliver a strategy for modernization that can be successfully deployed by the private sector:

- A federally funded and industry cost-shared program is technologically and organizationally neutral.

- Utilities must own the solution to successfully producing a plant-specific licensing case for modernized I\&C and monitoring technologies.

- National laboratories will collaborate with utilities to overcome barriers to technology deployment.

An overriding objective of this pathway is to ensure that legacy I\&C equipment does not become a limiting factor in the decisions on long-term operation of these nuclear power plants. Goals for technology introduction are to enhance efficiency, safety, and reliability; improve characterizations of the performance and capabilities of passive and active components during periods of extended operation; and facilitate introduction of new advanced II\&C systems technologies (Figure 12) by demonstrating performance and reducing regulatory uncertainties. The R\&D activities are intended to set the agenda for a long-term vision of future operations, including fleetwide integration of new technologies.
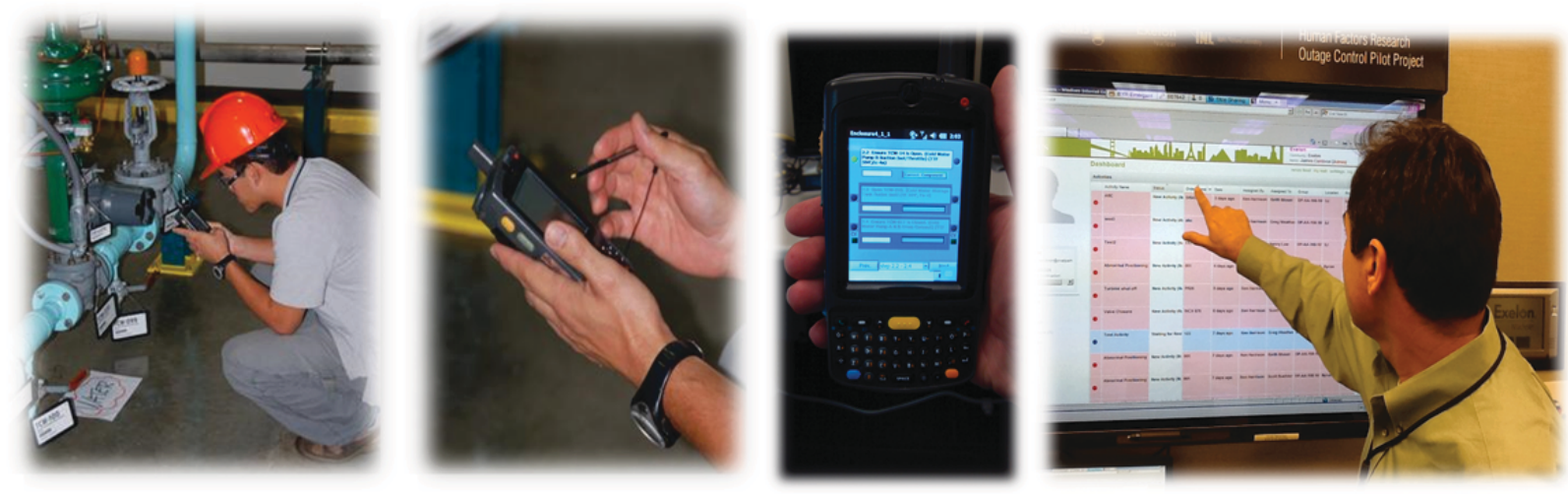

Figure 12. A nuclear power plant field worker performs his work using a portable, wireless, hand-held device developed for LWRS Program research instead of paper-based work packages.

\subsection{Pathway Research and Development Areas}

R\&D activities are being proposed to develop needed capabilities through digital technologies to support long-term nuclear power plant operations and management. The supporting technologies will enable the large integrated changes that industry cannot achieve without R\&D support. This includes comprehensive programs that achieve the following:

- Support creation of new technologies that can be deployed to address the sustainability of today's II\&C systems technologies shown in Figure 13 
- Improve understanding of, confidence in, and facilitate transition to these new technologies

- Support development of the technical basis needed to achieve technology deployments

- Create or renew infrastructure needed for research, education, and testing.

This research program will address aging and long-term reliability issues of the legacy II\&C systems used in the current LWR fleet by demonstrating new technologies and operational concepts in actual nuclear power plant settings. This approach drives the following two important outcomes:

- Reduces the technical, financial, and regulatory risk of upgrading the aging II\&C systems to support extended plant life to and beyond 60 years.

- Provides the technological foundation for a transformed nuclear power plant operating model that improves plant performance and addresses the challenges of the future business environment.
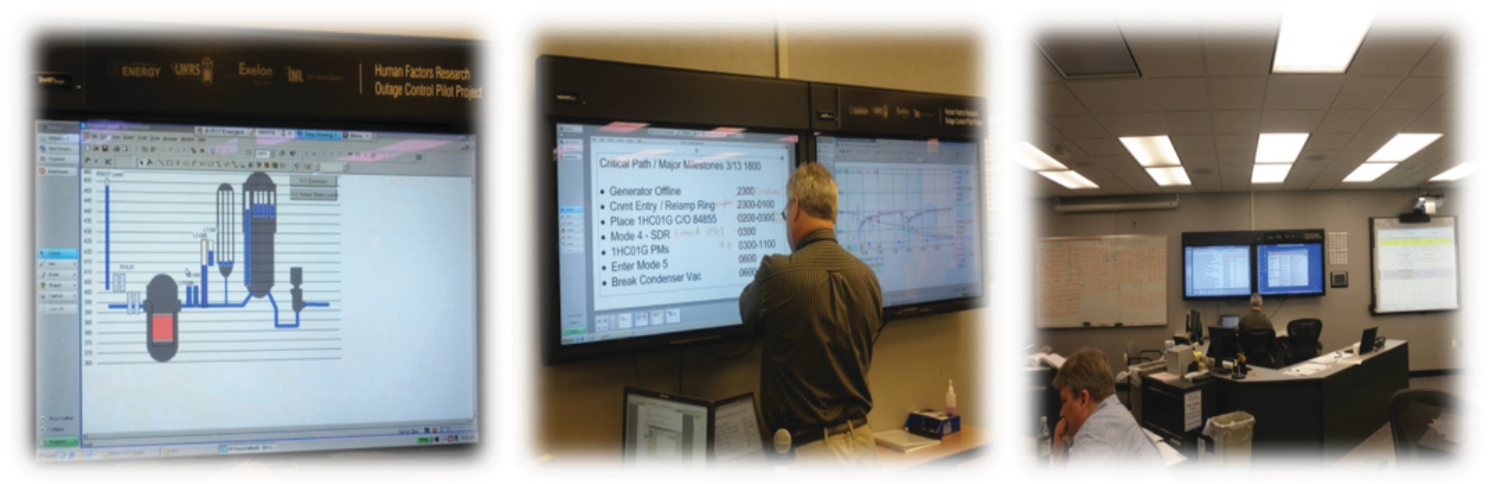

Figure 13. An outage manager at a commercial nuclear power plant uses new prototype interactive display technology developed by LWRS Program-sponsored research to monitor the progress of outage work activities at the station.

The research program is being conducted in close cooperation with the nuclear utility industry to ensure that it is responsive to the challenges and opportunities in the present operating environment. The scope of the research program is to develop a seamless integrated digital environment as the basis of the new operating model.

The program is advised by a Utility Working Group (UWG) composed of leading nuclear utilities across the industry and EPRI. The UWG developed a consensus vision of how a more integrated approach to modernizing plant II\&C systems could address a number of challenges to the long-term sustainability of the LWR fleet. ${ }^{n}$ A strategy was developed to transform the nuclear power plant operating model by first defining a future state of plant operations and support based on advanced technologies and then developing and demonstrating the needed technologies to individually transform the plant work activities. The collective work activities were grouped into the following major areas of enabling capabilities:

1. Highly integrated control room

2. Highly automated plant

3. Integrated operations

n Long-Term Instrumentation, Information, and Control Systems (II\&C) Modernization Future Vision and Strategy, INL/EXT11-24154, February 2012. 


\section{Human performance improvement for field workers}

\section{Outage safety and efficiency}

6. Centralized online monitoring and information integration.

Within these areas of enabling capabilities, 20 pilot projects were defined as the roadmap for industry to collectively integrate new technologies into nuclear power plant work activities. For online monitoring, two broad areas of development have been defined at the present, which will be further defined into additional pilot projects. A pilot project is an individual demonstration that is part of a larger strategy needed to achieve modernization according to a plan. Note that pilot projects have value on their own, as well as collectively. It is small enough to be undertaken by a single utility, it demonstrates a key technology or outcome required to achieve success in the higher strategy, and it supports scaling that can be replicated and used by other plants.

The pilot projects were defined as the appropriate points to introduce enabling technologies across the spectrum of plant work activities. These technologies serve as the stepping stones to the eventual digital environment that enables a transformed nuclear power plant operating model. In a September 2011 workshop, the UWG prioritized the pilot projects in terms of value to the utilities and validated the development order. The sequence of development is designed to achieve progressively greater benefits as the growing aggregate of integrated technologies enables higher degrees of automation and innovation. The pilot projects are scheduled over a 12 year period (i.e., 2010 to 2021) as depicted in Figure 14.

Prior to the time the individual pilot projects are scheduled to begin, members of the UWG are solicited to serve as host utilities for the R\&D activities in which the new technologies are demonstrated and validated for production usage. This arrangement has a number of advantages as follows:

- It assures the end-state vision for plant modernization is shared by a significant portion of the LWR fleet.

- It assures the near-term technologies are immediately beneficial while they comprise the long-term building blocks of a more comprehensive digital environment.

- It greatly reduces the risk of implementation for any one utility, and the oversight of the working group provides a competent peer review.

- It allows the utilities to move forward together in transforming their operating model to fully exploit these technologies, providing a transparent process for coordinated assistance from the major industry support organizations of EPRI, Institute of Nuclear Power Operations, and Nuclear Energy Institute.

The LWRS Program provides the structured research program and expertise in plant systems and processes, digital technologies, and human factors science as it applies to nuclear power plant human performance. The utilities provide a cost share in the form of their time, expenses, expertise in plant functions, plant documentation, and access to plant facilities, including the plant simulator. The products of the pilot projects are technology demonstrations and technical basis reports that can be cited in regulatory filings, vendor specifications, and utility feasibility studies.

Figure 15 provides a graphical summary of the goals of these planned R\&D activities. By carrying out the research activities shown in Figure 14, a collection of enabling capabilities will be created within the first 5 years of this $R \& D$ program. These capabilities are needed to enable near term modernization efforts by early adopters of pilot project technologies. The methods and processes developed from these early research efforts will provide needed know-how to transform traditional paper-based systems, work activities that rely on manual human efforts, and replace aging analog I\&C technologies with more flexible and functionally capable digital technologies. This first phase of modernized systems, processes, and technologies will develop the digital infrastructure and expertise in the operating fleet needed to 
create systems with greater functionality in the mid-term (i.e., 5-10 years from the initiation of research activities). In this phase, greater automation of manually performed activities will become the norm, and digital technologies will begin to figure more prominently in activities that are centralized in the main control room and for major operational activities, such as outage management. Online monitoring will begin to support greater centralization of asset management activities, providing real-time status information about equipment performance and plant status and configuration needed for safe operation as well as to realize improved condition-based maintenance of active components. From ten years and beyond, the program seeks to enable greater integration of digital technology functionalities and capabilities with the aim of creating a seamless digital work environment within more of the operating fleet. The main outcomes of this and subsequent phases of research and development are on the complete integration of digital technologies to support real-time awareness and management of operational activities, maintenance, outage, and emergency response. This future vision will be based on a set of technologies that are current, sustainable, reliable, and familiar to a future nuclear energy workforce.

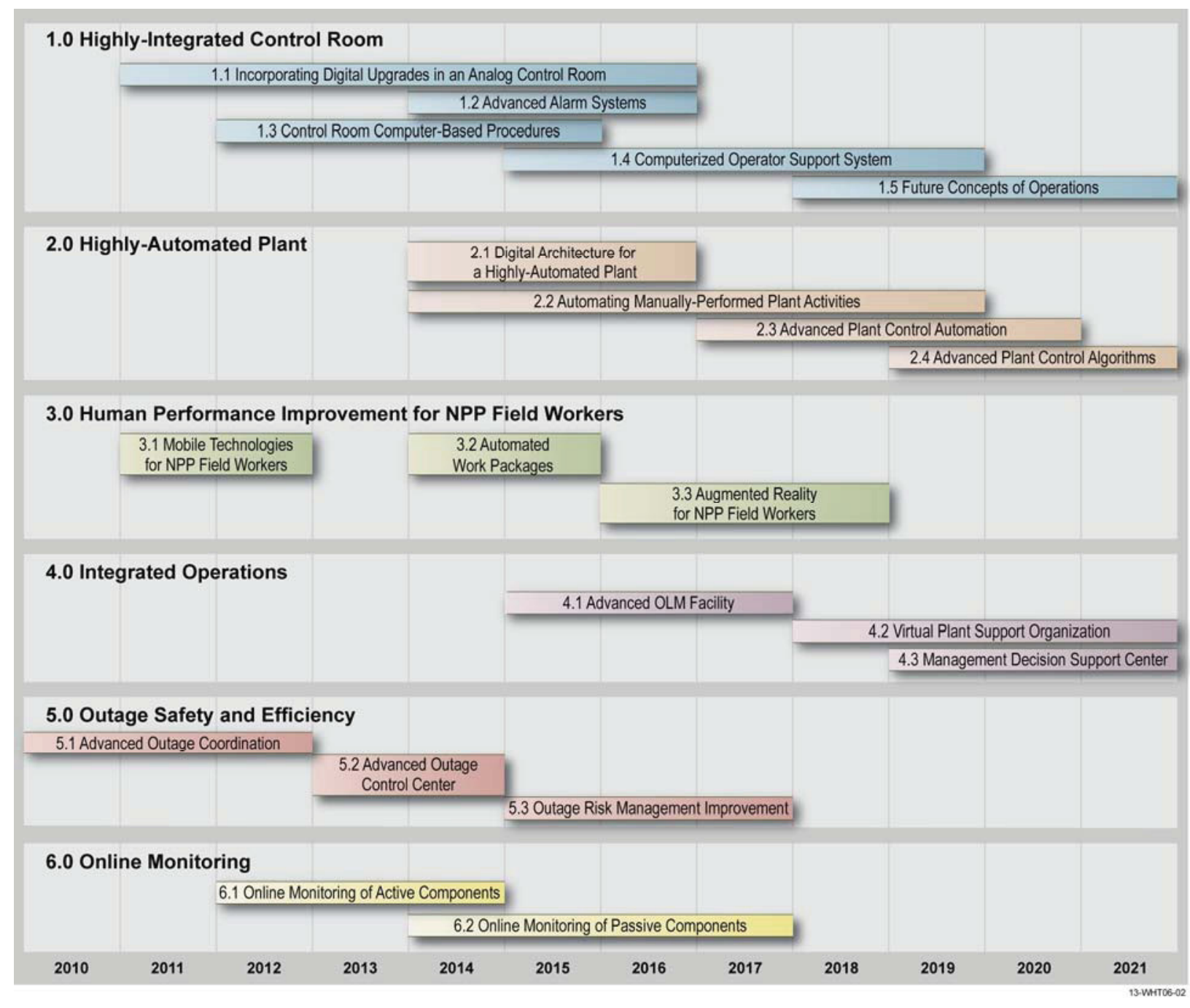

Figure 14. Pilot projects for the Advanced Instrumentation, Information, and Control Systems Technologies Pathway. 


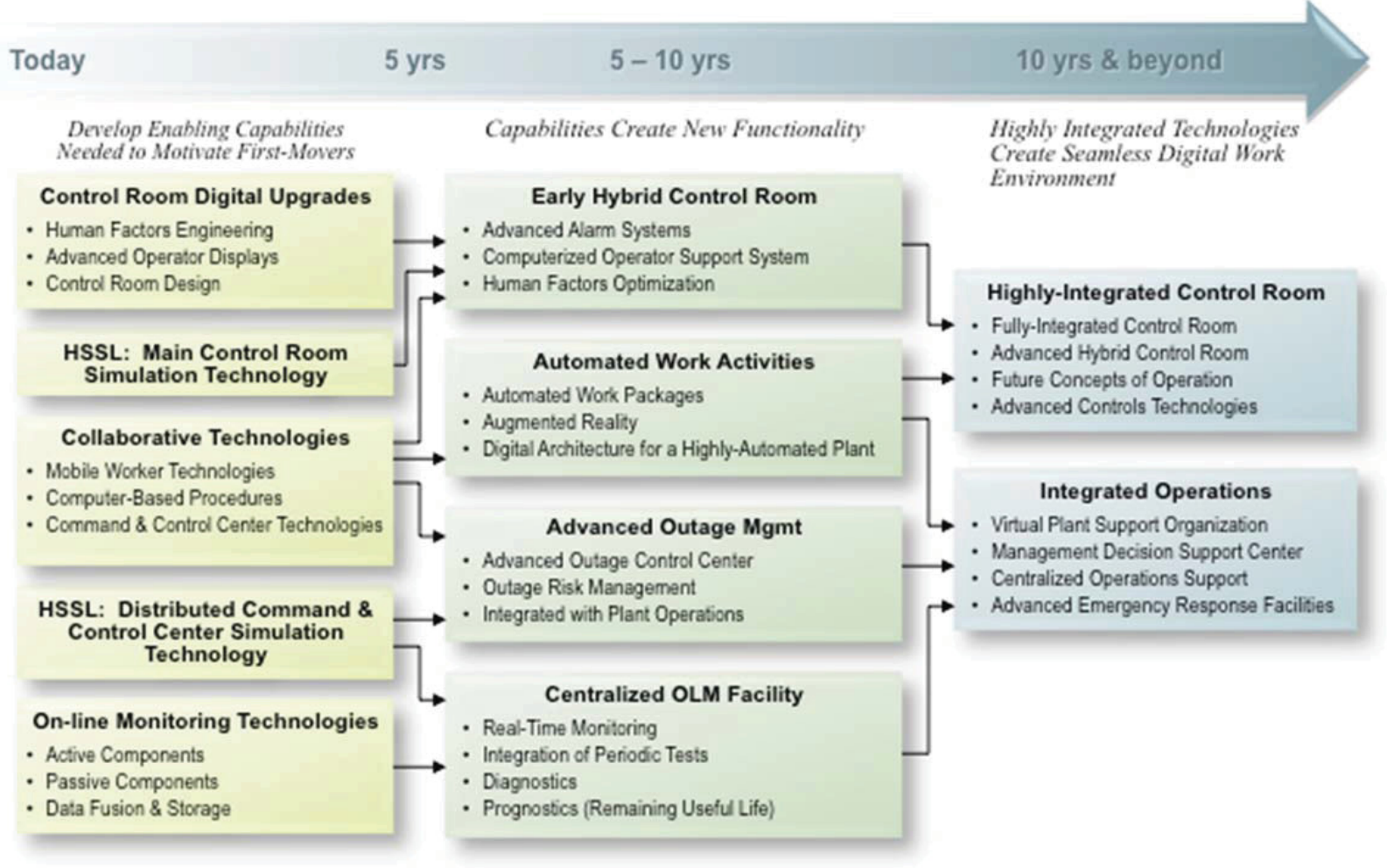

Figure 15. Goals of the Advanced Instrumentation, Information, and Controls Systems Technologies Pathway.

\subsubsection{Human Systems Simulation Laboratory}

The Human Systems Simulation Laboratory (HSSL) at the INL is used to conduct research in the design and evaluation of advanced reactor control rooms, integration of intelligent support systems to assist operators, development and assessment of advanced human performance models, and visualizations to assess advanced operational concepts across various infrastructures. This facility consists of a reconfigurable simulator that supports human factors research, including human-in-the-loop performance, human-system interfaces, and analog and digital hybrid control displays. It is applicable to the development and evaluation of control systems and displays for complex systems such as existing and advanced nuclear power plant control rooms, command and control systems, and advanced emergency operations centers. The facility also can be linked to a virtual reality system (known as the ComputerAided Virtual Environment, Figure 16) for expanded overview displays, to perform virtual walkthroughs of work environments, or to evaluate human interaction in simulated virtual environments.

The HSSL will be used to study human performance in a near-realistic operational context for advanced nuclear power plant control room design. The facility is equally suitable for human performance measurement in other nuclear power plant control centers such as an outage control center, a centralized online monitoring center, and emergency response facilities. 


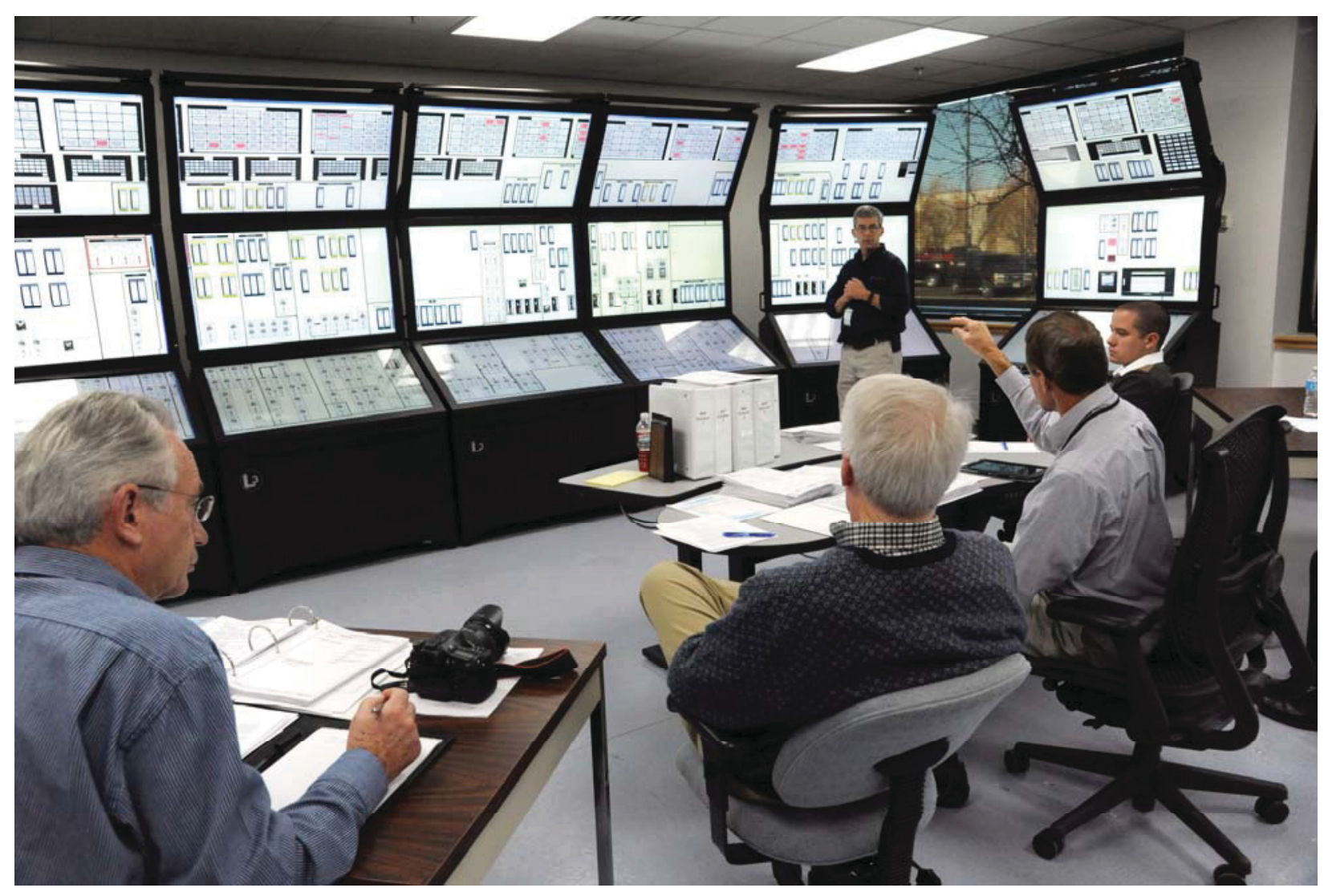

Figure 16. An operator workshop with a nuclear utility being conducted in the HSSL using the benchboard-style touch panel control bays.

HSSL provides the simulation, visualization, and evaluation capabilities needed for pilot projects involving development and evaluation of new technologies for the main control room and other control centers. As such, the new technologies will first be staged in HSSL for proof-of-concept prior to demonstration at host utility nuclear power plants. HSSL facilities will be configured in a variety of settings according to the functional context of each type of plant control center.

The key advantage of mimicking current control rooms comes from the ability to implement prototypes of new digital function displays into the existing analog control environment. Prior to full-scale deployment of technologies (such as control room upgrades), it is essential to test the performance of the system and the human operators' use of the system in a realistic setting. In control room research simulators, upgraded systems can be integrated into a realistic representation of the actual system and validated against defined performance criteria. The HSSL has recently been upgraded with 15 bench-board-style touch panel control bays. This will provide a more realistic representation of the panels found in the current LWR control rooms and will enable research on function allocation, task analysis, staffing, situational awareness, and workload in multiple-unit control rooms.

\subsubsection{II\&C Pilot Project Descriptions and Deliverables}

As discussed previously, a series of 20 pilot projects have been defined as the roadmap for industry to collectively integrate new technologies into nuclear power plant work activities. The pilot projects and major milestones associated with the pilot projects are provided in the following subsections. 


\subsubsection{Highly-Integrated Control Room}

Today's LWR control rooms consist of an array of discrete devices such as gauges, indicators, displays, alarms, and operator controls located on multiple large control boards. A highly-integrated control room is one in which these functions are integrated into operator workstations and overview displays that provide a compact and rich set of control functions and information presentations that greatly enhance operator performance. A hybrid control room is one in which there is a mixture of these concepts as the control rooms are progressively modernized.

The Advanced II\&C Systems Technologies Pathway will conduct R\&D activities to determine the optimum layout and concepts for a nuclear power plant hybrid control room based on engineering and human factors principles. The control room upgrades will be implemented and studied in INL's HSSL to ensure that new concepts are sound and will uphold all nuclear safety requirements. The Advanced II\&C Systems Technologies Pathway will assist a host utility in implementing the concepts in an actual nuclear power plant control room, conducting further studies on actual control room performance. Further work will develop the strategy into several tiers of control room modernization end-states, up to a highlyintegrated control room.

The major milestones associated with the pilot projects supporting the highly-integrated control room are:

- (2013) Publish a reference human factors engineering plan for an optimized, human-factored control board layout for integrating digital operator interface screens with analog controls and indicators.

- (2015) Publish a technical report for computer-based procedures that enhance worker productivity, human performance, plant configuration control, risk management, regulatory compliance, and nuclear safety margin.

- (2016) Publish a technical report for an advanced alarm management system in a nuclear power plant control room and a methodology for integrating diverse alarms and annunciators across all systems and digital platforms.

- (2016) Develop an end-state vision and strategy, based on human factors engineering principles, for the implementation of both a hybrid and a full highly integrated control room as new digital technologies and operator interface systems are introduced into traditional control rooms.

- (2017) Develop an operator advisory system fully integrated into a control room simulator that provides plant steady-state performance monitoring, diagnostics and trending of performance degradation, operator alerts for intervention, and recommended actions for problem mitigation, with application of control room design and human factors principles.

- (2018) Complete a technical report on operator attention demands and limitations on operator activities based on the current conduct of operations protocols. This report will identify opportunities to maximize operator efficiency and effectiveness with advanced digital technologies.

- (2019) Develop an end-state vision and implementation strategy for an advanced computerized operator support system, based on an operator advisory system that provides real-time situational awareness, prediction of the future plant state based on current conditions and trends, and recommended operator interventions to achieve nuclear safety goals.

- (2021) Develop validated future concepts of operations for improvements in control room protocols, staffing, operator proximity, and control room management, enabled by new technologies that provide mobile information and control capabilities and the ability to interact with other control centers (e.g., emergency response facilities for severe accident management guidelines implementation). 


\subsubsection{Highly Automated Plant}

The concept of a highly automated plant is one where important, safety-critical activities are automated using advanced technologies under the direction of a competent staff. Automation on a large scale enables a shift from a labor-intensive operating/support model to one that is technology-based. This transformed nuclear power plant operating model will address an array of future challenges facing the LWR fleet.

The Advanced II\&C Systems Technologies Pathway will develop an advanced digital architecture that integrates plant systems, plant processes, and plant workers in a manner that maximizes efficiency and shared-use of plant information. Opportunities for plant activity automation will be identified through a top-down analysis of nuclear power plant activities and define a transformed nuclear power plant operating model based on a highly-automated plant. Further, to increase nuclear safety margins and plant capacity factors, the Advanced II\&C Systems Technologies Pathway will develop strategies and guidance for specific automation improvements in plant control functions.

The major milestones associated with the pilot projects supporting the highly-automated plant are:

- (2014) Publish a technical report that provides a current state and gap analysis for integrating plant information residing in plant II\&C systems, plant work processes, and information resources needed for mobile worker technologies.

- (2016) Publish a technical report on an advanced digital architecture, integrating plant systems, plant work processes, and plant workers in a seamless digital environment, with guidance on how to apply the architecture to a nuclear power plant's established data network systems.

- (2016) For nuclear power plant chemistry activities, analyze the staffing, tasks, and cost models to identify the opportunities for application of digital technologies to improve nuclear safety, efficiency, and human performance based on optimum human-technology function allocation. Demonstrate representative activities as transformed by technology with results published in a technical report.

- (2017) For nuclear power plant maintenance activities, analyze the staffing, tasks, and cost models to identify the opportunities for application of digital technologies to improve nuclear safety, efficiency, and human performance based on optimum human-technology function allocation. Demonstrate representative activities as transformed by technology with results published in a technical report.

- (2018) For nuclear power plant radiation protection activities, analyze the staffing, tasks, and cost models to identify the opportunities for application of digital technologies to improve nuclear safety, efficiency, and human performance based on optimum human-technology function allocation. Demonstrate representative activities as transformed by technology with results published in a technical report.

- (2019) Develop and publish a transformed nuclear power plant operating model and organizational design derived from a top-down analysis of nuclear power plant operational and support activities, quantifying the efficiencies that can be realized through highly automated plant activities using advanced digital technologies.

- (2020) Develop the strategy and priorities and publish a technical report for automating operator control actions for important plant state changes, transients, and power maneuvers, resulting in nuclear safety and human performance improvements founded on engineering and human factors principles.

- (2021) Develop the strategy and priorities and publish a technical report for improving plant control algorithms, based on greater availability of sensed and derived plant parameters through the advanced digital architecture, resulting in more anticipatory, adaptive, and resilient control functions. 


\subsubsection{Human Performance Improvement for Nuclear Power Plant Field Workers}

To improve human performance for nuclear power plant field workers, a fundamental shift in approach is needed. Digital technology can be applied in a manner to perform the tedious error-prone tasks in nuclear power plant field activities, leaving the worker in more of a cognitive role. It has the potential to eliminate human variability in performing routine actions such as identifying the correct components to be worked on; the technology can perform tasks at much higher reliability rates, while the plant worker remains in a role of correctly applying the technology and validating the results.

The Advanced II\&C Systems Technologies Pathway will develop integrated mobile technologies for nuclear power plant field workers that connect the worker to plant information and plant processes in a manner that significantly enhances human performance and productivity. Human factors studies will be conducted, resulting in guidelines for utilities to use in applying these technologies to field activities. Additional work will be conducted in developing guidelines for providing augmented reality technologies to field workers, allowing workers to view invisible phenomena (such as radiation fields) as a means of reducing worker dose.

The major milestones associated with the pilot projects supporting human performance improvement for nuclear power plant field workers are:

- (2014) Develop automated work package prototype technologies for nuclear power plant work processes with associated study of field trials at a nuclear power plant.

- (2015) Develop human factors evaluations and an implementation strategy for deploying automated field activity work packages built on mobile technologies, resulting in more efficient and accurate plant work processes, adherence to process requirements, and improved risk management.

- (2016) Develop and demonstrate augmented reality technologies for visualization of radiation fields for mobile plant workers.

- (2017) Develop and demonstrate augmented reality technologies for visualization of real-time plant parameters (e.g., pressures, flows, valve positions, and restricted boundaries) for mobile plant workers.

- (2018) Publish a technical report on augmented reality technologies developed for nuclear power plant field workers, enabling them to visualize abstract data and invisible phenomena, resulting in significantly improved situational awareness, access to context-based plant information, and generally improved effectiveness and efficiency in conducting field work activities.

\subsubsection{Integrated Operations}

Many industries have taken advantage of new digital technologies to consolidate operational and support functions for multiple production facilities to improve efficiency and quality. This concept is sometimes referred to as integrated operations. It basically means using technology to overcome the need for onsite support, thereby allowing the organization to centralize certain functions and concentrate the company's expertise in fewer workers. These workers, in turn, develop higher levels of expertise because they are exposed to a larger variety of challenges and issues than if they supported just a single facility. The concept also enables standardized operations and economy of scale in maintaining a single organization instead of duplicate capabilities at each location.

The Advanced II\&C Systems Technologies Pathway will conduct human factors studies of various types of integrated operations in HSSL and, ultimately, at a host utility to maximize human, process, and organizational effectiveness using virtual collaboration technologies to connect remote parties supporting plant operations. This project will address the looming concerns on cost and availability of future plant staff by enabling nuclear utilities to build virtual organizations of trusted partners (fleet-level or external) rather than having to rely on onsite resources for time-critical support. 
The major milestones associated with the pilot projects supporting integrated operations are:

- (2017) Develop a digital architecture and publish a technical report for an advanced online monitoring facility, providing long-term asset management and providing real-time information directly to control room operators, troubleshooting and root cause teams, suppliers and technical consultants involved in component support, and engineering in support of the system health program.

- (2018) For chemistry activities, conduct a study and publish a technical report on opportunities to provide remote services from centralized or third-party service providers, based on advanced real-time communication and collaboration technologies built on the digital architecture for a highly automated plant. Demonstrate representative remote activities with a host nuclear power plant.

- (2019) For maintenance activities, conduct a study and publish a technical report on opportunities to provide remote services from centralized or third-party service providers, based on advanced realtime communication and collaboration technologies built on the digital architecture for a highly automated plant. Demonstrate representative remote activities with a host nuclear power plant.

- (2020) For radiation protection activities, conduct a study and publish a technical report on opportunities to provide remote services from centralized or third-party service providers, based on advanced real-time communication and collaboration technologies built on the digital architecture for a highly automated plant. Demonstrate representative remote activities with a host nuclear power plant.

- (2021) Publish human and organizational factors studies and a technical report for a virtual plant support organization technology platform consisting of data sharing, communications (voice and video), and collaboration technologies that will compose a seamless work environment for a geographically dispersed nuclear power plant support organization.

- (2021) Publish human and organizational factors studies and a technical report for a management decision support center consisting of advanced digital display and decision-support technologies, thereby enhancing nuclear safety margin, asset protection, regulatory performance, and production success.

\subsubsection{Outage Safety and Efficiency}

Nuclear power plant refueling outages are perhaps the most challenging times in the ongoing operations of the facilities, executing typically more than 10,000 activities in a 20 to 30 -day work period. Many of these activities are safety significant. This presents challenges in controlling the timing, quality, and cost of individual work activities in the face of shifting schedules, emergent problems, and strained human and equipment resources. This dynamic work mix must be analyzed continually to detect and avoid threats to nuclear safety margins, regulatory compliance, and outage schedule adherence.

The Advanced II\&C Systems Technologies Pathway will conduct R\&D activities for the application of advanced digital technologies that integrate outage control centers, field work crews, and real-time plant information to achieve collective situational awareness and enable timely decision-making to effectively allocate resources in an optimized manner. The HSSL will be used to develop concepts for an advanced outage control center specifically designed to maximize the use of digital technology for information analysis and shared understanding in outage control center team decision-making. The Advanced II\&C Systems Technologies Pathway will conduct further research and produce implementation guidance for technologies that improve outage risk management, especially in the area of configuration control for changing plant states, by integrating plant status information with configuration changes imposed by ongoing and near-term outage work activities.

The major milestones associated with the pilot projects supporting outage safety and efficiency are:

- (2013) Develop technologies for an advanced outage control center that improves outage coordination, problem resolution, and outage risk management. 
- (2014) Develop human factors studies and publish a technical report for an advanced outage control center that is specifically designed to maximize the usefulness of communication and collaboration technologies for outage coordination, problem resolution, and outage risk management.

- (2017) Develop a real-time outage risk management strategy and publish a technical report to improve nuclear safety during outages by detecting configuration control problems caused by work activity interactions with changing system alignments.

\subsubsection{Centralized Online Monitoring and Information Integration}

As nuclear power plant systems begin to be operated during periods longer than originally licensed, the need arises for more and better types of monitoring of material and component performance. This includes the need to move from periodic, manual assessments and surveillances of physical components and structures to centralized online condition monitoring. This is an important transformational step in the management of nuclear power plants. It enables real-time assessment and monitoring of physical systems and better management of components based on their performance. It also provides the ability to gather substantially more data through automated means and to analyze and trend performance using new methods to make more informed decisions concerning long-term plant asset management. Of particular importance will be the capability to determine the remaining useful life (RUL) of a component to justify its continued operation over an extended plant life.

Working closely with the MAaD Pathway and EPRI, this pathway will develop technologies to complement sensor development and monitoring of materials to assess the performance of SSC materials during long-term operation for purposes of decision making and asset management. The MAaD Pathway would be responsible for developing the scientific basis for modeling the degradation mechanisms and determining the types of sensors needed to monitor the degradation.

The major milestones associated with the pilot projects supporting centralized online monitoring and information integration are:

- (2015) Publish a technical report on measures, sensors, algorithms, and methods for monitoring active aging and degradation phenomena for a large passive plant component/structure, involving nondestructive examination-related online monitoring technology development, including the diagnostic and prognostic analysis framework to support utility implementation of online monitoring for the component type.

- (2017) Publish a technical report on measures, sensors, algorithms, and methods for monitoring active aging and degradation phenomena for second large passive plant component structure, involving nondestructive examination-related online monitoring technology development, including the diagnostic and prognostic analysis framework to support utility implementation of online monitoring for the component type.

\subsubsection{Cyber Security}

Cyber security is recognized as a major concern in implementing advanced digital II\&C technologies in nuclear power plants in view of the considerable security requirements necessary to protect these facilities from potential adversaries, as well as protect company-proprietary information. The members of the UWG have expressed the need to ensure that cyber security vulnerabilities are not introduced through adoption of these advanced digital technologies. Furthermore, these utilities have internal cyber security policies and regulatory obligations that must be upheld during implementation of the project technologies.

To this end, a project task has been created to address cyber security issues arising from the technology developments in the pilot projects. INL has significant cyber security expertise and resources that have been developed to address the security concerns of the laboratory, as well as those of many security-critical U.S. government facilities. INL's experience in identifying, characterizing, and 
mitigating cyber security threats is highly applicable to the type of concerns that potentially would be created in technology developments of the pilot projects.

A cyber security assessment template will be developed to identify possible threat vectors introduced by the new technologies. An individual assessment will be conducted for each pilot project to identify the threats specific to its technologies, characterize the degree of cyber security risk, and recommend effective mitigation measures. The assessment will be discussed with the host utility for the pilot projects and the information will be provided to the UWG in general.

Responsibility for cyber security ultimately lies with the utilities that implement technologies from this research program. They must ensure their own policies and regulatory commitments are adequately addressed. However, the cyber security resources, expertise, and experience of INL will provide a sound information basis to guide utilities in prudent technology implementation practices and mitigation measures.

\subsubsection{Contribution to Industry Consensus Guidelines}

To ensure appropriate transfer of technology to the nuclear power industry, guidelines documents will be published for each of the areas of enabling capabilities, incorporating the specific technologies and technical reports produced under each of the pilot projects for the respective areas. EPRI has agreed to assume responsibility for development and publication of these guidelines, using their standard methods and utility interfaces to develop the documents and validate them with industry. The LWRS Program Advanced II\&C Systems Technologies Pathway will support this effort by providing the relevant information and participating in the development activities.

The following schedule has been established to produce the guidelines for each area of the enabling capability:

- (2018) Publish final guidelines to implement technologies for human performance improvement for nuclear power plant field workers.

- (2018) Publish final guidelines to implement technologies for improved outage safety and efficiency.

- (2018) Publish final guidelines to implement technologies for centralized online monitoring and information integration.

- (2021) Publish final guidelines to implement technologies for a highly automated plant.

- (2022) Publish final guidelines to implement technologies for a highly integrated control room.

- (2022) Publish final guidelines to implement technologies for integrated operations.

\subsection{Research and Development Partnerships}

A systematic engagement activity is underway with nuclear power plant owner/operators, suppliers, industry support organizations, EPRI, and NRC. Together, these engagement activities are intended to ensure that $R \& D$ activities focus on issues of challenge and uncertainty for nuclear power plant owners and regulators alike, the products of research can be commercialized, and roadblocks to deployment are systematically addressed. Key partnerships include:

- Utility Working Group: The Advanced II\&C Systems Technologies Pathway utilizes a UWG to define and host a series of pilot projects that, together, will enable significant plant performance gains and minimize operating costs in support of the long-term sustainability of the LWR fleet. At this time, the UWG consists of 13 leading U.S. nuclear utilities. Additional membership will be pursued for the UWG with the intent to involve every U.S. nuclear operating fleet in the program. The UWG is directly involved in defining the objectives and research projects of this pathway. The UWG meets regularly several times annually. The pilot project partner will make the results of the R\&D available 
and accessible to other commercial nuclear utilities and participate in efforts to support deployment of systems, technologies, and lessons learned by other nuclear power plant owners.

- Electric Power Research Institute: EPRI is both a member of the UWG and serves in a direct role in collaborative research with the Advanced II\&C Systems Technologies Pathway. EPRI technical experts directly participate in the formulation of the project technical plans and in the review of the pilot project results, bringing to bear the accumulated knowledge from their own research projects and collaborations with nuclear utilities. EPRI will assist in the transfer of technology to the nuclear utilities by publishing formal guidelines documents for each of the major areas of development.

- Halden Reactor Project: The Halden Reactor Project's programs extend to many aspects of nuclear power plant operations; however, the area of interest to this R\&D program is the man-machinetechnology research program that conducts research in the areas of computerized surveillance systems, human factors, and man-machine interaction in support of control room modernization. Halden has assisted a number of European nuclear power plants in implementing II\&C modernization projects, including control room upgrades. The Advanced II\&C Systems Technologies Pathway will work closely with Halden Reactor Project to evaluate their advanced II\&C technologies to take advantage of the applicable developments. In addition to the technologies, the validation and human factors studies conducted during development of the technologies will be carefully evaluated to ensure similar considerations are incorporated into the pilot projects. The INL will enter into a bilateral agreement in areas of research where collaborative efforts with Halden Reactor Project will accelerate development of the technologies associated with the pilot projects.

- Major Industry Support Organizations: The LWR fleet is actively supported by major industry support groups; namely EPRI, the Nuclear Energy Institute, and the Institute of Nuclear Power Operations. All of these organizations have active efforts in the I\&C area, including technical developments, regulatory issues, and standards of excellence in conducting related activities. It is important that these organizations be informed of the purpose and scope of this research program, and that activities be coordinated to the degree possible. It is a task of this research program to engage these organizations to enable a shared vision of the future operating model based on an integrated digital environment and to cooperate in complementary activities to achieve this vision across the industry with the maximum efficiency and effectiveness. There are additional industry support groups (such as the Pressurized Water Reactor and Boiling Water Reactor Owners Groups) that need similar engagement for more focused purposes.

- Nuclear Regulatory Commission: Periodic informational meetings are held between DOE Headquarters personnel and members of NRC management to communicate about aims and activities of individual LWRS Program pathways. Briefings and informal meetings will continue to be provided to inform staff from NRC's Office of Nuclear Regulatory Research about technical scope and objectives of the LWRS Program.

- Suppliers: Ultimately, it will be the role of nuclear industry II\&C suppliers to provide commercial products based on technologies developed under this research program. An engagement strategy for nuclear industry II\&C suppliers will be conducted to facilitate communication.

\subsection{Summary of Research and Development Products and Schedule}

The strategic goal of this pathway is to develop an II\&C architecture that encompasses all aspects of nuclear power plant operations and support, integrating plant systems, plant work processes, and plant workers in a seamless digital environment enabling enhanced nuclear safety, increased productivity, and improved overall plant performance. A chronological listing of the major milestones in II\&C Pathway can be found in Appendix B. 


\section{RISK-INFORMED SAFETY MARGIN CHARACTERIZATION 4.1 Background}

Safety is central to the design, licensing, operation, and economics of nuclear power plants. As the current LWR fleet continues in service up to and beyond 60 years, there are possibilities for increased frequency of SSC failures that initiate safety-significant events, reduce existing accident mitigation capabilities, or create new failure modes. Plant designers commonly "over-design" portions of nuclear power plants and provide robustness in the form of redundant and diverse engineered safety features to ensure that, even in the case of well-beyond design basis scenarios, public health and safety will be protected with a very high degree of assurance. This form of defense-in-depth is a reasoned response to uncertainties and is often referred to generically as "safety margin." Historically, specific safety margin provisions have been formulated, primarily based on "engineering judgment." Further, these historical safety margins have been set conservatively (for example in design and operational limits) to compensate for uncertainties.

A systematic approach to the characterization of safety margins and the subsequent margins management options represent a vital input to the licensee and regulatory analysis and decision making that will be involved. In addition, as R\&D in the LWRS Program and other collaborative efforts yield new data and improved scientific understanding of physical processes that govern the aging and degradation of plant SSCs (and concurrently support technological advances in nuclear reactor fuels and plant instrumentation and control systems) needs and opportunities to better optimize plant safety and performance will become known. To support decision making related to economics, reliability, and safety, the RISMC Pathway will provide methods and tools that enable mitigation options known as margins management strategies.

\subsection{Research and Development Purpose and Goals}

The purpose of the RISMC Pathway R\&D is to support plant decisions for risk-informed margins management with the aim to improve the economics and reliability and sustain the safety of current nuclear power plants over periods of extended plant operations. The goals of the RISMC Pathway are twofold:

1. Develop and demonstrate a risk-assessment method that is coupled to safety margin quantification that can be used by nuclear power plant decision makers as part of risk-informed margin management strategies.

2. Create an advanced RISMC Toolkit that enables more accurate representation of nuclear power plant safety margins.

One of the primary items inherent in the goals of the RISMC Pathway is the ability to propose and evaluate margin management strategies. For example, a situation could exist that causes margins associated with one or more key safety functions to become degraded; the methods and tools developed in this Pathway can be used to model and measure those margins. These evaluations will then support development and evaluation of appropriate alternative strategies for consideration by key decision makers to maintain and enhance the impacted margins as necessary. When alternatives are proposed that mitigate reductions in the safety margin, these changes are referred to as margin recovery strategies. Moving beyond current limitations in safety analysis, the RISMC Pathway will develop techniques to conduct margins analysis using simulation-based studies of safety margins. 
Central to this pathway is the concept of a safety margin. In general terms, a "margin" is usually characterized in one of two ways:

- A deterministic margin, defined by the ratio (or, alternatively, the difference) of an applied capacity (i.e., strength) to the load. For example, a pressure tank is tested to failure where the tank design is rated for a pressure $\mathbf{C}$, and it is known to fail at pressure $\mathbf{L}$, thus the margin is ( $\mathbf{L}-\mathbf{C}$ ) (safety margin) or $\mathbf{L} / \mathbf{C}$ (safety factor).

- A probabilistic margin, defined by the probability that the load exceeds the capacity. For example, if failure of a pressure tank is modeled where the tank design capacity is a distribution $f(\mathbf{C})$, its loading condition is a second distribution $\mathrm{f}(\mathbf{L})$, the probabilistic margin would be represented by the expression $\operatorname{Pr}[\mathrm{f}(\mathbf{L})>\mathrm{f}(\mathbf{C})]$.

In practice, actual loads $(\mathbf{L})$ and capacities $(\mathbf{C})$ are uncertain and, as a consequence, most engineering margin evaluations are, in fact, of the probabilistic type. However, due to a number of reasons (insufficient data, complexity in analysis, resource constraints, etc.) the more simplistic deterministic approach is often applied in practice. In these cases where deterministic margins are evaluated, the analysis is typically very conservative in order to account for uncertainties; this approach, while historically quite effective in ensuring appropriate levels of safety are maintained, results in significant economic and operational constraints. Additionally, because uncertainties are not explicitly characterized and evaluated, the potential exists for margins to be exceeded during periods of abnormal operation resulting in unanticipated consequences. The RISMC Pathway uses the probability margin approach to quantify impacts to economics, reliability, and safety to avoid excessive conservatisms (where possible) and treat uncertainties directly. Further, this approach is used in risk-informed margins management to present results to decision makers as it relates to margin evaluation, management, and recovery strategies.

As a simplified illustration of the type of approach taken by the RISMC method and tools, consider a hypothetical example in Figure 17. For this example, we suppose that a nuclear power plant has two alternatives to consider: Alternative \#1 - retain the existing, but aging, component as-is or Alternative \#2 - replace the component with a new one. Using risk analysis methods and tools (described in Section 4.3), 30 simulations are run where this component plays a role in plant response under accident conditions. For each of the 30 simulations, the outcome of a selected safety metric is calculated - in this example peak fuel clad temperature - and compared against a capacity limit (assumed to be $2,200^{\circ} \mathrm{F}$ ). However, these simulations must be run for both alternative cases (resulting in a total of 60 simulations in this simplified example). The results of these simulations are then used to determine the probabilistic margin:

Alternative \#1: $\operatorname{Pr}($ Load exceeds Capacity $)=0.17$

Alternative \#2: $\operatorname{Pr}($ Load exceeds Capacity $)=0.033$.

In an actual application of the risk-informed safety margin approach a much larger number of simulations would need to be performed to more accurately quantify these results and obtain a more complete characterization of the relevant statistical distributions of the key decision variables. If the safety margin characterization were the only decision factor, then Alternative \#2 would be preferred (its safety characteristics are better). But, these insights are only part of the information that would be needed by the decision maker, for example the costs and schedules related to the alternatives would also need to be considered. In many cases, multiple alternatives will be available to the decision maker due to level of redundancy and several barriers for safety present in current nuclear power plants.

Because one LWRS Program objective is to develop technologies that can improve the reliability, sustain safety, and extend the life of the current reactors, any safety margin focus would need to consider more realistic load and capacity implications for operating nuclear power plants. For example, the notional diagram shown in Figure 18 illustrates that safety, as represented by a load distribution, is a complex function that varies from one type of accident scenario to the next. However, the capacity part of 
the evaluation may not vary as much from one accident to the next because the safety capacity is determined by physical design elements such as fuel and material properties (which are common across a spectrum of accidents) or regulatory safety limits (such as the 10 CFR 50.46 limit in the Figure 18).

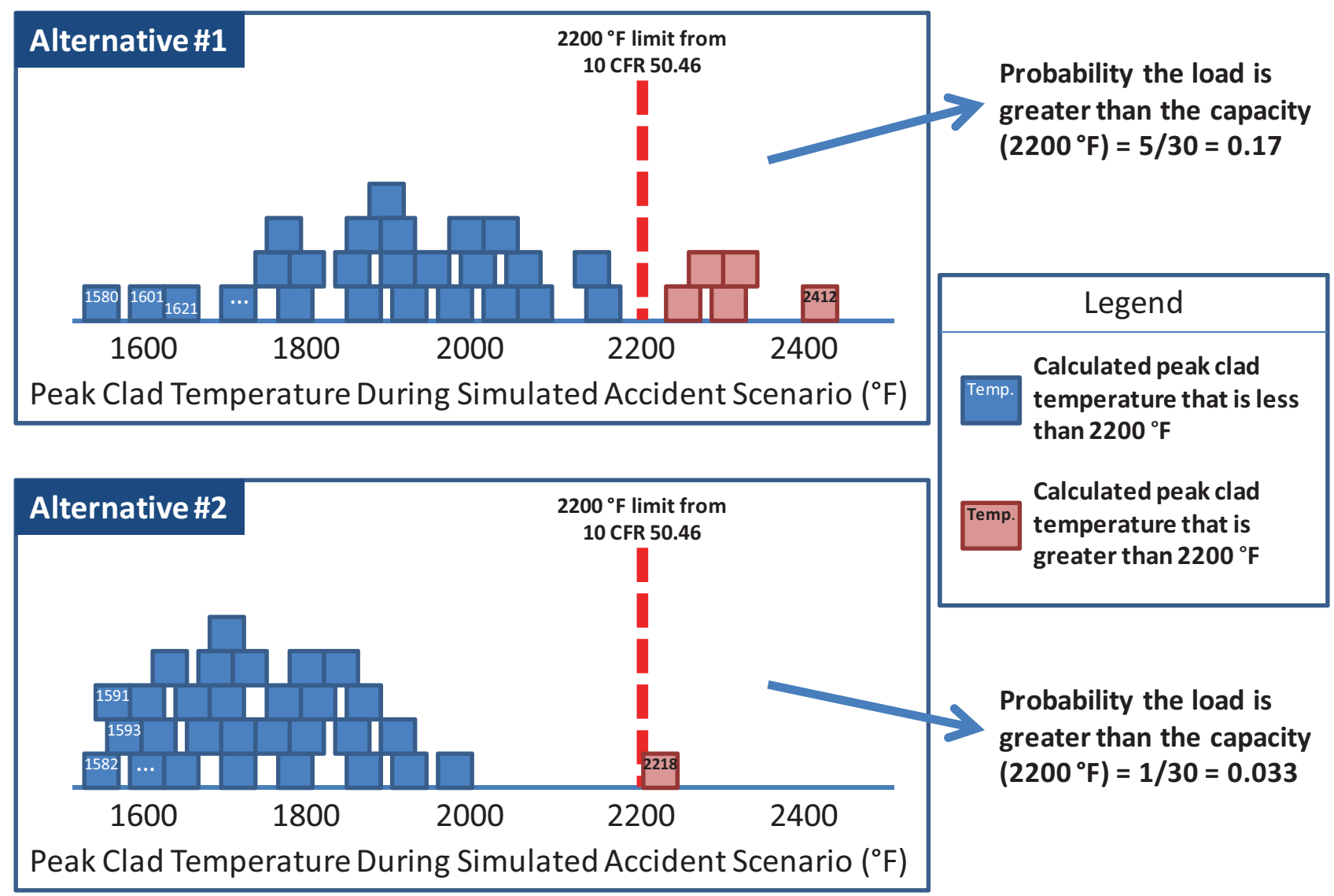

Figure 17. RISMC example when evaluating alternatives for risk-informed margins management. 


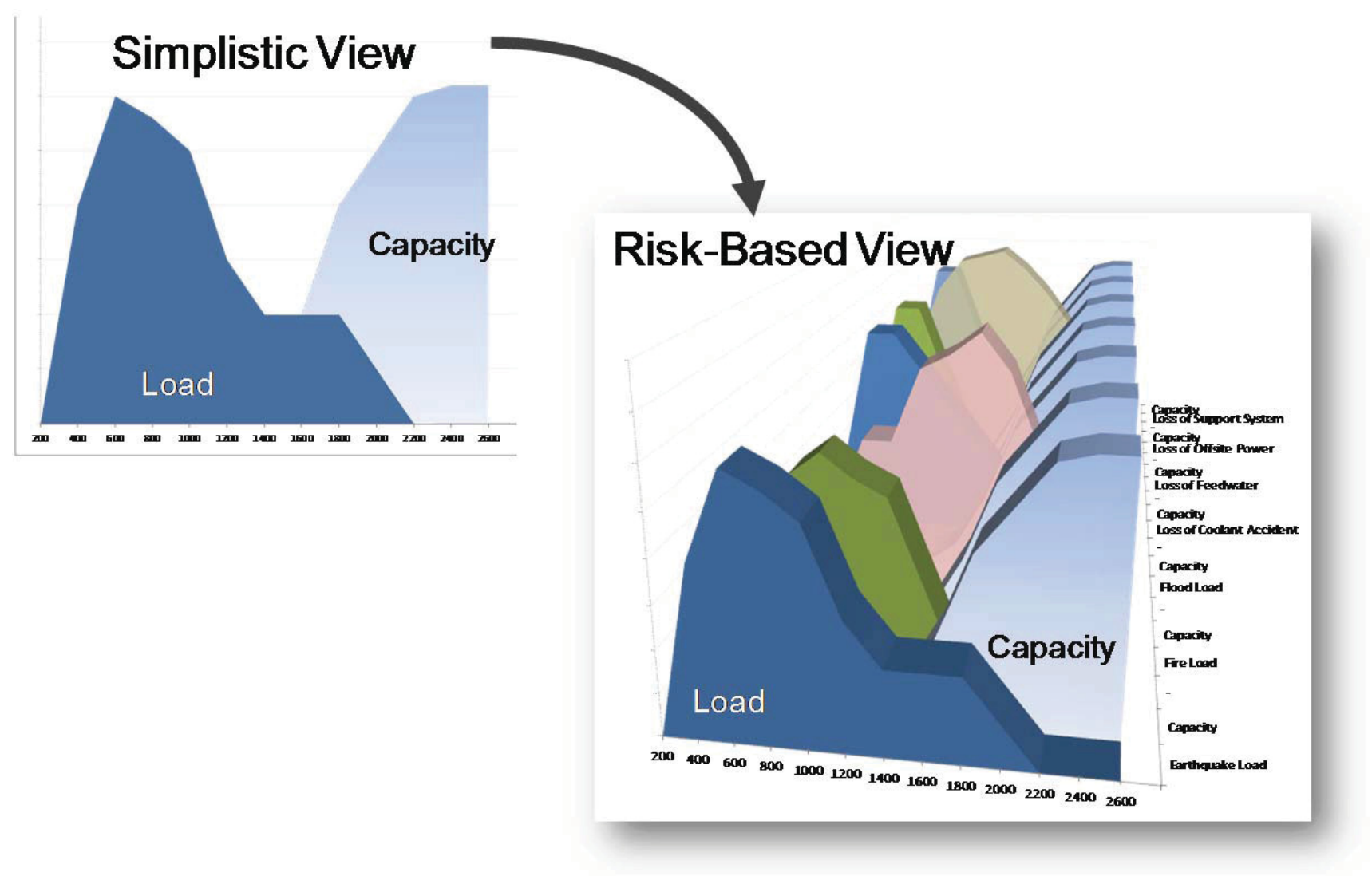

Figure 18. Family of load and capacity distributions representing different accident conditions.

To successfully accomplish the pathway goals, the risk-informed safety margin approach must be defined and demonstrated. The determination of the degree of a safety margin requires an understanding of risk-based scenarios. Within a scenario, an understanding of plant behavior (i.e., operational rules such as technical specifications, operator behavior, and SSC status) and associated uncertainties will be required to interface with a systems code. Then, to characterize safety margin for a specific safety performance metric ${ }^{\circ}$ of consideration (e.g., peak fuel clad temperature), the plant simulation will determine time and scenario-dependent outcomes for both the load and capacity. Specifically, the safety margin approach will use the physics-based plant results (the "load") and contrast these to the capacity (for the associated performance metric) to determine if safety margins have been exceeded (or not) for a family of accident scenarios. Engineering insights will be derived based on the scenarios and associated outcomes.

DOE (through the RISMC Pathway) is involved in this R\&D activity for the following reasons:

- The development of the advanced models is high-risk, requiring multiphysics modeling capabilities developed in the DOE national laboratory system.

- The DOE national laboratory system has broad experience in validation, verification, and uncertainty quantification, which are essential components for successful development of the RISMC Toolkit.

o Safety performance metrics may be application-specific, but in general are engineering characteristics of the nuclear power plant, for example as defined in 10 CFR 50.36, "safety limits for nuclear reactors are limits upon important process variables that are found to be necessary to reasonably protect the integrity of certain of the physical barriers that guard against the uncontrolled release of radioactivity." 
- The RISMC Toolkit will be a very significant component of the U.S. industry capability that will promote investment in the U.S. nuclear power industry by reducing technical and, potentially, regulatory uncertainty.

- The RISMC Toolkit will significantly benefit the entire operating fleet and important classes of new facilities (e.g., small modular reactors).

- Government and industry are sharing work on methods and tools for characterizing safety margin.

- The DOE role is to lead the development of advanced techniques, including building on uncertainty analysis methodology that has been under development for years at government laboratories and internationally.

- Industry, under EPRI's Long-Term Operations Program, is carrying out case studies to better understand the issues and to provide feedback and comparative results to DOE on the RISMC Toolkit development and the methods and tools for analysis of safety margins.

One result of a risk-informed approach in the RISMC Pathway is the use of "performance-based" margins management strategies. These strategies will be informed by the risk assessment and will focus on desired, measurable outcomes, rather than prescriptive processes, techniques, or procedures, with the aim of identifying performance measures that ensure an adequate safety margin is maintained over the lifecycle of a nuclear power plant.

\subsection{Pathway Research and Development Areas}

To better understand the approach to determine safety margins, two types of analysis used in this pathway are described (see Figure 19). Note that in actual applications, a blended approach is used where both types of analysis are used to support any one particular decision. For example, the approach could be either mostly probabilistic, mostly mechanistic, or both in nature.

\begin{tabular}{|ll|}
\multicolumn{1}{|c|}{ Types of Analysis Used in Safety Margin Evaluations } \\
\hline \multicolumn{1}{|c|}{ PROBABILISTIC } & \multicolumn{1}{c|}{ MECHANISTIC } \\
$\begin{array}{l}\text { Pertaining to stochastic (non-deterministic) } \\
\text { events, the outcome of which is described by a } \\
\text { probability. }\end{array}$ & $\begin{array}{l}\text { Pertaining to predictable events, the outcome of } \\
\text { which is known with certainty if the inputs are } \\
\text { known with certainty. }\end{array}$ \\
$\begin{array}{l}\text { Probabilistic analysis uses models representing } \\
\text { the randomness in the outcome of a process. } \\
\text { Because probabilities are not observable } \\
\text { quantities, we rely on models to estimate } \\
\text { probabilities for certain specified outcomes. }\end{array}$ & $\begin{array}{l}\text { Mechanistic analysis (also called "deterministic") } \\
\text { uses models to represents situations where the } \\
\text { observable outcome will be known given a } \\
\text { certain set of parameter values. }\end{array}$ \\
$\begin{array}{l}\text { An example of a probabilistic model is the } \\
\text { counting of } k \text { number of failures of an operating } \\
\text { component in time } t \text { : Probability (k=1) }=\lambda e^{-\lambda t} .\end{array}$ & $\begin{array}{l}\text { An example of a mechanistic model is the } \\
\text { one-dimensional transfer of heat (or heat flux) } \\
\text { through a solid: } q=-k \partial T / \partial x .\end{array}$ \\
\hline
\end{tabular}

Figure 19. Types of analysis that are used in the Risk-Informed Safety Margin Characterization Pathway. 
The RISMC Pathway has two primary focus areas to guide the R\&D activities. First, the Pathway is developing the methods that will be used to obtain the technical basis for safety margins and their use in the support of the risk-informed decision making process. These methods are to be described in a set of technical reports for Risk-Informed Margins Management (RIMM). Second, the Pathway is producing an advanced set of software tools used to quantify safety margins. This set of tools, collectively known as the RISMC Toolkit, will enable a risk analysis capability that currently does not exist.

\subsubsection{Technical Reports for Risk-Informed Margins Management}

The RISMC methodologies are captured in a set of technical reports. These reports describe how the RISMC Pathway captures the protocols for analysis and evaluation related to safety margin characterization. The RISMC technical reports are intended to be companion documents to EPRIproduced reports. The reports will be developed to support industry use in their life-extension decisions.

The major milestones associated with this task are:

- (2013) Produce technical report that outlines the RIMM process and its relation to RISMC characterization.

- (2016) Final technical report for RIMM process including description of pilot application of RISMC / RIMM to an issue of interest at a host plant.

\subsubsection{The Safety Case}

While definitions may vary in detail, "safety case" essentially means the following:

A structured argument, supported by a body of evidence that provides a compelling, comprehensible and valid case that a system is adequately safe for a given application in a given environment. ${ }^{p}$

A safety case will be the output from RISMC applications when applying the method shown notionally in Figure 20. The safety-margin claims will do the following:

1. Make an explicit set of safety claims about the facility and SSCs

2. Produce evidence that supports the claims from $\# 1$

3. Provide a set of safety margin arguments that link the claims to the probabilistic and mechanistic evidence

4. Make clear the assumptions, models, data, and judgments underlying the arguments

5. Allow different viewpoints and levels of detail in a graded fashion to support decision making.

\footnotetext{
p Bishop, P. and R. Bloomfield, “A Methodology for Safety Case Development,” Safety-Critical Systems Symposium, Birmingham, UK. 1998.
} 


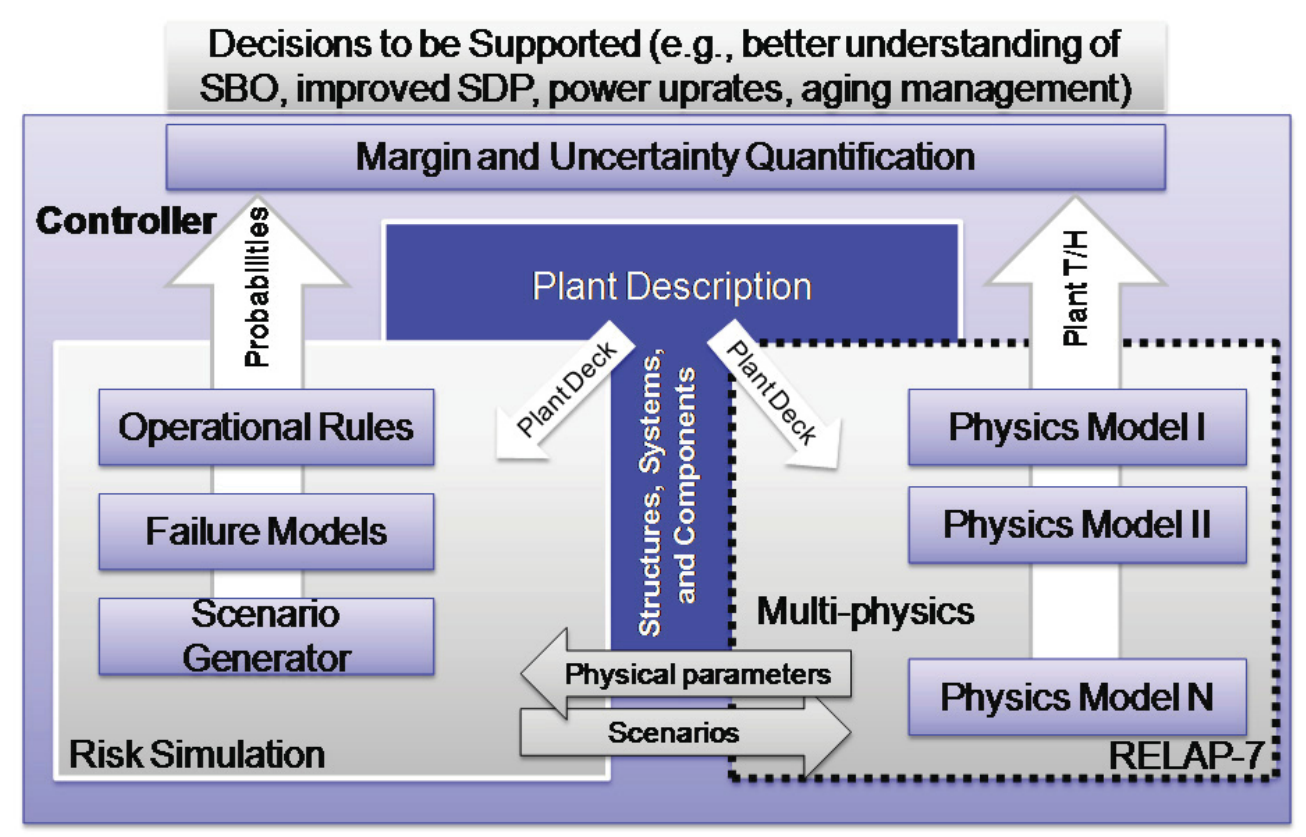

Figure 20. Attributes of the Risk-Informed Safety Margin Characterization approach for supporting decision-making.

The safety case of a facility or SSC should be regarded as having fundamental significance as opposed to being mere documentation of facility or SSC features. For practical purposes, "safety margin" is not observable in the way that many other operational attributes are (e.g., core temperature or embrittlement of pressure vessels). In decision-making regarding the facility or SSC, the safety case is, in practice, a proxy for the safety attribute. And, regardless of context, the formulation of a safety case is about developing a body of evidence and marshaling that evidence to inform a decision.

Since safety margins are inferred (not directly observable) unlike how power output, pipe thickness, water temperature, radiation level, etc., are observed, a combination of models (probabilistic and mechanistic) are used to make safety margin predictions. These models also rely on unobserved elements such as failure rates and probabilities. Consequently, the characterization of a safety margin requires the treatment and understanding of uncertainty to effectively manage margins in a risk-informed decision making approach.

\subsubsection{Margins Analysis Techniques}

This research area develops techniques to conduct margins analysis, including the methodology for carrying out simulation-based studies of safety margin, using the following generic process steps (as shown in Figure 21) for RISMC applications.

1. Characterize the issue to be resolved in a way that explicitly scopes the modeling and analysis to be performed. Formulate an "issue space" that describes the safety Figures of merit to be analyzed and proposed decision criteria to be employed.

2. Quantify the decision-maker and analyst's state-of-knowledge (uncertainty) of the key variables and models relevant to the issue. For example, if long-term operation is a facet of the analysis, then potential aging mechanisms that may degrade components should be included in the quantification. 


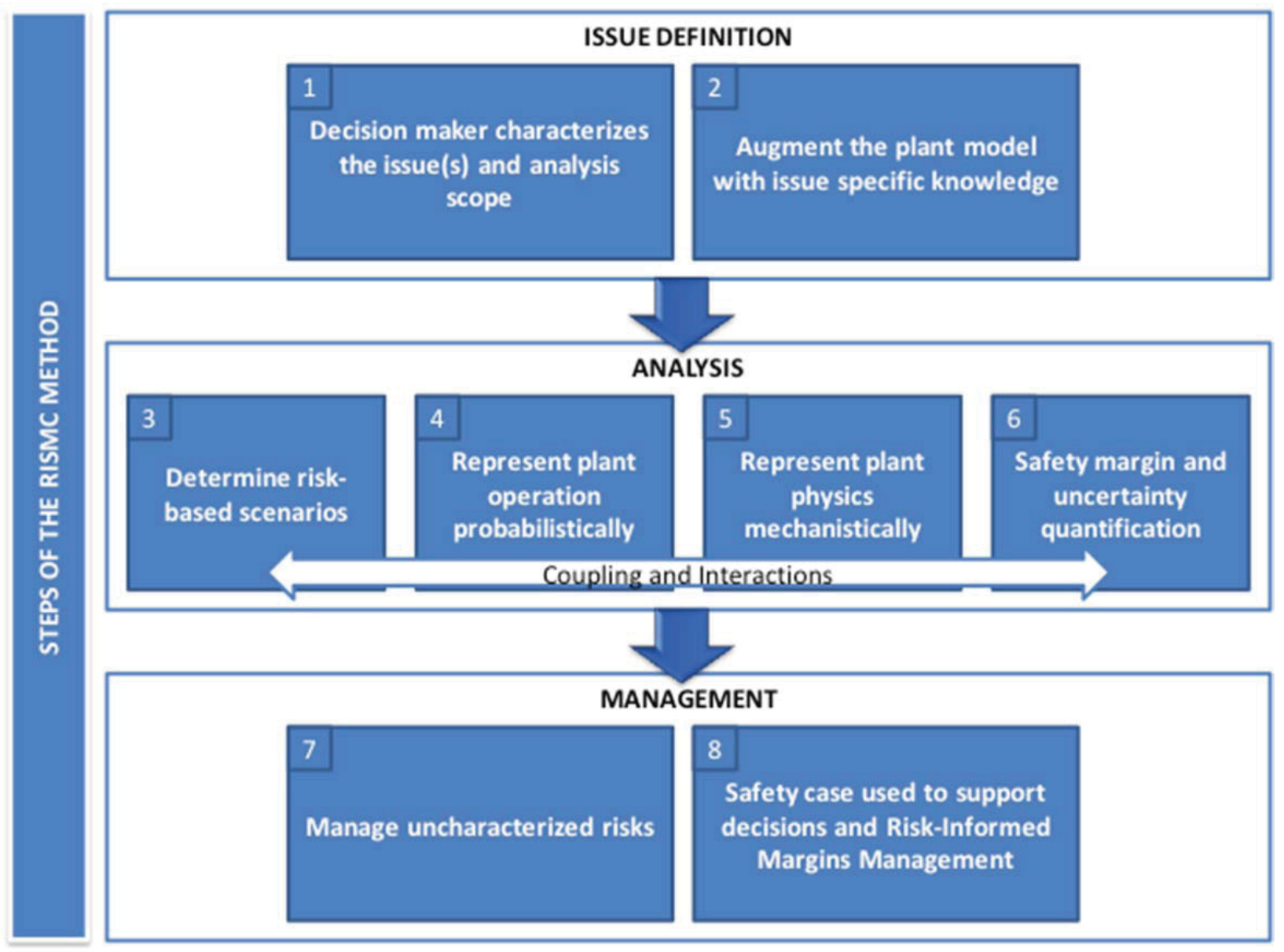

Figure 21. Depiction of the high-level steps required in the Risk-Informed Safety Margin Characterization method.

3. Determine issue-specific, risk-based scenarios and accident timelines (as shown in Figure 22). The scenarios will be able to capture timing considerations that may affect the safety margins and plant physical phenomena, as described in Steps 4 and 5. As such, there will be strong interactions between the analysis Steps 3-5. Also, to "build up" the load and capacity distributions representing the safety margins (as part of Step 6), a large number of scenarios will be needed for evaluation.

4. Represent plant operation probabilistically using the scenarios identified in Step 3. For example, plant operational rules (e.g., operator procedures, technical specifications, maintenance schedules) are used to provide realism for scenario generation. Because numerous scenarios will be generated, the plant and operator behavior cannot be manually created like in current risk assessment using event- and fault-trees. In addition to the expected operator behavior (plant procedures), the probabilistic plant representation will account for the possibility of failures. 


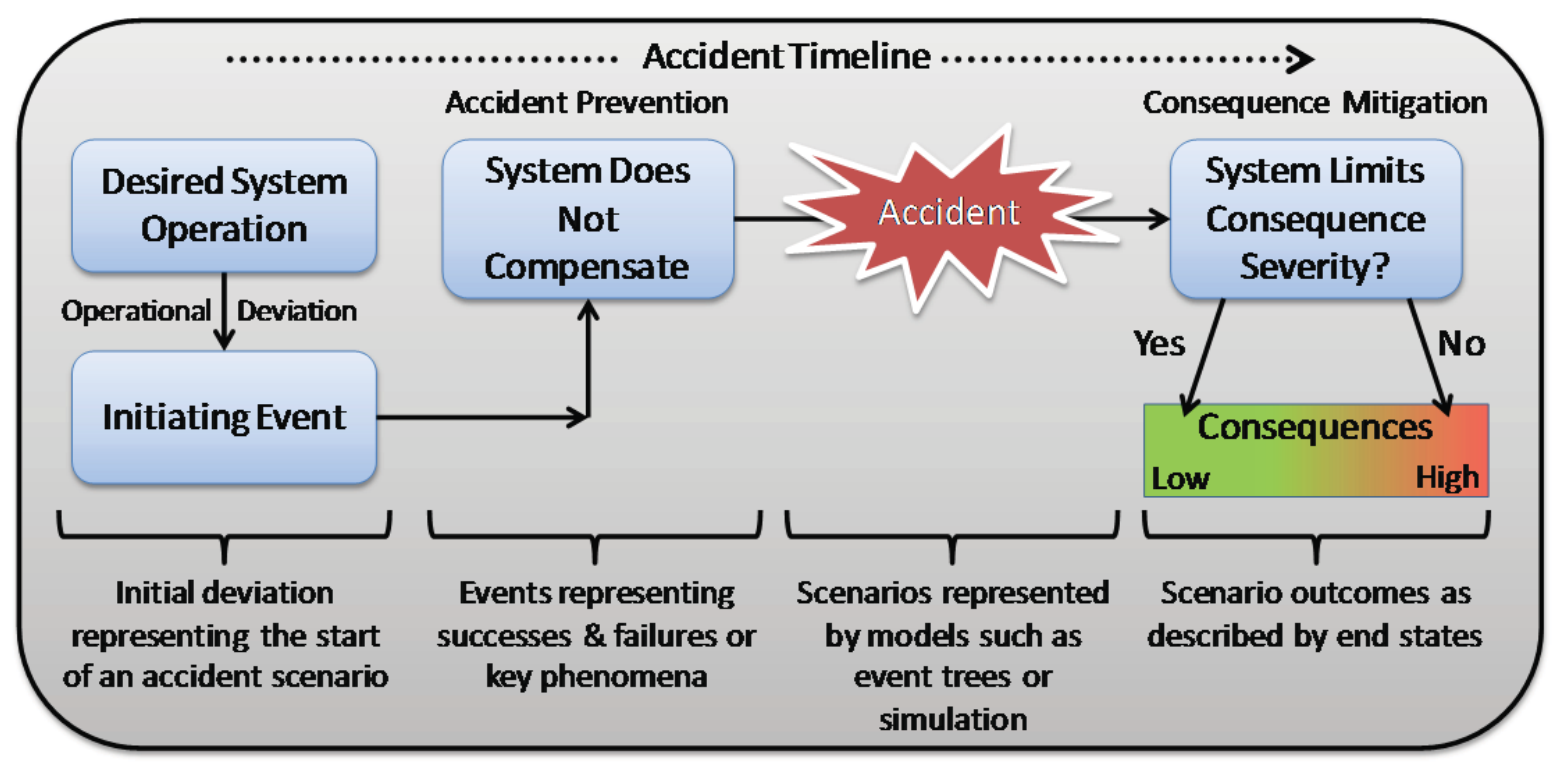

Figure 22. Accident scenario representation.

5. Represent plant physics mechanistically. The plant systems level code will be used to develop distributions for the key plant process variables (i.e., loads) and the capacity to withstand those loads for the scenarios identified in Step 4. Because there is a coupling between Steps 4 and 5, they each can impact the other. For example, a calculated high loading (from pressure, temperature, or radiation) in an SSC may disable a component, thereby impacting an accident scenario.

6. Construct and quantify probabilistic load and capacity distributions relating to the Figures of merit that will be analyzed to determine the probabilistic safety margins.

7. Determine how to manage uncharacterized risk. Because there is no way to guarantee that all scenarios, hazards, failures, or physics are addressed, the decision maker should be aware of limitations in the analysis and adhere to protocols of "good engineering practices" to augment the analysis. This step relies on effective communication from the analysis steps in order to understand the risks that were characterized. As part of this Step it also is appropriate to evaluate the decision criteria proposed in Step 1 and modify (the criteria, the analysis or both) as appropriate.

8. Identify and characterize the factors and controls that determine the relevant safety margins within the issue being evaluated to develop appropriate RIMM strategies. Determine whether additional work to reduce uncertainty would be worthwhile or if additional (or relaxed) safety control is justified.

The major milestones associated with this task are:

- (2014) Assess leading accident resistant fuel technologies to understand potential changes in safety margins that could be achieved by adoption of the technology using the RISMC methodology.

- (2014) Demonstrate RISMC approach using LWR Case Study for Enhanced Accident Tolerance design changes using Risk-Informed Margins Management approaches. (Note that these two RISMC activities will be coordinated with the Advanced Light Water Reactors Nuclear Fuel Pathway described in Section 5 below.)

- (2014) Demonstrate current margins analysis techniques on selected case studies using the completed software structure. The case studies will be selected in consultation with external stakeholders and 
will be chosen based on their potential to address an issue important to LWR sustainability and/or to achieve widespread stakeholder acceptance of the RISMC approach.

- (2015) The margins analysis techniques will be sufficiently mature to enable initial industry margins quantification exercises, including using the RISMC Toolkit.

- (2016) Complete a full-scope margins analysis of a commercial reactor. Use margins analysis techniques, including a fully coupled RISMC Toolkit, to analyze an industry-important issue (e.g., assessment of major component degradation in the context of long-term operation or assessment of the safety benefit of advanced fuel forms). Test cases will be chosen in consultation with external stakeholders.

- (2020) Ensure development and validation to the degree that by the end of 2020, the margins analysis techniques and associated tools are an accepted approach for safety analysis support to plant decisionmaking, covering analysis of design-basis events and events within the technical scope of internal events probabilistic risk assessment.

\subsubsection{Case Study Collaborations}

Jointly with EPRI, the LWRS Program's RISMC Pathway is working on specific case studies of interest to the commercial nuclear power plant industry. In Fiscal Year 2013, the team will be collaborating on a boiling water reactor extended power uprate case study. Safety margin recovery strategies will be determined that will mitigate the potential safety impacts due to the postulated increase in nominal reactor power that would result from the postulated extended power uprate. A second case study of interest to industry is the task to develop a technical report that will describe how to perform safety margin-based configuration risk management (see section 4.3.1). Configuration risk management currently involves activities such as the Significance Determination Process which traditionally uses core damage frequency as the primary safety metric - the research for the second case study will focus on how the safety-margin approach may be used to determine risk levels as different plant configurations are considered.

\subsubsection{The RISMC Toolkit}

The RISMC Toolkit is being built using the INL's Multi-physics Object Oriented Simulation Environment (MOOSE) High Performance Computing (HPC) framework. ${ }^{q}$ MOOSE is the INL development and runtime environment for the solution of multi-physics systems that involve multiple physical models or multiple simultaneous physical phenomena. Models built on the MOOSE framework can be coupled as needed for solving a particular problem. The RISMC Toolkit and roles are shown in Figure 23.

\footnotetext{
${ }^{\mathrm{q}}$ Gaston, D., Hansen, G., \& Newman, C. (2009). MOOSE: A Parallel Computational Framework for Coupled Systems for Nonlinear Equations. International Conference on Mathematics, Computational Methods, and Reactor Physics. Saratoga Springs, NY: American Nuclear Society.
} 


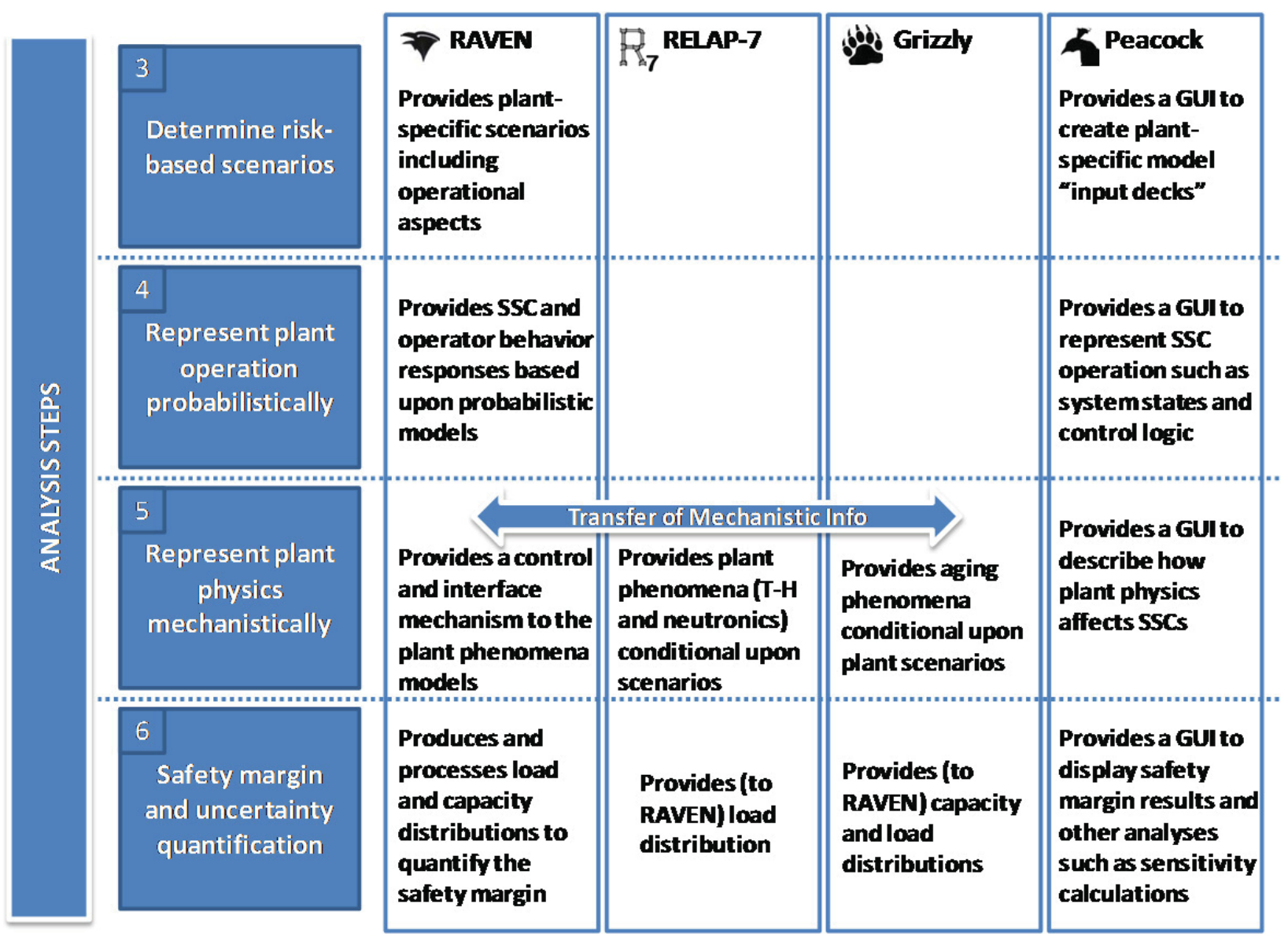

Figure 23. The RISMC Toolkit and roles in the analysis steps.

The major milestones associated with this task are:

- (2013) Upgrade the RELAP-7 capabilities through implementation of seven-equation two-phase flow model, including selected major physical components for BWR primary and safety systems.

- (2013) Perform the RELAP-7 simulation resolving an SBO scenario on a simplified geometry of a BWR.

- (2014) Complete the software structure of the coupled RAVEN/RELAP-7 portion of the RISMC Toolkit. At this time, RELAP-7 can be fully controlled by RAVEN for complete systems analysis. RELAP-7/RAVEN will have the capability to be coupled to other applications (e.g., aging and fuels modules) and perform as a balance-of-plant capability for the multidimensional core simulators under development in other DOE programs.

- (2014) Deliver the RELAP-7 verification and validation plan.

- (2014) Version 1.0 of Grizzly will be released. This version will include aging of steel (embrittlement), and a modular architecture to enable inclusion of additional mechanisms.

- (2015) RELAP-7 will be validated against an accepted set of data.

- (2016) Version 2.0 of Grizzly will be released. This version will include the capabilities of Version 1.0 as well as aging of selected concrete.

- (2018) Validation and benchmarking of Grizzly will be completed. 


\subsubsection{RELAP-7}

RELAP-7 will be the main reactor systems simulation tool for RISMC and the next generation tool in the RELAP reactor safety/systems analysis application series (the replacement for RELAP5). RELAP-7 development will leverage 30 years of advancements in software design, numerical integration methods, and physical models. RELAP-7 will simulate behavior at the plant level with a level of fidelity that will support the analysis and decision-making necessary to economically and safely extend and enhance the operation of the current nuclear power plant fleet. A software development plan for RELAP-7 was issued in $2012 .^{r}$

\subsubsection{RAVEN}

RAVEN (Reactor Analysis and Virtual Control ENvironment) is a multi-tasking application focused on RELAP-7 simulation control, reactor plant control logic, reactor system analysis, uncertainty quantification, and performing probabilistic risk assessments (PRA) for postulated events. RAVEN will drive RELAP-7 (and other MOOSE-based reactor applications) for conduct of RISMC analyses.

\subsubsection{Grizzly}

Grizzly will simulate component aging and damage evolution events for LWRS Program specific applications. Grizzly will be able to simulate component damage evolution for the RPV, core internals, and concrete support and containment structures subjected to a neutron flux, corrosion, and high temperatures and pressures. Grizzly will be able couple with RELAP-7 and RAVEN to provide aging analysis in support of the RISMC methodology.

\subsubsection{Peacock}

Peacock is a general Graphical User Interface (GUI) for MOOSE based applications. Peacock has been built in a very general fashion to allow specialization of the GUI for different applications. The specialization of Peacock for RELAP-7/RAVEN allows both a graphical input of the RELAP-7 input file and online data visualization, and is moving forward to provide direct user control of the simulation and data mining capabilities in support of PRA analysis.

The major milestones associated with the RISMC Toolkit are:

- (2013) Upgrade the RELAP-7 capabilities through implementation of seven-equation two-phase flow model, including selected major physical components for BWR primary and safety systems.

- (2013) Perform the RELAP-7 simulation resolving an SBO scenario on a simplified geometry of a BWR.

- (2014) Complete the software structure of the coupled RAVEN/RELAP-7 portion of the RISMC Toolkit. At this time, RELAP-7 can be fully controlled by RAVEN for complete systems analysis. RELAP-7/RAVEN will have the capability to be coupled to other applications (e.g., aging and fuels modules) and perform as a balance-of-plant capability for the multidimensional core simulators under development in other DOE programs.

- (2014) Deliver the RELAP-7 verification and validation plan.

- (2014) Version 1.0 of Grizzly will be released. This version will include aging of steel (embrittlement), and a modular architecture to enable inclusion of additional mechanisms.

r INL/MIS-13-28183, RELAP-7 Development Plan, Idaho National Laboratory, January 2013. 
- (2015) RELAP-7 will be validated against an accepted set of data.

- (2016) Version 2.0 of Grizzly will be released. This version will include the capabilities of Version 1.0 as well as aging of selected concrete.

- (2018) Validation and benchmarking of Grizzly will be completed.

\subsection{Research and Development Partnerships}

The RISMC Pathway relies on a strong partnership with industry to ensure that the tools under development will be useful and are targeting the right problems. Coordination with other DOE programs is also important, and international activities are pursued as warranted.

- EPRI: EPRI is the RISMC Pathway's primary interface with industry. EPRI plays an important role in high-level technical steering and in detailed planning of RISMC case studies. EPRI also will play a critical role in engaging industry stakeholders (i.e., personnel from operational nuclear power plants) to support pathway development, contribute technical expertise to use case development, and evaluate technical results from case study applications.

- Nuclear Energy Advanced Modeling and Simulation (NEAMS): The RISMC Pathway will leverage models developed (and under development) by NEAMS. NEAMS is using RELAP-7 as a systems code for non-water cooled reactor designs, and plans to use RAVEN, the RELAP-7 controller for non-water cooled reactor designs.

- Consortium on Advanced Simulation of LWRs (CASL): CASL is developing a detailed model of the LWR core; if investigations in the LWRS Program warrant it, the LWRS Program-developed models can couple with the CASL-developed models. CASL has an interest in using RELAP-7 for one or more of their challenge problems.

- Owners Groups: Interactions will continue with groups such as the BWR and PWR Owners Groups through information exchange and evaluations of specific topics via case studies.

- Multilateral International Collaboration: A variety of international researcher interactions are of potential interest to the RISMC Pathway, including the NEA-OECD Committee on the Safety of Nuclear Installations (CSNI), and the European Nuclear Plant Life Prediction (NULIFE) - A virtual organization funded by over 50 organizations and the European Union under the Euratom Framework Program. This organization is working on advancing safety and economics of existing nuclear power plants.

\subsection{Research and Development Products and Schedule}

The purpose of the RISMC Pathway R\&D is to support plant decisions for risk-informed margins management with the aim to improve economics, reliability, and sustain safety of current nuclear power plants over periods of extended plant operations. The goals of the RISMC Pathway are to develop and demonstrate a risk-assessment method that is coupled to safety margin quantification that can be used by nuclear power plant decision makers as part of risk-informed margin management strategies, and create an advanced RISMC Toolkit that enables more accurate representation of nuclear power plant safety margins. A chronological listing of the major milestones in the RISMC Pathway can be found in Appendix B.

\section{ADVANCED LIGHT WATER REACTOR NUCLEAR FUELS}

Nuclear fuel performance is a significant driver of nuclear power plant operational performance, safety, operating economics, and waste disposal requirements. Over the past two decades, the nuclear power industry has improved plant capacity factors with incremental improvements achieved in fuel 
reliability and use or burnup. However, these upgrades are reaching their maximum achievable impact within the constraints of the existing fuel designs, materials, licensing, and enrichment limits. The development, testing, and licensing cycle for new fuel designs is typically long (i.e., about 10 years from conception through utility acceptance).

Continued development of high-performance nuclear fuels through fundamental research is focused on enabling nuclear power plant operators to extend plant operating cycles and enhance the safety margins, performance, and productivity of existing nuclear power plants. However, to achieve significant safety margin improvements while improving operating margins and economics, significant steps beyond incremental improvements in the current generation of nuclear fuel are required. Fundamental changes are required in the areas of nuclear fuel composition, cladding integrity, and the fuel/cladding interaction to reach the next levels of fuel performance.

The Advanced LWR Nuclear Fuels Pathway has been performing research on improving reactor safety, increasing fuel economics, producing advanced cladding designs, and developing enhanced computational models to predict fuel performance. The strategic R\&D goals were directed at improving the scientific knowledge basis for understanding and predicting fundamental nuclear fuel and cladding performance in nuclear power plants, and applying the information to development of high-performance, high-burnup fuels with improved safety, cladding, integrity, and nuclear fuel cycle economics. This research was further designed to demonstrate each of the technology advancements while satisfying all safety and regulatory limits through rigorous testing and analysis. Silicon carbide ( $\mathrm{SiC}$ ) ceramic matrix composite (CMC) materials were chosen as the cladding material for fuels under investigation in this pathway because of their potential for significant improvements in performance.

Fiscal year 2013 is a transition year for this pathway. As the development of fuels with significantly increased safety benefits, now called "accident tolerant fuels" moves forward, the DOE Fuel Cycle R\&D Program's Advanced Fuels Campaign is taking the lead on all the associated R\&D activities. Test facilities developed in the Advanced LWR Nuclear Fuels Pathway will be used to support this work. The LWRS Program will maintain the lead role in performing analyses to determine the potential impact of advanced nuclear fuel rods on reactor safety margins via coordination with the RISMC Pathway; milestones associated with this activity are included in the RISMC section (Section 4.0). No new advanced light water reactor fuels development activities are planned under the LWRS Program.

Major accomplishments in this pathway are discussed in Section 5.1, and remaining major milestones are included in Section 5.2.

\subsection{Major Accomplishments in the Advanced Light Water Reactor Fuels Pathway}

A structured approach to the development of advanced LWR fuel cladding is outlined in the technical program plan for nuclear fuel cladding development released in 2012. The plan describes a series of steps, including testing and modeling activities. This pathway has developed several test facilities that can be used in the development of "accident tolerant" fuels. These facilities will be used for out-of-pile (nonnuclear) testing and characterization of candidate accident tolerant cladding materials. Out-of-pile tests provide an initial filter for advanced cladding technologies at a relatively low cost, delaying more expensive irradiation testing until the number of candidate technologies has been reduced. All environment conditions relevant to an operating LWR (e.g., water flow rate, temperature, chemistry) can be simulated in a nonnuclear environment, allowing early characterization of material corrosion behavior, strength, conductivity, etc. in the absence of radiation. Similarly, a steam environment emulating conditions during a loss of coolant accident (LOCA) can be established in a nonnuclear test laboratory. Cladding materials and designs must first demonstrate ability to withstand these nonnuclear environment conditions before they can be expected to withstand the same environment in the presence of neutron and gamma irradiation. Two facilities, a hot water corrosion flow test system, and an oxidation kinetics test 
system are highlighted in this section, as well as a Material Inventory Database used to manage materials and components intended for basic characterization, mechanical testing and possible future irradiation testing.

\subsubsection{Technical Program Plan for Nuclear Fuel Cladding Development}

The LWRS Program Advanced Nuclear Fuels Pathway developed a program plan for nuclear fuel cladding development in 2012. ${ }^{\mathrm{s}}$ The plan takes a staged approach to fuel clad development. The program will fully engage stakeholders throughout the development process to ensure that the investigated technologies are of interest to both researchers and the nuclear power industry, allowing for development of a revolutionary cladding system potentially applicable to all currently operating LWRs. A number of leading technologies will be selected based on established minimum performance criteria and scoping calculations for core safety under extreme conditions. The top-ranked concepts will undergo a rigorous series of mechanical, thermal and chemical characterization tests to better define their properties and operating potential in a relatively low-cost, nonnuclear test series. Only the top-ranked technologies that emerge from the nonnuclear test series will be recommended for test rodlet fabrication and in-pile nuclear testing. In this manner, cost associated with development of an advanced fuel cladding system will be minimized by performing nuclear tests on only one or two of the most promising technologies.

The steps taken in the advanced cladding system development will result in a detailed technology database for the investigated cladding materials, fabrication techniques and clad system designs. This database will include nonnuclear and nuclear properties that will be used as input data for advanced fuel performance modeling tools designed to better predict fuel system performance under both normal and postulated off-normal, accident conditions. Advanced computational models will encode experimental results to capture complex behavior of nuclear fuel pellets and cladding during reactor operation. Measured performance data will enable validation of the performance modeling tools. The detailed technology database for each clad design will later inform a commercial license application for the advanced nuclear fuel cladding system in the technology deployment phase of the program. Although the cladding development plan will not be implemented under the LWRS Program, the structure described in it is being implemented by the Fuel Cycle R\&D Program's Advanced Fuels Campaign.

\subsubsection{Hot Water Corrosion Flow Test System}

A hot water corrosion flow (HWCF) test system was designed and constructed to evaluate advanced cladding materials under simulated reactor flow conditions (normal operating conditions). The HWCF (Figure 24) was initially designed for and operated with INL Advanced Test Reactor water flow and chemistry conditions, but can be modified to represent flow conditions in other LWRs.

The HWCF system is used to evaluate the behavior of cladding materials in heated, pressurized flowing water, including corrosion and wear (erosion) behavior, thermal stress and heat transfer properties and chemical stability of cladding materials. Samples are internally heated using cartridge heaters while they are exposed to flowing coolant water to simulate the thermal stress that would be experienced by cladding in a nuclear fuel rod. Real-time changes in water temperature, pressure and chemistry ( $\mathrm{pH}$, conductivity and dissolved oxygen) are continuously monitored and recorded over extended periods; online adjustments to the water chemistry can be made if necessary.

\footnotetext{
${ }^{\text {s }}$ Shannon M. Bragg-Sitton, Light Water Reactor Sustainability Program Advanced LWR Nuclear Fuel Cladding System Development Technical Program Plan, INL/MIS-12-25696 Rev. 1, December 2012.
} 


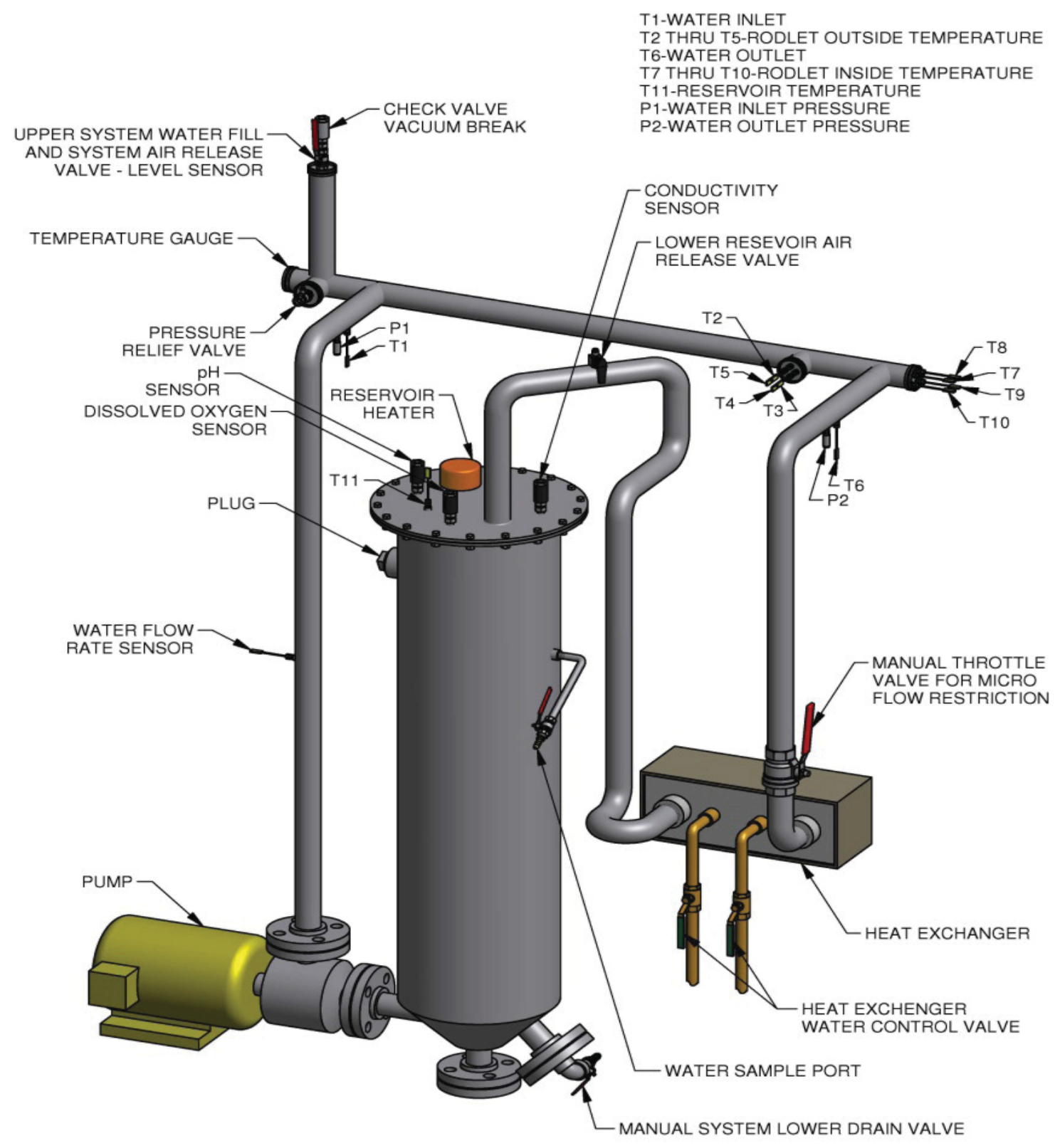

Figure 24. Schematic of the Hot Water Corrosion Flow (HWCF) test system.

Cladding performance is evaluated by visual and microscopic analysis of the clad surface both prior to and after unheated and heated flow tests and via in situ and tap measurements of the coolant water to assess any changes in the water chemistry or composition over time. All performance results for advanced cladding options are compared to the baseline zirconium alloy cladding to determine suitability of an advanced cladding material that can offer improvements to both safety and performance. 


\subsubsection{Oxidation Kinetics Test System}

A second test system was constructed to measure and evaluate potential performance improvements that may be offered by advanced cladding concepts under postulated off-normal accident conditions relative to standard zirconium-based cladding. The oxidation kinetics system (OKS) was designed and constructed to evaluate the behavior of candidate cladding materials in high-temperature oxidative environments (Figure 25).

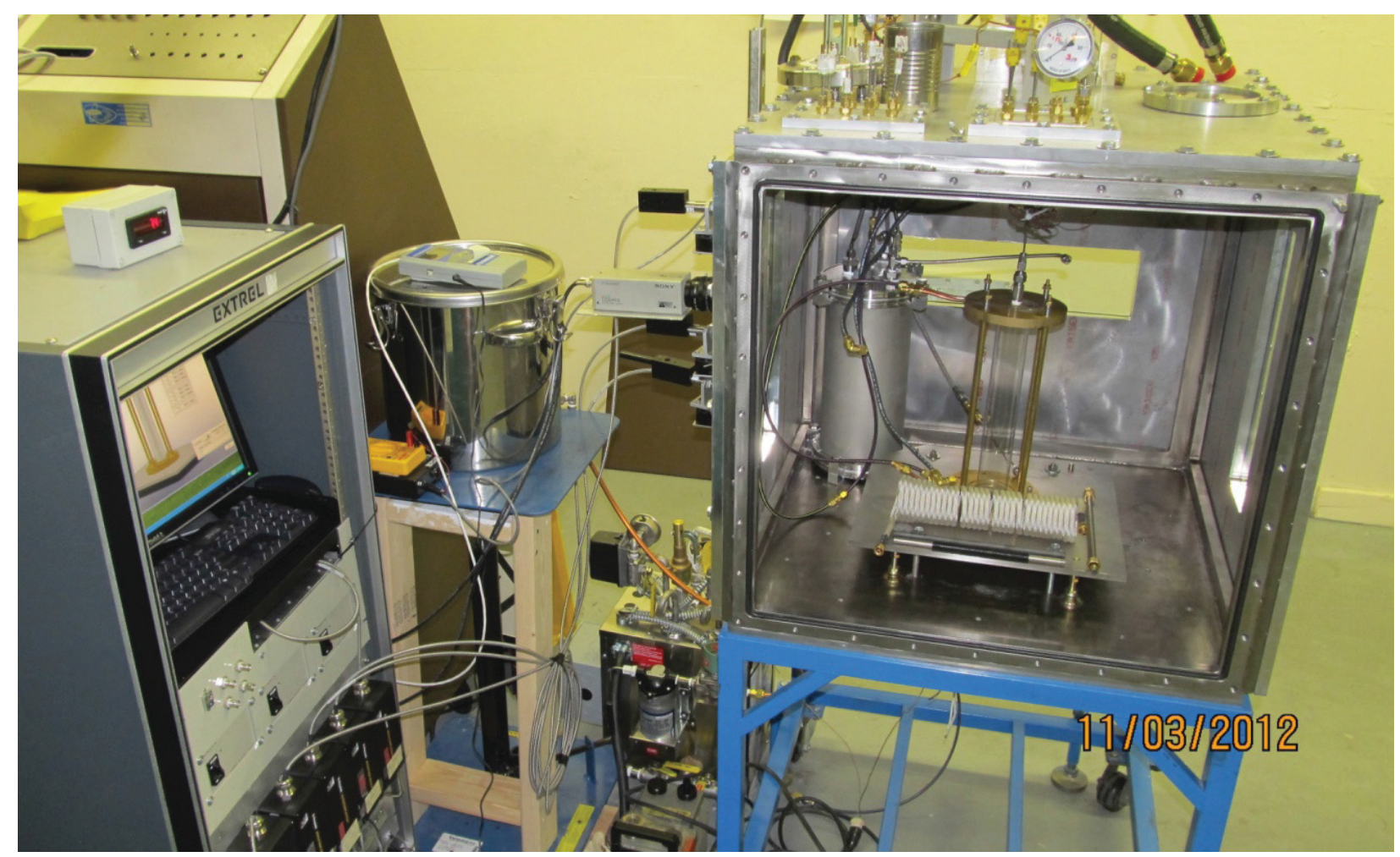

Figure 25. Oxidation Kinetics System (OKS) test chamber, steam generator, water reservoir and data acquisition system.

The system instrumentation monitors the onset and evolution of oxidation, internal phase changes, thermal stress behavior, and ballooning/rupture of pressurized rodlets. Samples are pressurized and induction-heated in an atmosphere-controlled chamber while exposed to wet or dry steam, steam and water (i.e. partially submerged rodlet), water, air or other gaseous mixtures, etc. Real-time changes in cladding emissivity, electrical resistivity, internal pressure, and gas-phase reaction products are recorded during oxidation. A gas chromatograph is used to analyze the vapor stream for low-level volatile oxidation products. System instrumentation also allows measurement of heat transfer characteristics both external (cladding-to-coolant) and internal (cladding-to-simulated fuel pellets) to the cladding tube. The system is designed such that the cladding performance can be evaluated under partial immersion conditions that would exist during the accident evolution and during quench (i.e. rapid introduction of coolant to cladding at elevated temperature that has been exposed to steam for some period of time) which would be used to lower cladding temperature if a LOCA is experienced. It is possible that some candidate cladding materials would shatter during quench; this behavior must be characterized and understood if a material is to be further considered. Two sample holders have been developed to date. The first configuration allows testing of a single cladding tube under the selected conditions to assess oxidation and burst behavior. The second holder allows testing of an array of four cladding tubes having 
pin-to-pin spacing set by a standard fuel assembly. This configuration allows assessment of the interaction between cladding tubes during oxidation and evaluation of flow blockage that may occur due to clad ballooning.

\subsection{Advanced Light Water Reactor Pathway Planned Activities}

As described above, the fuel cladding development activities are moving from the LWRS Program to the Fuel Cycle R\&D Program. However there are some important activities that are funded and will be completed in the next two years under the LWRS Program. Those activities are described in this section.

\subsubsection{Industry Activities Supporting $\mathrm{SiC} / \mathrm{SiC}$ Joining}

One of the key technology gaps for fully ceramic $\mathrm{SiC} / \mathrm{SiC}$ cladding is the development of a hermetic seal to attach ceramic SiC end caps to a SiC cladding tube capable of withstanding the LWR radiation and coolant flow environment. In 2012 a request for proposals was put out to industry to solicit $\mathrm{SiC} / \mathrm{SiC}$ joining solutions. After a series of white paper and full proposal reviews, contracts have been awarded to General Atomics and Hyper-Therm HTC for SiC joining technology. General Atomics and Hyper-Therm HTC are taking different approaches to the joint development. SiC joint samples will be delivered by each of these companies and although irradiation testing of $\mathrm{SiC} / \mathrm{SiC}$ joint samples is not planned under the LWRS Program, there may be opportunity to irradiate some samples as a part of irradiations planned for accident tolerant fuels within the Fuel Cycle R\&D Program Advanced Fuels Campaign.

The major milestones associated with the LWRS Program SiC joint industry activities are:

- (2013) General Atomics will deliver a final report documenting their $\mathrm{SiC} / \mathrm{SiC}$ joining solution together with $\mathrm{SiC} / \mathrm{SiC}$ joint samples.

- (2014) Hyper-Therm HTC will deliver a final report documenting their SiC/SiC joining solution together with $\mathrm{SiC} / \mathrm{SiC}$ joint samples.

\subsubsection{Material Inventory Database}

A material inventory database has been developed using Microsoft Access to manage materials and components intended for basic characterization, mechanical testing and possible future irradiation testing. The database allows tracking of materials throughout their life cycle: as-received, characterization activities (destructive or non-destructive), fabrication, and testing of a final configuration. In this manner, both forward and backward traceability are established to ensure that all materials are accounted for and that all data is properly traced to the as-received feedstock components. Traceability is a required component of the LWRS Program quality assurance to ensure accurate characterization materials and components and is a strict requirement for irradiation testing. The materials database also allows multiple documents to be attached to each record, such as data packages, chemical analysis, fabrication drawings, vendor qualifications, test data, etc. to provide easy access by project personnel.

The major milestone associated with the Material Inventory Database is:

- (2013) Complete LWRS Fuel Development Inventory Database.

\subsection{Path Forward for the Advanced LWRS Nuclear Fuels Pathway}

As already discussed, advanced LWRS fuel cladding development under the LWRS Program will transition to the DOE Fuel Cycle R\&D Program, beginning in 2013; this transition will be complete by the beginning of 2014. This will be the last LWRS Program Integrated Program Plan that discusses this pathway; the interested reader is referred to future work under the Fuel Cycle R\&D Program. A chronological listing of the major milestones remaining in this Pathway can be found in Appendix B. 


\section{CONCLUSIONS}

Utilizing the unique facilities and capabilities in the U.S. government laboratory system, the DOE LWRS Program is providing research results in the near- and longer-term to provide science-based data, methods and models to support the long-term operation of the nation's nuclear power plants. This information is being used by the nuclear industry to inform decisions on extended operation, as well as by the NRC to inform the regulatory framework for subsequent license renewals.

This Integrated Program Plan will be updated annually to reflect changes in plans and associated milestones. 
Appendix A

\section{LWRS Program Accomplishments}




$$
\text { A-2 }
$$




\section{Appendix A \\ LWRS Program Accomplishments}

Appendix A includes a summary of the Light Water Reactor Sustainability Program's previous years' major accomplishments. More detail on accomplishments is provided for the past year, with higher-level summaries of the preceding years. Reports on these topics can be found on the LWRS website, www.inl.doe.gov/lwrs.

\section{Fiscal Year 2012}

\section{Materials Aging and Degradation}

- Completed Expanded Proactive Materials Degradation Assessment Report

- Completed planning document on concrete measurements to be performed at the Barsebäck nuclear power plant

- Completed a report on metallurgical examination of the high-fluence reactor pressure vessel (RPV) specimens from the Ringhals nuclear power plants in Sweden

- Completed examination of reactor surveillance specimens from the Ginna, Ringhals, and Palisades nuclear power plants

- Completed initial assessment of feasibility of obtaining concrete core samples from identified candidate sites

- Completed plan for collection of materials from the Nine Mile Point 1 nuclear power plant during their 2013 outage

- Documented results of examinations of the surveillance specimens from the Ginna and Palisades nuclear power plant reactors

- Developed guidelines for risk-informed condition assessment and evaluation of aging concrete

- Completed nondestructive examination (NDE) roadmaps

- $\quad$ Concrete research and development (R\&D)

- Cables R\&D

- Fatigue damage R\&D

- Reactor pressure vessel R\&D

- Completed upgrades to test equipment for evaluation of advanced weldments on irradiated materials

- Completed plan for modeling of high-fluence phase transformations in core internals

- Completed a report on high-fluence effects on microstructural evolution of irradiated materials

- Completed plan for modeling of high-fluence swelling effects in core internals

- Completed a report on evaluating the influence of bulk and surface microstructures on alloy 600 stress corrosion cracking initiation behavior

- Completed a report on high-fluence effects on irradiation-assisted stress corrosion cracking of stainless steels

- Completed research plan for surrogate materials and attenuation studies, building on RPV results and findings in Fiscal Years 2009 to 2012

- Completed review of potential replacement alloys for light water reactors. 


\section{Advanced Instrumentation, Information, and Control System Technologies}

- Completed the Advanced Instrumentation, Information, and Control Systems Technologies Pathway vision document

- Developed prototype technologies for nuclear power plant status control and field work processes, with associated study of field trials at a nuclear power plant

- Developed outage work status capabilities, providing a means for communicating work progress and completion status directly from the field activities to the nuclear power plant outage control centers

- Completed a digital full-scale mockup of a conventional nuclear power plant control room

- Developed guidelines and demonstration technologies for nuclear power plant operations and maintenance work processes

- Completed a report on outage emergent issue resolution capabilities

- Completed a report on strategy and technical plans for online monitoring technologies in support of nondestructive examination deployment

- Completed a report on the online monitoring technical basis and analysis framework for large power transformers

- Completed a report on demonstration and data collection for prototype computer-based procedures

\section{Risk-Informed Safety Margin Characterization}

- Completed a verification and validation strategy for LWRS Program modeling and simulation activities

- Demonstrated the Risk-Informed Safety Margin Characterization methodology using a test case based on the Idaho National Laboratory's (INL's) Advanced Test Reactor (ATR)

- Completed the RELAP-7 development plan (funded by the Department of Energy [DOE] Nuclear Energy Advanced Modeling and Simulation Program)

- Demonstrated a single-phase, steady-state version of RELAP-7 (funded by the DOE Nuclear Energy Advanced Modeling and Simulation Program)

- Completed the RELAP-7 quality assurance plan (funded by the DOE Nuclear Energy Advanced Modeling and Simulation Program)

- Completed an initial demonstration of the Grizzly model for pressurized thermal shock effects on an aged section of a pressurized water reactor RPV and assess through-wall attenuation effects of embrittlement

- Completed the plan for RELAP-7 support of a boiling water reactor major plant uprate analysis using Risk- Informed Safety Margin Characterization

\section{Advanced Light Water Reactor Nuclear Fuels}

- Completed the development plan for silicon carbide ceramic matrix composite (SiC CMC) nuclear fuel cladding

- Completed failure mode and performance analysis for SiC CMC

- Documented a plan to codify American Society for Testing and Materials standards for ceramic composites for nuclear applications

- Documented the required analyses to support irradiation readiness for SiC CMC rodlets in the INL's ATR 
- Completed fuel clad trade-off study

- Documented the status of irradiation test preparation activities for the joining and irradiation studies

- Completed the design and installation of a nuclear fuel cladding test system that simulates nuclear fuel heating and provides a steam atmosphere

- $\quad$ Selected two industry proposals for SiC CMC joining technology development.

\section{Fiscal Year 2011}

- Completed a report documenting information gaps on concrete performance and cable aging degradation from an examination of the R. E. Ginna nuclear power plant during the calendar year 2011 refueling outage

- Published an implementation plan for the development of a nuclear concrete materials database

- Developed a baseline computational model for proactive welding stress management to suppress helium induced cracking during weld repair

- Completed an initial assessment of thermal annealing needs and challenges, assessment of needs for environmental fatigue under extended service conditions, assessment of alloy options and performed alloy downselect, evaluation of in-situ cable repair, and assessment of further irradiation experiment needs

- Published the II\&C industry working group vision document for II\&C technologies

- Began pilot projects on real-time configuration management and control to overcome limitations with existing permanent instrumentation and real-time awareness of plant configurations

- Completed fueled irradiation safety case documentation to support irradiations in the Idaho National Laboratory Advanced Test Reactor

- Completed initial evaluations of prototype fuel rodlets

- Completed a report documenting the results of collaborations with EPRI/industry to identify, define and prioritize power uprate challenges and develop power uprate R\&D strategies.

\section{Fiscal Year 2010}

- Completed literature review on concrete durability and aging

- Completed the planning document for harvesting material from the R. E. Ginna and Nine Mile Point nuclear power plants

- Completed report on architectural and algorithmic requirements for a next-generation system analysis code for that can be used to support the safety case of the LWR life extension.

\section{Fiscal Year 2009}

Fiscal year 2009 was primarily a planning year. The LWRS Program Plan was issued, a workshop on advanced fuel design was held, and a report on testing and analysis of reactor degradation was completed. 
Appendix B

\section{Chronological Listing of Planned LWRS Program Milestones}


B-2 


\section{Appendix B \\ Chronological Listing of Planned LWRS Program Milestones}

This appendix has a chronological listing of the milestones discussed in the pathway plan descriptions in Sections 2 through 5.

\section{Materials Aging and Degradation Pathway}

- (2013) Complete and deliver gap analysis of key materials degradation modes via the Expanded Materials Degradation Analysis

- (2013) Complete a detailed review of the NRC Pressurized Thermal Shock (PTS) re-evaluation project relative to the subject of material variability and identify specific remaining issues

- (2013) Complete detailed analysis of RPV samples from Ringhals and Ginna nuclear power plants.

- (2013) Complete detailed experimental plan, timeline, and assessment of irradiation needs for highfluence IASCC testing

- (2013) Complete validation of data contained in the concrete performance database and place database in public domain

- (2013) Complete down-selection and development plan on advanced replacement alloys in cooperation with EPRI

- (2013) Complete Containment Inspection Guidelines for extended-service conditions through partnership with Constellation Energy and EPRI

- (2014) Complete acquisition of experimental data on commercial and model RPV alloys

- (2014) Complete basic model development for phase transformations in LWR components

- (2014) Complete model development for swelling in LWR components

- (2014) Complete Phase 1 mechanistic testing for SCC research

- (2014) Complete base model development for environmentally-assisted fatigue in LWR components

- (2014) Complete analysis of key degradation modes of cable insulation

- (2015) Provide validated model for transition temperature shifts in RPV steels

- (2015) Complete mechanistic testing for IASCC research

- (2015) Complete assessment of cable mitigation strategies

- (2015) Complete assessment of cable insulation precursors to correlate with performance and NDE signals

- (2015) Demonstrate initial solid-state welding on irradiated materials

- (2016) Complete analysis of hardening and embrittlement through the RPV thickness for the Zion RPV sections

- (2016) Deliver predictive capability for swelling in LWR components

- (2016) Complete analysis of cast stainless steel specimens harvested from service conditions

- (2016) Complete prototype proof-of-concept system for NDE of concrete sections 
- (2017) Deliver experimentally validated, physically-based thermodynamic and kinetic model of precipitate phase stability and formation in Alloy 316 under anticipated extended lifetime operation of LWRs

- (2017) Deliver predictive model capability for Ni-base alloy SCC susceptibility

- (2017) Complete capability demonstrations for crack precursor detection on prototypic materials

- (2017) Complete experimental validation and deliver model for environmentally-assisted fatigue in LWR components

- (2017) Demonstrate key prototypes of fatigue damage NDE sensors in field test

- (2017) Complete analysis and simulations on aging of cast stainless steel components and deliver predictive capability for cast stainless steel components under extended service conditions

- (2017) Deliver predictive model for cable degradation

- (2017) Demonstrate field testing of prototype system for NDE of cable insulation

- (2018) Complete and deliver revised Expanded Materials Degradation Analysis

- (2018) Complete concrete and civil infrastructure toolbox development with EPRI and Materials Aging Institute partners

- (2018) Complete prototype of concrete NDE system

- (2018) Complete transfer of weld-repair technique to industry

- (2019) Demonstrate and deploy new or improved NDE technologies for RPV components

- (2019) Deliver predictive model capability for IASCC susceptibility

- (2019) Complete demonstration of the technical basis and feasibility for use of crack precursor detection NDE, diagnostics, and prognostics for LWR long-term operation (60 to 80 years)

- (2021) Complete validation of fatigue damage NDE sensors

- (2023) Complete characterization of demonstration of RPV sections (harvested from a reactor) that have been irradiated, annealed (post-harvesting), and then reirradiated in a test reactor.

\section{Advanced Instrumentation, Information, and Control Systems Technologies Pathway}

- (2013) Publish a reference human factors engineering plan for an optimized, human-factored control board layout for integrating digital operator interface screens with analog controls and indicators.

- (2013) Develop technologies for an advanced outage control center that improves outage coordination, problem resolution, and outage risk management.

- (2014) Publish a technical report that provides a current state and gap analysis for integrating plant information residing in plant II\&C systems, plant work processes, and information resources needed for mobile worker technologies.

- (2014) Develop automated work package prototype technologies for nuclear power plant work processes with associated study of field trials at a nuclear power plant.

- (2014) Develop human factors studies and publish a technical report for an advanced outage control center that is specifically designed to maximize the usefulness of communication and collaboration technologies for outage coordination, problem resolution, and outage risk management.

- (2015) Develop human factors evaluations and an implementation strategy for deploying automated field activity work packages built on mobile technologies, resulting in more efficient and accurate plant work processes, adherence to process requirements, and improved risk management. 
- (2015) Publish a technical report for computer-based procedures that enhance worker productivity, human performance, plant configuration control, risk management, regulatory compliance, and nuclear safety margin.

- (2015) Publish a technical report on measures, sensors, algorithms, and methods for monitoring active aging and degradation phenomena for a large passive plant component/structure, involving nondestructive examination-related online monitoring technology development, including the diagnostic and prognostic analysis framework to support utility implementation of online monitoring for the component type.

- (2016) Publish a technical report for an advanced alarm management system in a nuclear power plant control room and a methodology for integrating diverse alarms and annunciators across all systems and digital platforms.

- (2016) Publish a technical report on an advanced digital architecture, integrating plant systems, plant work processes, and plant workers in a seamless digital environment, with guidance on how to apply the architecture to a nuclear power plant's established data network systems.

- (2016) Develop and demonstrate augmented reality technologies for visualization of radiation fields for mobile plant workers.

- (2016) Develop an end-state vision and strategy, based on human factors engineering principles, for the implementation of both a hybrid and a full highly integrated control room as new digital technologies and operator interface systems are introduced into traditional control rooms.

- (2016) For nuclear power plant chemistry activities, analyze the staffing, tasks, and cost models to identify the opportunities for application of digital technologies to improve nuclear safety, efficiency, and human performance based on optimum human-technology function allocation. Demonstrate representative activities as transformed by technology with results published in a technical report.

- (2017) Develop an operator advisory system fully integrated into a control room simulator that provides plant steady-state performance monitoring, diagnostics and trending of performance degradation, operator alerts for intervention, and recommended actions for problem mitigation, with application of control room design and human factors principles.

- (2017) Develop and demonstrate augmented reality technologies for visualization of real-time plant parameters (e.g., pressures, flows, valve positions, and restricted boundaries) for mobile plant workers.

- (2017) For nuclear power plant maintenance activities, analyze the staffing, tasks, and cost models to identify the opportunities for application of digital technologies to improve nuclear safety, efficiency, and human performance based on optimum human-technology function allocation. Demonstrate representative activities as transformed by technology with results published in a technical report.

- (2017) Develop a digital architecture and publish a technical report for an advanced online monitoring facility, providing long-term asset management and providing real-time information directly to control room operators, troubleshooting and root cause teams, suppliers and technical consultants involved in component support, and engineering in support of the system health program.

- (2017) Develop a real-time outage risk management strategy and publish a technical report to improve nuclear safety during outages by detecting configuration control problems caused by work activity interactions with changing system alignments.

- (2017) Publish a technical report on measures, sensors, algorithms, and methods for monitoring active aging and degradation phenomena for second large passive plant component structure, involving nondestructive examination-related online monitoring technology development, including the 
diagnostic and prognostic analysis framework to support utility implementation of online monitoring for the component type.

- (2018) Complete a technical report on operator attention demands and limitations on operator activities based on the current conduct of operations protocols. This report will identify opportunities to maximize operator efficiency and effectiveness with advanced digital technologies.

- (2018) For nuclear power plant radiation protection activities, analyze the staffing, tasks, and cost models to identify the opportunities for application of digital technologies to improve nuclear safety, efficiency, and human performance based on optimum human-technology function allocation. Demonstrate representative activities as transformed by technology with results published in a technical report.

- (2018) For chemistry activities, conduct a study and publish a technical report on opportunities to provide remote services from centralized or third-party service providers, based on advanced real-time communication and collaboration technologies built on the digital architecture for a highly automated plant. Demonstrate representative remote activities with a host nuclear power plant.

- (2018) Publish a technical report on augmented reality technologies developed for nuclear power plant field workers, enabling them to visualize abstract data and invisible phenomena, resulting in significantly improved situational awareness, access to context-based plant information, and generally improved effectiveness and efficiency in conducting field work activities.

- (2019) Develop and publish a transformed nuclear power plant operating model and organizational design derived from a top-down analysis of nuclear power plant operational and support activities, quantifying the efficiencies that can be realized through highly automated plant activities using advanced digital technologies.

- (2019) For maintenance activities, conduct a study and publish a technical report on opportunities to provide remote services from centralized or third-party service providers, based on advanced realtime communication and collaboration technologies built on the digital architecture for a highly automated plant. Demonstrate representative remote activities with a host nuclear power plant.

- (2019) Develop an end-state vision and implementation strategy for an advanced computerized operator support system, based on an operator advisory system that provides real-time situational awareness, prediction of the future plant state based on current conditions and trends, and recommended operator interventions to achieve nuclear safety goals.

- (2020) Develop the strategy and priorities and publish a technical report for automating operator control actions for important plant state changes, transients, and power maneuvers, resulting in nuclear safety and human performance improvements founded on engineering and human factors principles.

- (2020) For radiation protection activities, conduct a study and publish a technical report on opportunities to provide remote services from centralized or third-party service providers, based on advanced real-time communication and collaboration technologies built on the digital architecture for a highly automated plant. Demonstrate representative remote activities with a host nuclear power plant.

- (2021) Develop validated future concepts of operations for improvements in control room protocols, staffing, operator proximity, and control room management, enabled by new technologies that provide mobile information and control capabilities and the ability to interact with other control centers (e.g., emergency response facilities for severe accident management guidelines implementation). 
- (2021) Develop the strategy and priorities and publish a technical report for improving plant control algorithms, based on greater availability of sensed and derived plant parameters through the advanced digital architecture, resulting in more anticipatory, adaptive, and resilient control functions.

- (2021) Publish human and organizational factors studies and a technical report for a virtual plant support organization technology platform consisting of data sharing, communications (voice and video), and collaboration technologies that will compose a seamless work environment for a geographically dispersed nuclear power plant support organization.

- (2021) Publish human and organizational factors studies and a technical report for a management decision support center consisting of advanced digital display and decision-support technologies, thereby enhancing nuclear safety margin, asset protection, regulatory performance, and production success.

\section{Risk Informed Safety Margin Characterization Pathway}

- (2013) Upgrade the RELAP-7 capabilities through implementation of the seven-equation two-phase flow model, including selected major physical components for BWR primary and safety systems.

- (2013) Perform the RELAP-7 simulation resolving an SBO scenario on a simplified geometry of a BWR.

- (2013) Produce technical report that outlines the RIMM process and its relation to RISMC characterization.

- (2014) Complete the software structure of the coupled RAVEN/RELAP-7 portion of the RISMC Toolkit. At this time, RELAP-7 can be fully controlled by RAVEN for complete systems analysis. RELAP-7/RAVEN will have the capability to be coupled to other applications (e.g., aging and fuels modules) and perform as a balance-of-plant capability for the multidimensional core simulators under development in other DOE programs.

- (2014) Deliver the RELAP-7 verification and validation plan.

- (2014) Version 1.0 of Grizzly will be released. This version will include aging of steel (embrittlement), and a modular architecture to enable inclusion of additional mechanisms.

- (2014) Assess leading accident resistant fuel technologies to understand potential changes in safety margins that could be achieved by adoption of the technology using the RISMC methodology.

- (2014) Demonstrate RISMC approach using LWR Case Study for Enhanced Accident Tolerance design changes using Risk-Informed Margins Management approaches.

- (2014) Demonstrate current margins analysis techniques on selected case studies using the completed software structure. The case studies will be selected in consultation with external stakeholders and will be chosen based on their potential to address an issue important to LWR sustainability and/or to achieve widespread stakeholder acceptance of the RISMC approach.

- (2015) RELAP-7 will be validated against an accepted set of data.

- (2015) The margins analysis techniques will be sufficiently mature to enable initial industry margins quantification exercises, including using the RISMC Toolkit.

- (2016) Complete a full-scope margins analysis of a commercial reactor. Use margins analysis techniques, including a fully coupled RISMC Toolkit, to analyze an industry-important issue (e.g., assessment of major component degradation in the context of long-term operation or assessment of the safety benefit of advanced fuel forms). Test cases will be chosen in consultation with external stakeholders. 
- (2016) Final technical report for RIMM process including description of pilot application of RISMC / RIMM to an issue of interest at a host plant.

- (2016) Version 2.0 of Grizzly will be released. This version will include the capabilities of Version 1.0 as well as aging of selected concrete.

- (2018) Validation and benchmarking of Grizzly will be completed.

- (2020) Ensure development and validation to the degree that by the end of 2020, the margins analysis techniques and associated tools are an accepted approach for safety analysis support to plant decisionmaking, covering analysis of design-basis events and events within the technical scope of internal events probabilistic risk assessment.

\section{Advanced Light Water Reactor Nuclear Fuels Pathway}

- (2013) Complete LWRS Fuel Development Inventory Database.

- (2013) General Atomics will deliver a final report documenting their $\mathrm{SiC} / \mathrm{SiC}$ joining solution together with $\mathrm{SiC} / \mathrm{SiC}$ joint samples.

- (2014) Hyper-Therm HTC will deliver a final report documenting their $\mathrm{SiC} / \mathrm{SiC}$ joining solution together with $\mathrm{SiC} / \mathrm{SiC}$ joint samples. 